Portland State University

PDXScholar

\title{
Toward a behavioral analysis of attentiveness as a style of communication
}

\author{
Ray Alan Coker \\ Portland State University
}

Follow this and additional works at: https://pdxscholar.library.pdx.edu/open_access_etds

Part of the Interpersonal and Small Group Communication Commons, Social Psychology Commons, and the Speech and Hearing Science Commons

Let us know how access to this document benefits you.

\section{Recommended Citation}

Coker, Ray Alan, "Toward a behavioral analysis of attentiveness as a style of communication" (1983). Dissertations and Theses. Paper 3239.

https://doi.org/10.15760/etd.3227

This Thesis is brought to you for free and open access. It has been accepted for inclusion in Dissertations and Theses by an authorized administrator of PDXScholar. Please contact us if we can make this document more accessible: pdxscholar@pdx.edu. 
AN ABSTRACT OF THE THESIS OF Ray Alan Coker for the Master of Science in Speech Communication presented December 9, 1983.

Title: Toward a Behavioral Analysis of Attentiveness as a Style of Communication

APPROVED BY MEMBERS OF THE THESIS COMMITTEE:

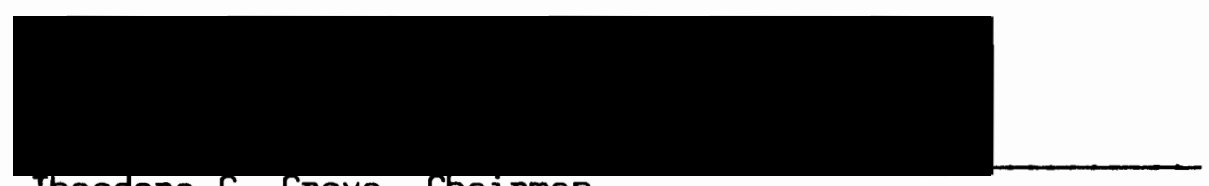

Theodore G. Grove, Chairman
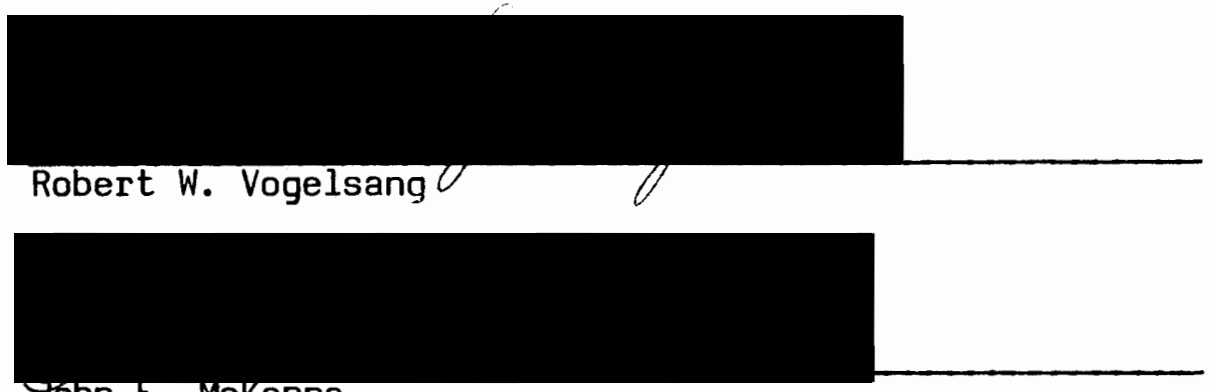

John $F$. McKenna

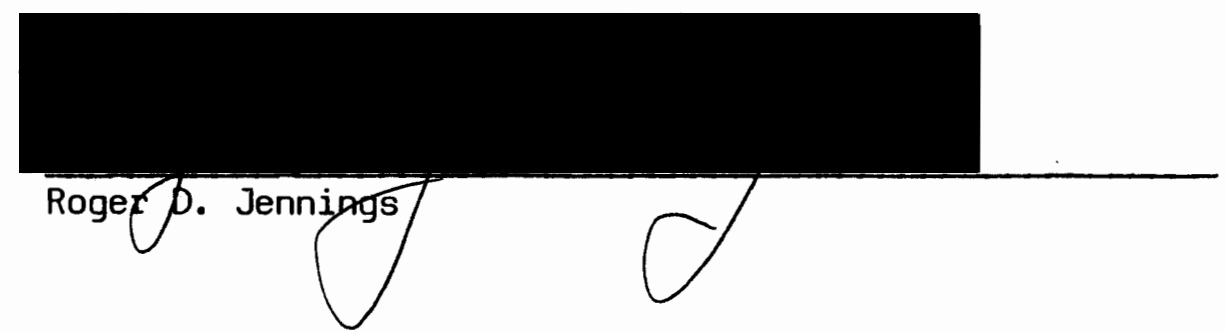

Attentiveness, a variable of communication, primarily serves a stylistic function in the communicative process by providing behavioral evidence that an individual is actively involved in message reception. Past research suggests that while both verbal and nonverbal behaviors signal attentiveness, nonverbal cues are more closely associated with this construct. Among the many nonverbal behaviors of individuals in interactions, postural positions have been deemed highly indicative of 
attentiveness. At present however, most of the empirical evidence attesting to this notion has been established through the use of selfreport measures. As a result of the felt need by this author to improve upon the methdology used in substantiating the construct of attentiveness, this investigation was conducted in order to apply a multiplicity of methods to testing this relatively new construct. This research is believed to be significant as it adds to the existing knowledge on the communication process in general and assists in theory-building a construct to which considerable attention of late has been given by communication theorists.

In order to substantiate or disprove the claim that attentiveness is strongly related to postural activity, the author utilized an external variable approach to investigating this phenomenon. That qualitative data might be derived to validate or invalidate the research hypotheses, an experiment was executed whereby videotaped interaction was correlated with self-reports, other reports, and independent observer reports. The actual experiment consisted of: (1) development of mutually exclusive and exhaustive coding categories, (2) recruitment and training of coders to assist in data collection, (3) compilation of three attentiveness measures, (4) videotaping of subjects, (5) implementation of a pilot study, (6) data analysis, assessment of interrater reliability, and experiment refinement, and (7) administration and subsequent analysis of data from the final study.

Thirteen scoring categories were used to detail the postural activity of the 62 videotaped subjects. Eight coders were trained to discern the postural positions and code approximately 20 minutes of dyadic interaction. The derived data was compared with three attentiveness measures 
based primarily on the work of Norton and Pettegrew (1979) which were constructed in order to determine a subject's level of attentiveness. The scoring procedure for assessing interrater reliability on the pilot and final studies was the statistic Kappa as it assessed nominal scale agreement rather than percentage agreement between coders. The fact that Cohen's Kappa was high at +.83 in the final study indicates a high degree of stability between coders after chance agreement had been excluded.

Results from both a correlation and a regression analysis indicated the existence of a low to moderate correlation between an individual's level of attentiveness and the specific postural positions he or she assumed, hence, the first research hypothesis was disproved. The second hypothesis was not verified as a high inverse correlation was not produced between an individual's level of attentiveness in a seated dyadic interaction and the number of his or her postural shifts in position.

The empirical evidence generated by this experiment shows that there is a predictable low to moderate link between either postural positions or postural shifts and levels of attentiveness. These data however, are not commensurate with previous research that suggests that postural activity is highly representative of attentiveness; in fact, this investigation indicates that the assertion is unwarranted that postural behavior is a strong nonverbal indicator of attentiveness. 
TOWARD A BEHAVIORAL ANALYSIS OF ATTENTIVENESS

AS A STYLE OF COMMUNICATION

by

RAY ALAN COKER

A thesis submitted in partial fulfillment of the requirements for the degree of

\author{
MASTER OF SCIENCE \\ in \\ SPEECH COMMUNICATION
}

Portland State University

1983 
TO THE OFFICE OF GRADUATE STUDIES AND RESEARCH:

The members of the Committee approve the thesis of Ray Alan Coker presented December 9, 1983.

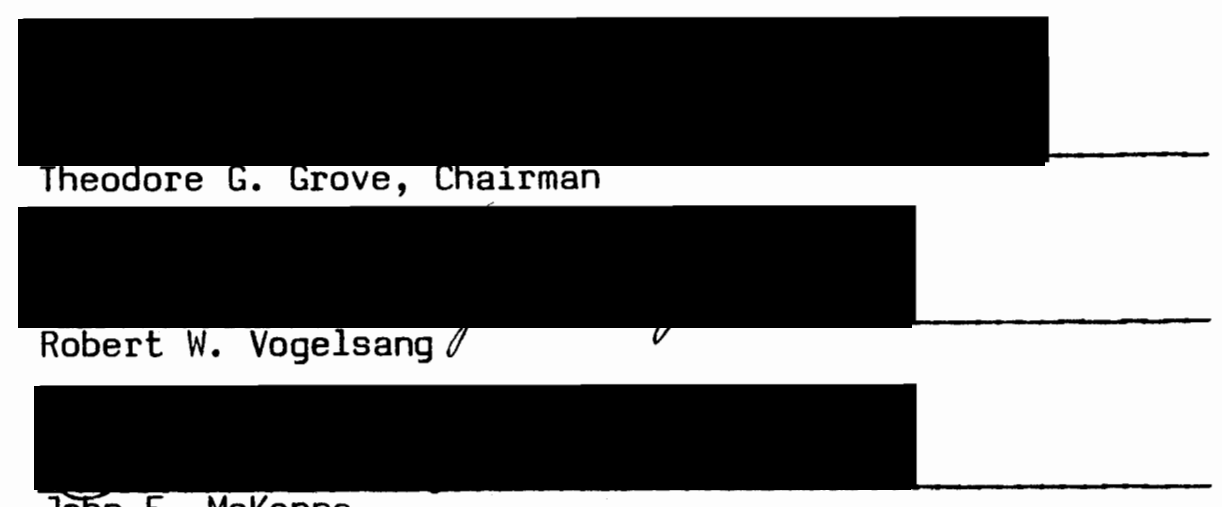

John F. McKenna

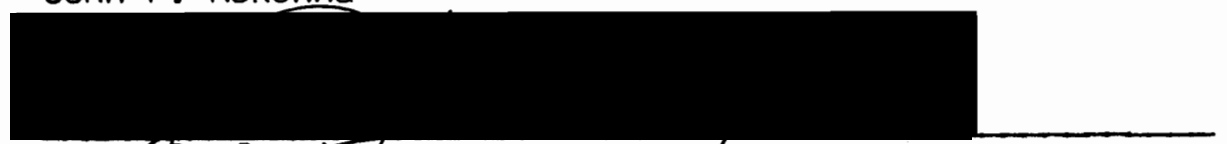

Rogefp. Jenptings

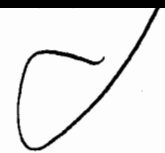

APPROVED:

Theodore G. Grove, Head, Department of Speech Communication

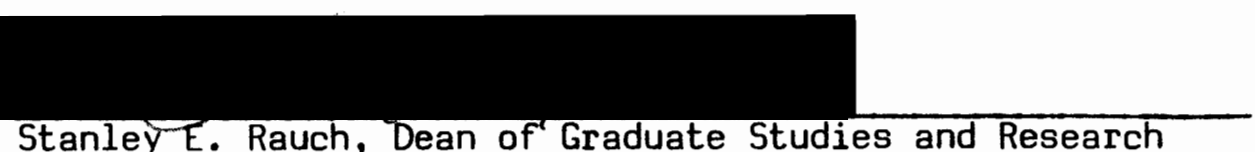

Stanley E. Rauch, Dean of Graduate Studies and Research 


\section{ACKNOWLEDGEMENTS}

My sincere appreciation and acknowledgement is extended to all those individuals who were indispensible in the execution of this study.

Special thanks is extended to my thesis committee. Primarily, to Dr. Theodore Grove, my committee chairman and graduate advisor for his empirical expertise, for his emphasis on "doing it over," and for his sacrificing more than one Friday afternoon for the cause. Dr. Robert Vogelsang is thanked for his availability and encouragement throughout my course work and for his part in helping me set up the experiment. Mr. John McKenna is noted for teaching the first course I ever took in nonverbal communication, as is $\mathrm{Dr}$. Roger Jennings for introducing me to coding categories, interrater reliability, and Cohen's Kappa.

I am amazed at the number of people who assisted me in carrying out this study. I appreciate the help of the departmental secretary, Pat Hamilton, for her advice on policy matters in running the experiment and setting up the coding center as well as her willingness to be interrupted on numerous occasions for the key to room 24. Several individuals are thanked for their help in recruiting the 68 subjects that were involved. In particular, I acknowledge Betsy Crist for gathering together fourteen people one Saturday afternoon for filming, Doris Werkman for promoting this study in her classes, and Noury Al-Khaledy for his salesmanship in the lunchroom.

I would also like to thank the coders: Duane King, Katrina Leeding, Brendan McVicker, Mariann Sing, Jody Smalley, Thomas Thorpe, Elaine Walmer, 
and Vinton Whiles, all who proved to be very dependable and willing to adjust to the changing demands of the experiment. I am additionally grateful to Mr. Jim Kimball, from the Audio Visual Department, for spending two sessions training me on the video equipment.

Special acknowledgement goes to my wife Deborah, who aided in this study without one complaint by being a typist, editor, critic, photocopier, errand runner, appointment maker, data processor, and financial contributor. Lastly, I would like to recognize the friends and family members who continually proded me along with comments such as, "Are you done yet?" To them I answer, "Yes . . . finally." 
TABLE OF CONTENTS

PAGE

ACKNOWLEDGEMENTS . . . . . . . . . . . . . . . . . . . iii

LIST OF TABLES . . . . . . . . . . . . . . . . . . . viii

LIST OF FIGURES . . . . . . . . . . . . . . . . . . . ix

CHAPTER

I INTRODUCTION . . . . . . . . . . . . . . . 1

Statement of Purpose .............. 5

Significance of the Study ............ 6

I I THEORETICAL FRAMEWORK: RESEARCH IN NONVERBAL COMMUNI-

CATION . . . . . . . . . . . . . . . . . 10

Historical Approaches . . . . . . . . . 12

Contemporary Approaches ............. . . . . . 16

Summary ..................... 21

II REVIEW OF LITERATURE: POSTURE AND ATTENTIVENESS . . . 23

Posture Defined ....... . . . . . . 23

Posture and Expression ............. 23

Attentiveness Defined ............... 29

Attentiveness and Communicator Style . . . . . 30

Summary .................. 35

IV EXPERIMENTAL DESIGN AND METHODOLOGY . . . . . . . . 37

Operational Definitions . . . . . . . . 38

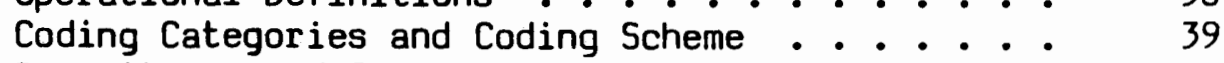

Recruitment and Training of Coders . . . . . . . 51

Attentiveness Measures .............. 52

Subjects . . . . . . . . . . . . . . . 454

Group 1

Group 2

Summary . . . . . . . . . . . . 57

$\checkmark$ ANALYSIS AND INTERPRETATION OF RESULTS . . . . . . . 59 
Pilot Study . . . . . . . . . . . . .

Experimental Design

Assessment of Interrater Reliability

Discussion

Final Study and Data Analyses . . . . . . .

Experimental Design

Descriptive Characteristics of the Sample

Assessment of Interrater Reliability

Assessment of Frequency of Postural Positions Analysis of Hypothesis 1

Analysis of Hypothesis 2

Discussion .................

VI SUMMARY AND IMPLICATIONS . . . . . . . . . . . .

Summary . • . . . . . . . . . . . . . .

Limitations and Recommendations . . . . . . .

REFERENCES . . . . . . . . . . . . . . . . . . .

Appendix A - Brandt's Conceptual Definitions and Empirical Indicators of Communicative Style

Appendix B - Course Description for Research Practicum . . . . . . . . . . . .

Appendix C - Photograph of Coding Center . . . .

Appendix D - Instructions to Coders . . . . .

Appendix E - Coding Chart . . . . . . . . .

Appendix F - Dyadic Attentiveness Measure . . .

Appendix G - Attentiveness Measure by Norton and Pettegrew ..................

Appendix $\mathrm{H}$ - Structure of Attentiveness Variables Used by Norton and Pettegrew .........

Appendix I - Perception of Partner's Attentiveness Scale ................ 
Appendix $K$ - Appointment Reminder for Subjects from PSU ...................... 121

Appendix L - Indexing of Subjects on Videotape . . 122 Appendix M - Cohen's Kappa Statistic on Data from Final Study .. . . . . . . . . . . 


\section{LIST OF TABLES}

TABLE

PAGE

I Thirteen Coding Categories for Scoring Postural

Positions . . . . . . . . . . . . .

II Summary of Descriptive Characteristics of the Sample . .

II Pearson Product-Moment Correlation Coefficients Indexing Degree of Relationship Between the DAM, PPAS, CGRA and the Postural Positions Used in the Coding Scheme

IV Interpretation of Correlation Coefficients as Suggested

by Williams . . . . . . . . . . . . . .

V Pearson Product-Moment Correlation Coefficients for the Dyadic Attentiveness Measure, Perception of Partner's Attentiveness Scale, and Coder's Global Report of Attentiveness ...................

VI Sweep Matrix Showing Degree of Contribution of Variables in the Multiple Prediction of DAM . . . . . . . .

VII Sweep Matrix Showing Degree of Contribution of Variables in the Multiple Prediction of PPAS . . . . . . .

VIII Sweep Matrix Showing Degree of Contribution of Variables in the Multiple Prediction of CGRA . . . . . .

IX Summary Tables for the DAM, PPAS, and CGRA Displaying Statistics in the Regression Equation . . . . . . . .

$X$ Pearson Product-Moment Correlation Coefficients for the DAM, PPAS, CGRA, and the Number of Postural Shifts. 


\section{LIST OF FIGURES}

F IGURE

PAGE

1. The Two Opposing Research Approaches of Nonverbal Investigators . . . . . . . . . . . . .

2. Norton and Pettegrew's Mapping Sentence of the Attentiveness Construct ..............

3. Degrees of Relaxation Utilized in Coding Categories . .

4. Coding Category \#1 - Least Relaxation, Direct Orientation, Open Position . . . . . . . . . . .

5. Coding Category \#2 - Least Relaxation, Indirect Orientation, Open Position ..............

6. Coding Category \#3 - Least Relaxation, Direct Orientation, Closed Position . . . . . . . . . .

7. Coding Category \#4 - Least Relaxation, Indirect Orientation, Closed Position ..............

8. Coding Category \#5 - Moderate Relaxation, Direct Orientation, Open Position (Photograph 1)........

9. Coding Category \#5 - Moderate Relaxation, Direct Orientation, Open Position (Photograph 2)........

10. Coding Category \#6 - Moderate Relaxation, Indirect Orientation, Open Position (Photograph 1).......

11. Coding Category \#6 - Moderate Relaxation, Indirect Orientation, Open Position (Photograph 2).......

12. Coding Category $\$$; - Moderate Relaxation, Direct Orientation, Closed Position .............

13. Coding Category \#8 - Moderate Relaxation, Indirect Orienation, Closed Position ...........

14. Coding Category \#9 - Extreme Relaxation, Direct Orientation, Open Position (Photograph 1)........

15. Coding Category 非 - Extreme Relaxation, Direct Orientation, Open Position (Photograph 2). . . . . . 
F IGURE

PAGE

16. Coding Category \#10 - Extreme Relaxation, Indirect Orientation, Open Position (Photograph 1).....

17. Coding Category \#10 - Extreme Relaxation, Indirect Orientation, Open Position (Photograph 2). . . .

18. Coding Category 非1 - Extreme Relaxation, Direct Orientation, Closed Position (Photograph 1) . . . . .

19. Coding Category $\# 11$ - Extreme Relaxation, Direct Orientation, Closed Position (Photograph 2) ......

20. Coding Category $\$ 12$ - Extreme Relaxation, Indirect Orientation, Closed Position (Photograph 1). . . .

21. Coding Category $\# 12$ - Extreme Relaxation, Indirect Orientation, Closed Position (Photograph 2). . . 50

22. Summary Matrix for Pilot Data for Assessment of Cohen's Kappa on Interrater Reliability ..........

23. Summary Matrix for Final Study for Assessment of Cohen's Kappa on Interrater Reliability . . . . . . .

24. Histogram of Postural Positions Assumed by 57 Coded Subjects . . . . . . . . . . . . . . 


\section{CHAPTER I}

\section{INTRODUCT ION}

There now exists a substantial body of literature, both empirical and anecdotal that attests to the significant role nonverbal behavior plays in communicative interactions. Efforts over the past decade have been toward the development of a theoretical framework and methodology for studying specific nonverbal behaviors. Currently, researchers are paying increased attention to nonverbal communication in relation to communication systems, total communication ecology, interpersonal skills acquisition, and communicator style. Diverse attempts are consequently represented in the literature toward understanding the behavioral manifestation of an individual's thoughts, feelings, and attitudes through nonverbal communication and the impact this has on communicative situations. As a result of these efforts, the everyday significance of the function of nonverbal behavior within the domain of communication seems well established.

The majority of studies in nonverbal communication investigate perception and interpretation of nonverbal behavior (e.g., Bull, 1978; Ekman et al., 1972; Knapp, 1965; Mehrabian, 1970, 1981; Scheflen, 1974). These studies have essentially been context-dependent where examination of context variables have been conducted; variables such as the characteristics of the social situation, the roles and status of the participants, the attributions of the participants, and verbal and nonverbal 
concurrent messages have been studied. A related area of research more recently investigated assesses individual or group differences in accuracy of sending nonverbal signals and accuracy of decoding the meanings of nonverbal signals via such channels as facial expressions, eye behavior, and body movements (e.g., Davitz, 1964; Norton and Pettegrew, 1979; Rosenthal et al., 1979). Invesitgating the accuracy in sending or decoding nonverbal signals is an important step in the development of a conceptual framework by which those behaviors that produce optimum communication can be examined.

One way in which an analysis is made concerning the attributions individuals make regarding the nonverbal messages of others is through the identification of 'communicator style.' Norton and Pettegrew (1979, p. 16) broadly define communicator style as "the way one verbally and paraverbally interacts to signal how message content should be taken, interpreted, filtered, or understood." Norton (1978) operationally defines 'communicator style' in terms of nine independent variables (dominant, dramatic, contentious, animated, impression, leaving, relaxed open, friendly, and attentive) and one dependent variable (communicator image). Influenced by Norton's work, Brandt (1979) conceptually defined these variables and related them to indicators of communicative style (see Appendix A). This operationalizing provided a comprehensive list of variables comprising the communicator style construct.

Norton and Pettegrew (1979) also state that communicator style is the meta-message about literal meaning. Wilmot (1980, p. 63) explains metacommunication as being "... anything that 'contextualizes' or 'frames' messages to assist the participants in understanding the communication event." He believes that the utility of this concept depends 
upon clear distinctions between the types of metacommunication that occur in interpersonal interactions. According to Wilmot (1980), Norton (1978) has equated metacommunication with a person's communicator style (a type of metacommunication) because it verbally and nonverbally expresses to others how they are to interpret transactional messages.

Communicator style is contingent upon three important aspects of the communicative process: the context, the situation, and time. Norton (1978, p. 111) says that "the context refers to the interactive stage and its setting including props, rituals, and expectations. The situation refers to the people and their purpose within the context .... time is a complex operant which can impinge across different hours in the day or across broader demarcations ranging from youth to old age."

As a variable of communicator style and a construct in its own right, attentiveness has been found to produce information regarding how completely a person's message is being noticed in an alert, aware, or understanding manner (Norton and Pettegrew, 1979). In an interaction, participants verbally and nonverbally express to others their own level of attentiveness rather than affirming their attentiveness by continually saying, "I am currently alert, in-touch, aware, and understanding what you are saying." An attentive individual may use smiling, head nodding, verbal following, forward body and trunk lean, accessibility, direct orientation, direct eye contact, and relating similar experiences or feelings to express to others his or her own attentiveness. These verbal and nonverbal behaviors are referred to as "signals."

Attentiveness is considered a construct in its own right because a relationship can be observed between attentiveness and communicator 
style in interpersonal or small group interactions. In particular, attentiveness (as a variable of communicator style) is considered a construct since it has been adapted for a particular theoretical and scientific aim and empirical support is available to substantiate its significance (Kibler, 1970).

Since attentiveness serves as a stylistic function in the communicative process, it is entirely possible for an individual to adopt an attentive communicator style and be 'tuned out' and indifferent toward another individual. We are all aware of situations where we behaviorally display an attitude of interest or empathy and psychologically or emotionally experience just the opposite attitude. Attentiveness, like empathy, is a combination of behavioral and psychological activities. It is possible to mask an indifferent attitude with empathic behavioral signals as well as mask inattentiveness with attentive signals (smiling, head nodding, verbal following, and so forth).

The major assumption underlying the present study is that all people engaged in interaction verbally and nonverbally express their inner state of attentiveness to others. Whether or not this expression is a conscious or unconscious act is not an issue in this investigation. Rather, what is important in this study is whether specific behavioral signals do indeed indicate that a person, at a certain moment in time, is being attentive to another person or persons.

A strong predictive relationship has been found between attentiveness and projection of interpersonal attractiveness, positive communicator image, and effectivness in teaching and psychotherepeutic situations (Norton, 1977; Norton and Pettegrew, 1977, 1979; Pettegrew, 1977). In order to understand the dynamic and systemic properties of the process 
of communication, greater detail and analysis should be given to attentiveness as a stylistic component. By understanding the structural relationships that constitute an attentive construct, we can gain a more accurate view of the behaviors that constitute communicative interactions.

\section{Statement of Purpose}

The purpose of this study is to further establish attentiveness as a stylistic construct of communication. In that attentiveness relies heavily on nonverbal signals, the most important of which is postural position (Norton and Pettegrew, 1979), this particular signal has been chosen to be investigated. The present study entails an analysis of the nonverbal postural positions that individuals use to indicate their level of attentiveness.

Self-report measures have shown specific postural positions to be strongly associated with an individual's attentiveness in the interactive setting. The specific goal of this research is to design and execute a study whereby the videotaped interaction of subjects is correlated and analyzed with reports on their attentiveness by themselves, their dyadic partners, and independent coders so as to provide empirical evidence that validates or invalidates the following hypotheses:

$H_{1}$ : An individual's level of attentiveness in a seated dyadic interaction will produce a high direct correlation with the specific postural positions he or she assumes.

$H_{2}$ : An individual's level of attentiveness in a seated dyadic interaction will produce a high inverse correlation with the number of his or her postural shifts in position. 
Essentially, the objective of this investigation is to determine the strength of the link between the postural behavior of individuals and the communicator style of attentiveness. Evidence from past research indicates that the two are indeed linked, however stringent quantitative analysis has been lacking.

\section{Significance of the Study}

Much of the systematic research on nonverbal behavior has focused on the interpretation of one set of nonverbal cues, usually those provided by the face or the body. The face has been found to be more informative about the nature of the person's specific emotions (anger, fear, happiness, and so forth) while the rest of the body appears to be more informative about the person's attitude-his or her general manner or feeling toward a person or thing (Ekman and Friesen, 1967). Ekman and Friesen (1967) have observed that the face is generally alive and mobile during conversation which gives it the ability to be expressive of the entire range of emotions. At the same time, the face lacks the innate or socially conditioned ability to clearly communicate a person's general attitude as well as it does emotional states. In contrast to the face, the body has been found to be more reflective of attitude than emotion. This does not suggest that fear cannot be easily seen in the positions or movements of the body. What it does suggest, is that the face more clearly expresses the momentary emotion of fear, while the body may reveal a general state of apprehension.

In the wide range of emotions and attitudes, there are those that are considered socially positive and those that are considered socially negative. Communication of negative emotions and attitudes in an overt 
fashion is culturally discouraged in many social contexts. A person may express anger at a football game, but in most cases, is not expected to express such emotions with his or her co-workers. Boredom is an acceptable expression with a spouse, but not at a board meeting. This does not mean that anger is not felt toward a co-worker or that boredom is not felt at a board meeting, however in that anger and boredom are socially unacceptable in these contexts they are often masked-at least facially.

Ekman and Friesen (1969) have argued that in deceptive situations most people express or 'leak' their true emotion or attitude through bodily rather than facial cues. More specifically, through feedback from others and detailed internal feedback, people learn to control their facial expressions but normally do not monitor their body posture and movements. A teacher in school may call on a student to give an account of the required reading; the unprepared student may respond nonverbally with a stoic facial expression, and at the same time, reveal extreme tension in his or her body movements and/or posture. It follows that if the true affect or attitude of an individual is to be discerned, the observer must be capable of accurately perceiving bodily nonverbal expression along with facial expression (Trout and Rosenfeld, 1980). In deceptive situations, or in social contexts where certain negative emotions are not acceptable, evidence suggests that bodily cues are a more reliable indicator of true emotional or attitudinal states than are verbal messages (Ekman and Friesen, 1969, 1974).

A review of the literature reveals that several studies have been conducted on the relationshp between emotional states or attitudes and postural behavior (Ekman, 1964, 1965a, 1965b, Ekman and Friesen, 1967, 
1969; Mehrabian, 1967, 1968b, 1968c, 1969b, 1970, 197la, 1971b; Mehrabian and Friar, 1969). The research cited suggests that posture is intimately linked with the attitute an individual has toward another; though posture is less clearly decoded than other nonverbal cues, it is still a valid indicator of a person's attitude and a significant variable for further investigation.

At this point it is important to make explicit the notion that a person's attitude is not synonymous with his or her attentive communicator style, although it is arguable that a person's emotional state or attitude does have a certain amount of effect on his or her style. The similarity between an attitudinal state an attentive communicator style is that the list of postural behaviors for a positive attitude and attentiveness (moderate relaxation, direct orientation, and accessibility), or a negative attitude and inattentiveness (least or extreme relaxation, indirect orientation, and inaccessibility) are related enough to warrent comparision.

Given that research shows a strong association between attitude and specific postural behaviors, the present inquiry will assess whether attentiveness can be accurately discerned from those postural behaviors that have been deemed by investigators to be indicative of attentiveness.

Norton and Pettegrew (1979) conclude their article by saying that nonverbal cues are more intimately linked with attentive communicator style than are verbal cues. They state that, "... this is especially true for posture; leaning toward the speaker, maintaining a relaxed posture.... These cues can be reinforced through both eye contact and verbal (other-oriented) behavior" (p. 24). The weakness of this 
conclusion is that their evidence is entirely based on inferences made through utilization of a self-report methodology and relying on similar contributions by other authors. Not unaware of this weakness, the authors acknowledge it by writing, "... it is reasonable to adopt more advanced methods such as coding schemes based on live or videotaped communicative interactions" (p. 18).

In summary, the present investigation is significant for the following reasons:

1. This study will add to the existing information on the communicative process

2. This study will provide a more advanced methodology for analysis of communicator style

3. This study will add to the sparse information on postural positions as related to attentiveness.

It is also projected that the results of this investigation will provide investigators with a behavioral index of easily recognizable postural behaviors indicative of attentiveness. The results may also provide individuals with information regarding how their postural behavior is interpreted by others. 


\section{CHAPTER II}

THEORETICAL FRAMEWORK: RESEARCH IN NONVERBAL COMMUNICATION

On a fundamental level, nonverbal behavior in interactional situations is informative. It is impossible not to behave, and it is impossible not to communicate. Watzlawick, Beavin, and Jackson (1973) proposed the axiom, "one cannot not communicate" (p. 36). These authors suggest that all nonverbal activities have message value and can influence others. Communication between individuals does not take place only when mutual understanding occurs. Rather, communication takes place all of the time on all cognitive and affective levels and is expressed both verbally and nonverbally.

Definitions of nonverbal communication vary among researchers. Edward Sapir (1949) offered one of the more elementary definitions when stating, "nonverbal communication is an elaborate code that is written nowhere, known to none, and understood by all" (p. 556). The concept of nonverbal communication has not proven to be as simple as expressed almost forty years ago by Sapir. Rather, it has been open to a variety of renditions as scholars have attempted to discover which communicative behaviors actually fall under the rubric of nonverbal communication.

By way of example, Burgoon and Saine (1978) distinguish nonverbal communication from verbal communication by "...the basis of its origin, the way it is neurophysiologically processed, its coding system, its language characteristics, and its message potential" (p. 24). Dance 
(1967) suggests that there may not be uniquely human communication that is nonverbal. He does not deny that we may engage in nonverbal behaviors, but once these behaviors are interpreted by another symbolically, Dance posits that they become verbal phenomena. Albert Mehrabian (1981) believes that the generalized use of the term 'nonverbal communication' is often a misnomer and prefers to use the designation 'implicit communication' arguing that the former refers only to those behaviors distinct from speech, not including paralinguistic or vocal phenomena.

Other communication scholars express the notion that 'communication' should not be broken up into verbal or nonverbal categories and studied independently. Birdwhistell is reported to have said that isolating nonverbal behavior from the total communication process is as "...inconceivable as studying noncardiac physiology" (Knapp, 1978, p. 3). Even the label 'nonverbal' has been the object of controversy and authors and researchers have suggested such replacement terms as: bodylanguage, pasimology, kinesics, coenisis or coentics, and semiotics.

Due to the diversity and complexity of nonverbal communication behaviors, many authors have attempted to compile a specific list of the nonverbal areas or groups of behaviors that they believe engender meaning. Specifically, Argyle (1969) has listed six areas, Duncan (1969) discusses six areas, Barker and Collins (1970) present eigtheen areas, Eisenburg and Smith (1971) list three areas, Ruesch and Kees (1971) offer three areas, and Knapp (1978) gives seven areas. These lists are not attempts by authors to define nonverbal communication, rather, they are offered to clarify, for the reader, those communicative behaviors that can be labeled nonverbal. The succeeding discussion will give some indication of the evolution of research techniques and methodology in nonverbal 
communication and the contemporary approaches to the study of this phenomenon.

\section{Historical Approaches}

Prior to this century, the most monumental work in nonverbal communication was Darwin's The Expression of the Emotions in Man and Animals written in 1872 (Ekman, 1973; Mahl, 1968). In the summary of his book, Darwin states that "the power of communication... by means of language has been of paramount importance in the development of man; the force of language is much aided by the expressive movements of the face and body" (1872/1965, p.345). With keen observation, scientific methodology, and biological perspective, Darwin accounts for many of the expressions and gestures used by man and the lower animals. The scientific study of decoding was conducted by Darwin with the use of photographs and drawings. In the area of nonverbal communication prior to 1973 , serious attention had not been paid to Darwin's work nor had the real merits of his findings been appreciated (Ekman, 1973).

Several years after Charles Darwin had developed his thesis concerning the origin, development, and biologically determined expressive movements in man and animals, Sigmund Freud (1915/1957) proposed that repressed-unconscious impulses, wishful thoughts, emotions and memories were often expressed in the nonverbal communication of his clients. Wilhelm Reich (1945) advanced Freud's views on the concept of character armor; as a result of the significance of this approach Reich is considered one of the founders of modern kinesics.

In the classic study, Gesture and Environment written in 1941, anthropologist David Efron focused on the observation, recording, and 
analysis of head and hand movements, space, and posture. Efron's study of Eastern European Jews and Southern Italians that had emigrated to the United States showed that body movements were not the result of racial determinism, as believed by segments of German psychology under the influence of Nazism, but varied from culture to culture (Efron, 1941, 1972). The theoretical rigor and the use of appropriate methodology contributed to the credibility of Efron's work. It is still considered one of the best studies in the field of nonverbal behavior today (Scherer and Ekman, 1982).

The 1950's show a notable increase in the quantity of nonverbal studies culminating with emphasis on specific areas of the human body as the subject of empirical investigations in the early 1960's. In nonverbal studies and reviews there is some disagreement concerning nonverbal communication modalities, however a list of areas of primary concern to nonverbal researchers would probably include the following: (a) body motion or kinesic behavior: body movements, gestures, posture, facial expression and eye movement; (b) paralanguage: voice qualities, vocal characterizers, vocal qualifiers, and vocal segregates; (c) proxemics: personal and social space; (d) environment; (e) touching; (f) appearance: body types, color, smells, and artifacts. Of the modalities listed, body motion, paralanguage, and proxemics have been the subjects of the majority of investigations by researchers.

A pioneering investigator can be identified for each of these three distinct areas of nonverbal communication-George Trager (1958) for paralanguage, Ray Birdwhistell (1952) for kinesics, and Edward Hall (1959) for proxemics (Duncan, 1969). A common thread linking these three nonverbal investigators is their synthesis of previous efforts, 
the widely adopted name they coined for their specific area of expertise, and the formulation of a transcription system (Duncan, 1969).

Trager's 'first approximation' of paralanguage was developed from the collaborating efforts of several individuals whose concern was to define and differentiate vocal behaviors. His transcription of paralinguistic behaviors fell into the following categories: (1) voice qualities: pitch range, vocal lip control, articulation, rhythm control, resonance and tempo; (2) vocal characterizers: laughing, crying, whispering, snoring, moaning, groaning, yawning, whining, stretching, sucking, spitting, sneezing, coughing, clearing of the throat, sniffing, sighing, swallowing, inhaling, exhaling, belching, and hiccuping; (3) vocal qualifiers: intensity, pitch height, and extent; (4) vocal segregates: 'uh,' 'um,' 'uh-huh,' and variants, silent pauses, and intruding sounds (Trager, 1958). Trager has not only applied his system to middle-class Americans but also to several cultural situations (Trager, 1960, 1961). Transcription systems in paralanguage that are analogous to Trager's system can be found in Pittenger and Smith (1957), Pittenger, Hockett, and Daneht (1960), Austin (1965), and Crystal and Quirk (1964).

Birdwhistell's (1952) transcription system in kinesics provides a symbol for every possible human movement and is so comprehensive that it cannot be presented here in detail. His notation system allows for the classification of movements that evoke general and specific 'meaning' in interpersonal interactions. The broad categories of Birdwhistell's system include: (1) total head: nods, sweeps, tilt, etc.; (2) face: brow movements, eye movements, mouth movements, tightened temples, ear wiggles, scalp movements, etc.; (3) trunk and shoulders: spinal positions, shoulder positions, pectoral, chest and stomach muscle tension and relaxation, 
etc.; (4) shoulder, arm and wrist; (5) hand and finger activity: extended, hooked, curled, touching, nail picking, clapping, etc.; (7) foot behavior: toe teeter, toe dig, bounce, glide, etc.; (8) neck: twists, projections, swallowing, tensing or sagging, etc. Birdwhistell does not offer validity data for his findings but does present sufficient detail insofar as to provide independent checking (1952, 1966, 1967, 1970, 1979).

Where Birdwhistell has described in minute detail the communication of a single interactant, Albert Scheflen has focused on communication on the social level (Duncan, 1969). Trained as a psychotherapist and psychoanalyst, Scheflen has done extensive research in kinesics since 1957. He has also attempted to provide a synthesis of the two major approaches of studying bodily behavior-the psychological and communicational approaches (Scheflen, 1964, 1967, 1972, 1974, 1976).

Anthropologist, Edward Hall, like Birdwhistell, has taken principles from linguistics and used them in developing a notation system for proxemic phenomena. On a 1 to 9 scale, Hall records proxemic behavior in nineteen areas which regulate and structure the distance between individuals during interaction (1974). The proxemic areas are: posture; body orientation; lateral displacement of bodies; change of orientation; change of distance; body distance; gestures; kinesic isomorphism or mirroring; affect of kind or emotional tone of the interaction; affect of intensity; eye behavior; talking; linguistic style; voice loudness; listening behaiovr; olfaction and thermal zones; bodily involvement; and touching. The research of Garfinkel (1964) and Felipe and Sommer (1966), has supported Hall's observations regarding the interpersonal consequences of violating implicit cultural and/or subcultural proxemic norms. 
Research in nonverbal communication in the 1960 's, 1970 's, and early 1980's has taken a different direction than in previous years and there has been an establishment of a firm basis from which nonverbal investigations continue to grow. Beginning in the 1970's journals in communication, psychology, social psychology, and other associated disciplines began to frequently publish articles concerning nonverbal behavior. This trend was followed by the emergence of several nonverbal journals and several published monographs. Later in the decade, nonverbal conferences began to appear and the first National Conference on Body Language was held in New York City in 1977. The research on nonverbal communication has continued to spiral in quality and quantity well into the early 1980 's. The general characteristic of this period is a concentrated effort toward summarizing and synthesizing the previous work of many individuals.

\section{Contemporary Approaches}

Investigations have been conducted in recent years on almost every conceivable aspect of nonverbal communication. Some of the more notable studies include: Argyle's (1975) study of body movement and eye behavior, Birdwhistell's (1952) and Scheflen's (1972) kinesic research, Argyle's and Cook's (1976) work on gaze and mutual gaze, Efron's (1941) work on racial determinism, Eibl-Eibesfeldt's (1975) comprehensive ethology, Ekman's and Friesen's (1972) investigation on emotions expressed by the face and Ekman's (1973) extension of Darwin's epic work in human and animal expression, Hall's (1974) study on proxemics, Hess' (1975) interesting examination of pupil dialation, Knapp's (1978) synthesis of nonverbal research, Montagu's (1971) analysis of touching, and Mehrabian's (1968b, 1972, 
1981) inquiries into status and immediacy. Along with the numerous books and articles written with a nonverbal theme, the following jourals have also emerged: Environmental Psychology and Nonverbal Behavior, Kinesics, Semiotica, Somatics, and Sign Language Studies.

Studies in nonverbal behavior have been done in a variety of contexts ranging from laboratory settings to organizational environments; books and articles have been written on almost every subject; conferences have been held; journals have been established. Even outside the domain of the social sciences, nonverbal research has become an important area of consideration for such disciplines as law, business, and education. As a result of these phenomena, academicians and other professionals have secured a place for nonverbal communication in the academic world and our society as a whole. Nonverbal communication research is on the verge of considerable development in theory and practice as it emerges from the embryo stage with the aid of technological advances, refined research tools, and the interest of communication and social scientific scholars.

Concerning the manner in which nonverbal research is currently conducted, Starkey Duncan Jr. of the University of Chicago, in his classic paper on nonverbal communication (1969), has divided the research in this field into two major categories-the 'structural' and the 'external variable' approaches. Duncan describes these categories in the following:

One strategy is to study communication as a tightly organized and self-contained social system, like language. This system operates according to a definite set of rules, and the task of the researcher is to explicate these rules. I shall call this the structural approach. The other strategy is to relate the rate of occurrence of specified nonverbal behaviors to a variety of external variables, such as the interaction situation, the personality characteristics of the interactants, or the reactions of 
judges to the interaction. I shall call this the external variable approach. . . A central methodological difference between the two approaches is in the use of statistics. The structural approach is nonstatistical, while the external variable approach is primarily statistical ( $p .121$ ).

Partially influenced by linguists, structuralists view nonverbal communication as verbal communication. Rosenthal (1979) describes this approach as " .. . largely descriptive, relying on observational rather than experimental data. Its major thrust is that nonverbal language is learned early, is culturally determined, and that a great deal of what transpires between individuals and groups is predetermined, even rituallike, in its regularity" (p. 3).

The three primary investigators already mentioned, Trager, Birdwhistell, and Hall, are all committed to the structural approach. Other structural studies in paralinguistics have been done by Crystal and Quirk (1964) and Stockwell, Bowen, and Silva-Fuenzalida (1956). In kinesics, Scheflen (1967), Condon and Ogston (1967a, 1967b), and Kendon and Ex (1969) have all used notation systems. Sommer (1967) has done related work in proxemics.

Schleflen, as a spokesperson for the structural approach, believes that investigators who isolate nonverbal elements of communication only run across 'untested speculations' (1964). He explains to his readers:

My co-workers and I believe that the essential discipline for determining meaning is to examine the relations of an element to its context. The physiologist could not determine the function of the thyroid if he threw away the dog and examined only the isolated thyroid. Behavioral scientists could go through endless rituals of counting and measuring and speculating about the meaning of an event and having judges vote on the most popular speculation. But the chance to determine experimentally the function of an element is lost if the system in which it functions is scrapped (p. 319). 
With reference to the external variable approach, Duncan believes that the methodology for this approach can be seen in the studies of such researchers as Ekman (1957, 1964, 1965a, 1965b) and Ekman and Friesen (1967, 1968). In essence, Duncan has divided the research in nonverbal communication into two categories, however, not all of the nonverbal investigators accept these divisions. For example, Scherer and Ekman (1982) do not draw as fine a line in their review of nonverbal behavior research and feel that methodologies of research are more complementary than contradictory.

The distinction Scherer and Ekman (1982) make in nonverbal research is on the focus of interest or research tradition that individual investigators may hold, rather than the various methodologies they might employ. This emphasis is not totally inconsistent with Duncan's analysis for he does state that both approaches should be vigorously pursued in the study of nonverbal phenomena and that both appear to be "complementary and mutually facilitating" (1969, p. 121). The discrepancies between Scherer and Ekman, and Duncan appear to be the result of Duncan's attempt to overclarify and categorize research methodology.

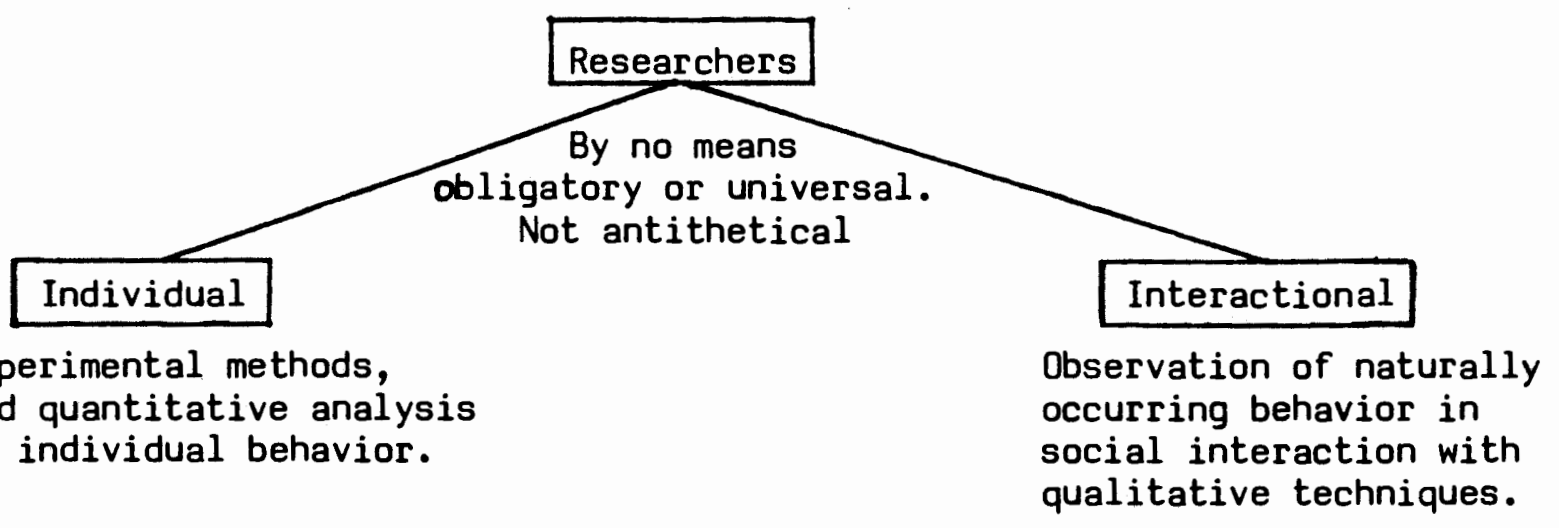

Figure 1. The two opposing research approaches of nonverbal investigators. 
It would be unfair to Duncan to suggest that he believes that all research conveniently falls in line with either of his defined approaches, for in fact, he does not. Rosenthal's research (1979) is one such example. Using the Profile of Nonverbal Sensitivity file test, his findings are based on a more personality-oriented approach, since he believes that aspects of nonverbal behavior-skill or styles are somewhat enduring characteristics of a person (Rosenthal, 1979, p. 3).

The two major foci in nonverbal research, as perceived by Scherer and Ekman (1982), are the individual and the interaction. These authors claim that researchers focusing on the behavior of the individual have been interested in three major issues: "(1) externalization or expression of traits and states, (2) inferences from nonverbal cues, and (3) intraindividual organization of behavior" (p. 9). Additionally, studies on the interaction process also have three distinct approaches according to Scherer and Ekman (1982): "(1) the nature of the cultural communication code, (2) the coordination of behavior in social interaction, and (3) the study of interpersonal relationships" (p. 10).

Burgoon and Saine (1978) state that the research in nonverbal communication can be divided into six specific but overlapping areas. The first of these areas is the body language approach which is the more popular commercial treatment of the subject. The overly simplified goal of this approach is the discovery of the inner thoughts and feelings of others by subjectively deciphering nonverbal behaviors. (This approach is not adhered to by credible nonverbal investigators and is more often presented by laypersons.) The ethological approach is the comparative study of animal behavior which focuses on the origins, development, and functions of nonverbal behavior in animal life. The third approach, 
the linguistic approach, is divided into two camps: the structure-centered approach, which determines how messages are organized and what the units of organization are, and the meaning-centered approach, which emphasizes how people assign meaning to nonverbal messages. The psychoanalytic approach is embedded in psychoanalytic tradition and assumes that nonverbal behaviors are a response to the psychological condition of the communicator. The psychological approach is the product of those interested in how the anatomical constraints and physiological structure determine nonverbal expression. Lastly, the functional approach is characterized by an interest in the interpersonal ramifications of action and users of this approach attempt to coordinate both the verbal and the nonverbal realms of behavior.

\section{Summary}

The scientific and interdisciplinary study of nonverbal communication has been of recent interest to communication scholars, particularly when compared to other areas in the field of speech communication. Although early investigators made significant contributions to the field, only in the last 25 years have nonverbal communication studies increased in quality and quantity. Today anyone concerned with measuring individual behavior and human interaction, will find pertinent information and relevant methods. Those who desire to come to a more explicit understanding of nonverbal communication for practical reasons will discover a great deal of literature on the subject.

As in all communicative studies, the approach taken by the investigator plays a very significant role in determining the direction of the study, the type of research methodology used, and the subsequent 
and predictable data that is gleened from the investigation. The present study, in a general sense, can be viewed as an external variable approach utilizing experimental methods and qualitative analysis of individual behavior. More specifically, this study can be classified as a meaningcentered approach and is based on the following assumptions gleaned from the work by Burgoon and Saine (1978):

1. The nonverbal variable in communication is a continuous, dynamic, and systemic process

2. The behaviors displayed by an individual, no matter how small, have communicative value

3. The study of nonverbal communication should be approached as a social rather than psychological phenomenon

4. The systematic nonverbal behaviors of any individual or group are culturally determined

5. The recognition of emotion or attitude can be inferred from behavioral cues. That is, certain behaviors are more important than others in the organization of nonverbal messages and these behaviors are instrumental in conveying information that will allow other communicants to accurately judge the emotion or attitude expressed

6. The study of specific channels and their character does not hinder the legitimacy of the study nor the relevance of its outcome.

The leading proponents of the meaning-centered approach are Paul Ekman, Wallace Friesen, and Paul Dittmann.

No one study fits neatly into any one approach, nor do researchers always take the same approach in different investigations. The above list of assumptions has been an attempt to fit the present study into an already established approach to nonverbal investigation so that the reader can more clearly see the direction of the study and understand its significance. 


\section{CHAPTER III}

\section{REVIEW OF LITERATURE: POSTURE AND ATTENTIVENESS}

\section{Posture Defined}

There are three main postures in American culture: standing, sitting, and lying. 'Posture' differs from 'gesture,' a reference to specific movements, and also differs from 'body movement,' a reference to the frequency of gestures and changes in posture (Cook, 1971). The range of stable postures is large since each has many variations corresponding to different positions of the arms, legs, and angles of the spine. Anthropologist Gordon Hewes (1957), lists 1,000 postural variations which can vary significantly from culture to culture. The variations in posture are numerous; there are approximately thirty "culturally-standard postural configurations which are shared communicative significance for Americans" (Scheflen, 1964, p. 316). Postural configurations are not universal for all Homo sapiens nor are they individual and unique for each person (Scheflen, 1964). There are rather social and cultural tendencies that would influence male students at Oxford to sit in class with their legs crossed while male students in Hati may squat on the floor.

\section{Posture and Expression}

In the clinical context where overt expressions of attitude were not socially acceptable, nonverbal communication became an area of 
interest to the psychoanalyst. In this context, "posture was used as a source of information about client's characteristics, feelings, and attitudes toward others and themselves" (Mehrabian, 1969b, p. 359). In early years psychoanalyst Wilhelm Reich (1945) presented the view that a client's defenses were expressed by his speech and skeletal behavior. An earlier study (Allport and Vernon, 1933) shows the relation of postural style to personality characteristics. Writing informally on this area, Deutsch $(1947,1949,1952)$ noted that observation showed that a client's posture was related to his motivations, attitudes, and intentions. Braatoy (1954) suggested that rigidity or tension in posture was a signal to the clinician of the difficulty they might encounter when trying to introduce changes in the client. Taking a different approach to the study of posture, Fromm-Reichman (1950) imitated her client's postures in order to make inferences about their feelings.

Many psychoanalysts have suggested relationships between postural cues and feelings or attitudes, but their observations have been, for the most part, informal (Mehrabian, 1972). According to George Mahl (1968) psychoanalysts have neglected the study of posture in clinical interviews. Mahl finds this remarkable in view of the fact that "clinical lore has it that some of the most significant interaction between patients and therapists transpires by means of the nonverbal channel, and that experienced, skillful clinicians are preconsciously, if not consciously, guided by the bodily behavior of their patients (1968, P. 295).

One of the early investigations of posture most relevant to the present study are three experiments executed by William James (1932). The purposes of his experiments were to determine to what extent posture 
was expressive, what was the relative expressive value of the various parts to the total posture, and whether there was a correlation attitudinal or emotional pattern on the part of observers. James photographed 347 different postures of one masked male model. The five postural variables considered in James' study were the head, trunk, feet, knees, and arms. From the first experiment, 30 photographs were selected by observers wich had the highest agreement concerning the attitude being communicated. The second and third experiments yielded the following four postural categories:

(a) Approach, an attentive posture communicated by a forward lean of the body

(b) Withdrawal, a negative, refusing, or repulsed posture communicated by drawing back or turning away

(c) Expansion, a proud, conceited, arrogant, or disdainful posture communicated by an expanded chest, erect or backward-leaning trunk, erect head, and raised shoulders

(d) Contraction, a depressed, downcast or dejected posture communicated by a forward-leaning trunk, a bowed head, drooping shoulders, and a sunken chest (Mehrabian, 1969b, p. 36l).

James found that head and trunk positions were the most important indicator of attitude and a forward lean communicates a positive attitude in contrast to a backward lean or turning away which communicates a more negative attitude.

Experimental evidence on the importance of posture as a nonverbal channel of communicator attitude or emotion has greatly increased since James' experiments. Most of the early research focused on the interpretation of only one set of nonverbal cues such as aspects of the face or in studies of posture and gestures. Ekman (1964) and Ekman and Friesen (1967) have attempted to draw a comparison between different nonverbal cues in terms of the type of information communicated. They 
suggest that body and face movements are more likely to communicate specific emotions, whereas stationary facial expressions and postures are more likely to communicate gross affect (liking and disliking or positive and negative attitude). The intensity of specific emotions can be inferred from stationary or moving bodily or facial cues. Movements of some duration communicate the specific emotional states while the nonmoving positions of some duration, head tilts and leaning, communicate gross affective states-usually. The body indicates the intensity of the emotion while the face identifies it. As already mentioned in the introduction, a central assumption in Ekman's formulation of the types of nonverbal cues is that "the face is an affect display system while the body shows the. person's adaptive efforts regarding affect, or pictorial illustrations of some aspect of an affective experience" (Ekman and Friesen, 1968, p. 183).

Body orientation, the degree to which a person's shoulders and legs are turned toward other communicants, is an indicator of communicator attitude. Mehrabian has studied head, shoulder, and leg orientation along with eye contact of standing (1968b) and seated (1968c) subjects. His findings show that there is considerable consistency among the various orientation measures and that shoulder orientation can be used as a summary index of body orientation. Mehrabian (1967) also discovered that eye contact and body orientation were separate in design and can be studied as separate indices of attitude.

The four experiments conducted by Mehrabian on standing subjects suggest that relaxation, a forward lean, and small proxemic distance communicate a more positive attitude, whereas a backward lean of the torso and larger distances communicate a more negative attitude in 
interpersonal situations. Mehrabian also found that for male communicators, more eye contact, smaller distance, and absence of an armsakimbo position communicates a more positive attitude. Female communicators convey a positive attitude by absence of arms-akimbo position, smaller distances, and arm openness.

The following dependent measures were used by Mehrabian in studying the relationship of attitude and seated posture: eye contact; distance; head, shoulder, and leg orientation; arm and leg openness; backward lean of the torso; hand, leg, and body relaxation. His findings indicate that there is more eye contact with liked rather than disliked people and this is consistent with other findings (Exline et al., 1965; Sommer, 1967 ). Shoulder orientation, along with the various indexes of orientation, is most direct for intensely liked addressees in contrast to a less direct orientation toward intensely disliked addressees. Hand and leg relaxation were not found to be significant indexes of communicator attitude, while body relaxation, the degree of backward lean, decreased for liked addressees. Males communicated a high degree of relaxation for disliked females and showed a high degree of body tension and vigilance toward intensely disliked males. Females exhibited body relaxation with both disliked male and female addressees.

In Mehrabian's studies of seated communicants (1968c, 1969b), least relaxation is observed as obvious muscular tension in the hands and rigidity of posture as exhibited by a $20^{\circ}$ forward lean and a less than $10^{\circ}$ sideways lean, curved back and in the case of females, an open arm position. Extreme relaxation is exhibited in a greater than $20^{\circ}$ backward lean and a greater than $10^{\circ}$ sideways lean.

Broadly summarizing Mehrabian's research on attitude and bodily 
posture, liking is communicated by a forward lean of the torso, openness of arms and body, direct body orientation, and a moderate degree of postural relaxation. In contrast, disliking is communicated by a backward lean of the torso, closed positions of arms and body, indirect body orientation, and tense and/or extreme postural positioning.

Other research on attitude as related to nonverbal communication can be seen in numerous investigations. Schlosberg (1954) proposed that there are three dimensions of emotional expression: pleasant-unpleasant, acceptance-rejection, and sleep-tension. Schlosberg's measurable dimension of sleep tension (level of arousal and intensity of affect) is relevant to the expression of emotions or attitudes in head and body cues. Reece and Whitman (1962) noted that shifts in posture toward another person indicated warmth while postural slumping and less direct orientation indicated coldness. Using female nude figures, Machotka (1965) found that subjects were drawn to bodily configurations that had moderate open-arm positions rather than to very open or closed-arm positions. Dittman, Parloff, and Bommer (1965) selected relaxed postures with little movement as an indicator of pleasant bodily cues. Rosenfeld (1966a) found that when subjects were instructed to seek approval there was little difference in body orientation, but when told to avoid approval, a significant difference was observed. Mehrabian and Williams (1969) suggest that trunk-swivel movement indicates an unwillingness on the part of the communicant to interact. Breed (1972) found that subjects evaluated confederates more highly on a semantic differential and rated them as having a more positive attitude towards them as intimacy increased. He also observed a greater number of forward leans as intimacy increased, and females shifted their body position more often if they 
perceived the confederates' interest and attitude to be less favorable than did males. When a communicator and an addressee hold similar attitudes, McGinley, Nicholas, and McGinley (1978) discovered, the communicator who displays open body positions is evaluated more positively by the addressee than if the communicator displayed closed body positions. Using the PONS film test, DiMatteo, Friedman, and Taranta (1979) showed than medical patients tended to prefer physicians who can understand their feelings even when they were not willing or able to express them verbally.

A person's expressed attitude is not synonymous with a person's attentive style of communication. Attitude is an individual's general manner or feeling toward a person or thing which is often expressed in certain postural positions. Whereas an individual's attentive style is what is behaviorally used to signal to others that he or she is being attentive. The research reviewed above has primarily been concerned with those specific nonverbal behavioral cues indicative of an individual's attitudinal state while the present study concerns those specific nonverbal behavioral cues that individuals use to signal their attentiveness. Expression of attitude and attentive style are alike in that they appear to have similar identifiable postural positions. The list of postural positions for a positive attitude and attentiveness, or a negative attitude and inattentiveness are closely related.

\section{Attentiveness Defined}

Attentiveness is a particular manner of interacting which is expressed by an individual's verbal and nonverbal behavior. This particular component of interaction signals to those involved that the communi- 
cative process is working.

Attentiveness is not synonymous with attention, the latter being a description of a person's reception and cognition. Regarding attention, researchers in the communication field have tended to limit their focus to the role 'audience attention' plays in the persuasiveness of the speaker (Baken, 1966; Deutsch and Deutsch, 1963; Makworth, 1970; Norman, 1976; Ross, 1974; Scheidel, 1967; Simons, 1976). In contrast, attentiveness is the way individuals behaviorally signal to others that their activities and energies are focused on something that occupies them (Norton and Pettegrew, 1979). Head nodding, restatement and other nondirective phrases, body and trunk lean, eye contact, physical proximity and relating similar experiences or feelings are all behavioral evidence of an individual who is attentive.

\section{Attentiveness and Communicator Style}

Berger (1977) states that "the general thrust of research on communicator style is to isolate various facets of self-presentation with such factors as attractiveness and effectiveness in interactions" (p. 219-220). The most ambitious attempt to develop a comprehensive communicative style construct was undertaken by Norton (1978) and his colleagues (Norton and Miller, 1975; Norton and Pettegrew, 1976; Norton and Warneck, 1976).

Others have also done work in the area of communicator style. Bradley and Baird (1977) examined the relationship between communicator style and managerial behaviors in organizational contexts in order to describe the communicative styles associated with varying approaches to 
management. Brandt (1979) has explored the process of impression formation in initial interactions as a function of a person's communicator style, and attempted to identify the relationship between communicator style and an observer's perception of an interactant's interpersonal attractiveness and communicative effectiveness.

As a collection of intentional verbal and nonverbal behavioral signals, attentiveness is an active facet of an individual's communicator style. An individual's communicator style is the way he or she has learned to show others how the message content of an interaction should be taken, interpreted, filtered, or understood (Norton and Pettegrew, 1979).

One's impression might be that attentiveness is most closely related to listening, an element that is highlighted in contemporary models of communication. However, until recently, little has been written on this subject presumably because the concept of listening is very difficult to treat thoroughly and clearly (Stewart, 1983a). In his recent article on listening, Stewart (1983b) writes,

... .although listening is widely viewed as a primary skill in the organizational context and is an important component of the basic speech communication, there is relatively little research that carefully identifies the nature of the listening process or specifies its qualities or components" (p. 379).

Past research on listening infers that investigators are primarily concerned with intrapersonal cognitive behavior, e.g., thinking ahead of the speaker.

At this time, attentiveness is most closely related to the literature on empathy (Bayes, 1972; Cook, 1964; Haase and Tepper, 1972; Hackney, 1974; Rogers, 1951; Truax and Carkhuff, 1967), at least that which is written about empathy in behavioristic terms. Notwithstanding 
this association, the author believes that in the future the relatively new construct of attentiveness will be most closely related to the notion John Stewart (1983b) has recently discussed as 'interpretive listening.' The emphasis on interpretive listening is placed, "... not on what is happening inside communicators but on what transpires between them" says Stewart (1983b, p. 389). The skills involved in interpretive listening are similar to those associated with empathic listening and include paraphrasing, mirroring, and asking clarifying questions (Stewart, 1983b).

At present, the assumptive roots of empathic listening are being questioned by individuals in the field of speech communication (Arnett, 1981, Arnett and Nakagawa, 1983; Ruben, 1978; Simmons, 1974; Stewart, 1983b). Arnett and Nakagawa (1983) suggest a

... shift from psyche to the linguisticality of human relationships, analogous to the Copernican Revolution. The self, like the earth, can no longer be viewed as the center, but the person must be studied as situated in relationship with the ecological system or relational system between persons (p. 375).

Empathy overlaps attentiveness along behavioral dimensions rather than conceptual lines. Conceptually, empathy is defined by Howell as, "the ability to replicate what you perceive another to be feeling or thinking" (1982, p. 245). Kenneth B. Clark defined empathy in a speech to the American Psychological Association as being, "the capacity of an individual to feel the needs, the aspirations, the frustrations, the joy, the sorrows, the anxieties, the hurt, indeed, the hunger of others as if they were his or her own ...." (1980, p. 188). Behaviorally, empathy is strongly related to attentiveness in that empathy is a combination of understanding the feelings of another person and then providing feed- 
back to that person via attentive behavioral cues that communicate an empathic attitude (Norton and Pettegrew, 1979).

Carl Rogers (1951) is well known for identifying the behavioral components that are common to both attentiveness and empathy. These components have gone through some revision in the last thirty years and now include eye contact, forward trunk lean, physical proximity, verbal following, listener silence and gestures (Bayes, 1972).

Empathy and listening are also not synonymous with attentiveness. Norton and Pettegrew (1979) explain the difference by saying:

The empathic communicator must be attentive but the attentive communicator need not be empathic. In a like manner, listening behavior is characterized by attentiveness but attentive behavior need not be marked by listening activity. For example, one could adopt an attentive style while communicating as a critic which would preclude both empathy and listening; the critic would choose to neglect the personal feelings of the other and focus on the nonverbal rather than verbal aspects of the message (p. 14).

Attentiveness is unlike empathy and listening in that it primarily serves as a stylistic function in the communication process and gives behavioral evidence that the individual is actively involved in message reception. The counterpart to attentiveness is inattentiveness, a combination of activities that indicate than individual has assumed an indifferent attitude toward a speaker, a message, or both (Norton and Pettegrew, 1979).

Norton and Pettegrew (1979) are primarily responsible for the distinction made between attention, listening, empathy, and attentive-ness, along with their establishing attentiveness as a stylistic component and construct. While theoretically developing this communicative style construct, these authors produced the following mapping sentence of attentiveness with the intention that it be expanded or modified to 
enrich the theory of attentiveness (Norton and Pettegrew, 1979, p. 16).

a

The Attentiveness Measure (ATT) is the ( $a_{1}$ cognitive) assessment by respondent $(x)$ of his/her

b (b $b_{1}$ self perception) of the way he/she verbally and paraverbally interacts to signal how literal meaning is taken, interpreted, filtered, or understood in

C

( $c_{1}$ general face-to-face) communication with respect to d

( $d_{1}$ behavioral signals)

( $d_{2}$ sensitivities/empathy according to normative criterion)

( $d_{3}$ self evaluation)

for this behavioral style ranging from (very strong) to (very weak) manifestation of the respective item.

Figure 2. Norton and Pettegrew's mapping sentence of the attentiveness construct.

In the final analysis, Norton and Pettegrew's research and the implementation of the Attentiveness Measure with 158 students and 170 adults has led the authors to the following conclusions:

- . the attentive style of communication is a complex process involving both sending and receiving messages during the interpersonal transaction. The attentive communicator focuses his/her regard toward the other wile simultaneously signaling verbally and paraverbally that interest, concern, sensitivity, and notice are being shown. . . . In short, attentiveness is an important element in the communication process. It serves an active, confirming function-testifying to the worth of the other's communication (1979, p. 26).

As a result of their testing, Norton and Pettegrew (1979) further believe that attentiveness accounts for 75 percent of being a good communicator. 
In evaluating communicator style, Norton and Pettegrew (1979) offer three assumptions that are helpful for the purpose of gathering qualitative data on this element of communicator style. First, behavioral signals are acted out by individuals that demonstrate that they are actively involved in the communicative process or that they are active in avoidance behavior or preoccupied with something else. Second, the attentive person is more knowledgeable about the message of another communicant as a result of being more 'co-oriented' and more empathic. This means that the attentive person is more sensitive to the feelings and emotions of another communicator and more tuned in to the content of the message that is being sent. And third, because attentiveness is a conscious act, the individual can become aware of and evaluate his or her own communicator style.

\section{Summary}

From the research cited on posture, the succeeding generalizations about the interpretability of attitudes from nonverbal behavior can be made: (1) communication of attitude can be accurately decoded from nonverbal behavioral cues from the face and body, (2) the face and body can be studied as separate indices of communicator attitude, and ( 3 ) nonmoving positions of some duration tend to more clearly communicate these gross affective states. The investigations reviewed also suggest that postural related variables indicate the following:

1. There are specific postural positions that are strongly associated with attitude. For example, a forward lean of the torso communicates a more positive communicator attitude and a backward lean or turning away communicates a more negative attitude. The degree to which a 
communicator's shoulders and legs are turned in the direction of, rather than away from the addressee is indicative of communicator attitude. In some instances a difference has been observed between male and female communication of attitude through posture.

2. There are specific postural positions that correlate with individual self-report measures. For example, in the encoding studies subjects are able to exhibit specific postural positions when asked to act out certain attitudes.

From the research cited on attentiveness, certain observations can be made concerning this active aspect of an individual's communicator style which include: (a) attentiveness is a stylistic construct in its own right, (b) attentiveness is expressed by an individual's verbal and nonverbal behavior, and (c) attentiveness as a communicator style is more closely related to empathetic behaviors than with listening or attention. Finally, as a result of the research done by Norton and Pettegrew (1979) and related contributions by other scholars, the information on attentiveness also suggests that nonverbal cues are more intimately linked with attentiveness than are verbal cues. Posture, in particular, was discussed as exemplifying attentiveness and involved leaning toward the speaker, maintaining a relaxed posture, and showing interest via body attitude (Norton and Pettegrew, 1979, p. 24). The literature reviewed thus provides a foundation for empirical verification of this aspect of communicator style and determination of the specific relationship between posture and attentiveness. 


\section{CHAPTER IV}

\section{EXPERIMENTAL DESIGN AND METHODOLOGY}

The goal of this research was to substantiate or challange the claim by Norton and Pettegrew (1979) that attentiveness is strongly related to postural activity, and if the claim was supported, to deduce which specific postural positions were indicative of attentiveness. Data on attentiveness and postural positions were obtained from subjects and coders in order to ascertain the relationship between these two phenomena. The methods and procedures utilized in this study will be elaborated on in the succeeding two chapters. In summary, the experimental design included the following steps:

1. Development of coding categories and a coding scheme

2. Recruitment and training of coders to assist in data collection

3. Compilation of attentiveness measures

4. Recruiting and videotaping of subjects

5. Implementation of a pilot study

6. Data analysis, assessment of interrater reliability, and experiment refinement

7. Collection and subsequent analysis of data from the final study.

The problem area under investigation in this study was whether or not there exists a strong association between 12 selected postural positions and the reported level of attentiveness indicated by subjects, their partners, and independent observers. The research hypotheses that 
were tested were:

$H_{1}$ : An individual's level of attentiveness in a seated dyadic interaction will produce a high direct correlation with the specific postural positions he or she assumes.

$H_{2}$ : An individual's level of attentiveness in a seated dyadic interaction will produce a high inverse correlation with the number of his or her postural shifts in position.

The attentiveness variable and its association with postural positions was the central theoretical concern in this study. The direct correlation in Hypothesis 1 was predicted as attentiveness and postural positions were expected to vary together. That is, an individual's level of attentiveness was expected to correlate highly with certain postural positions. The inverse correlation predicted in Hypothesis 2 suggests that the two variables will vary inversely; as one measure is high, the other is low. Thus, if attentiveness is high, frequency of shifts is expected to be low; if attentiveness is low, frequency of shifts is expected to be high.

In order to determine these correlations, three different attentiveness measures were utilized in the experiment. Subjects in the study completed the Dyadic Attentiveness Measure (DAM), partners of the subjects completed the Perception of Partner's Attentiveness Scale (PPAS), and independent observers completed the Coder's Global Report of Attentiveness (CGRA). Results of these three paper-and-pencil measures were then separately correlated with the actual behavior of subjects as determined by the coding of 20 minutes of their postural behavior during a dyadic interaction. The hypotheses were subsequently analyzed by these data.

\section{Operational Definitions}

The following operational definitions may provide greater under- 
standing of the experimental design and methodology used in this study:

Attentiveness: a stylistic construct expressed by an individual's verbal and nonverbal signaling that the communicative process is working. Individuals are thought to be conscious of, and continually monitoring this behavioral signaling; research suggests that nonverbal cues are more strongly linked with attentiveness than are verbal cues.

Postural shift: an observable change from one postural position to a distinctly different position. Postural shifts are not the number of times a subject may have moved back and forth between two or more positions, rather, they are the number of different categorically defined positions the subject assumed. In that there are 12 different postural categories, 12 shifts are the maximum number a subject could produce.

Dyadic interaction: the communication process between two people in which information, meanings, and feelings are shared through the exchange of verbal and nonverbal messages.

Postural positions: specific positions which include: (1) least, moderate, or extreme relaxation of the torso, (2) direct or indirect orientation of the head and shoulders, and (3) accessibile or inaccessible positions of either the arms or legs.

Reported level of attentiveness: the scores given to an individual as the result of the three attentiveness measures utilized in the study. A high mean score on any of these measures indicates a high level of attentiveness, a low mean score indicates a low level of attentiveness.

High correlation: A numerical degree of relationship expressed by either a positive or negative coefficient that ranges from .70 to 1.0 . Such a coefficient describes a marked to a very dependable relationship between variables (Williams, 1979, p. 128).

\section{Coding Categories and Coding Scheme}

The categories used in the coding scheme were mutually exclusive and exhaustive. Mutually exclusive because only one set of behaviors could be coded at any one time and exhaustive because the classification 
included all the behaviors that were expected to occur as well as the category of 'other' for any behavior or set of behaviors that did not fall into the expected and defined categories. As a result of the review of literature on posture (see Chapter III), and independent observation by the experimenter, the postural configurations were defined as:

Least relaxation: exhibited by a straight back, upright trunk, less than a $10^{\circ}$ forward or backward lean, and less than a $10^{\circ}$ sideways lean Moderate relaxation: exhibited by a greater than $10^{\circ}$ and less than $20^{\circ}$ forward or backward lean and less than $10^{\circ}$ sideways lean

Extreme relaxation: exhibited by a greater than $20^{\circ}$ forward or backward lean or greater than $10^{\circ}$ sideways lean

Direct orientation: shoulders and head facing the speaker Indirect orientation: shoulders or head turned away from the speaker Accessibility: open position of the arms and legs Inaccessibility: closed positions of either the arms or legs Other: any behavior that does not fall into these defined categories.

The illustration below shows the approximate degrees of relaxation determined as the basis of the scoring categories.

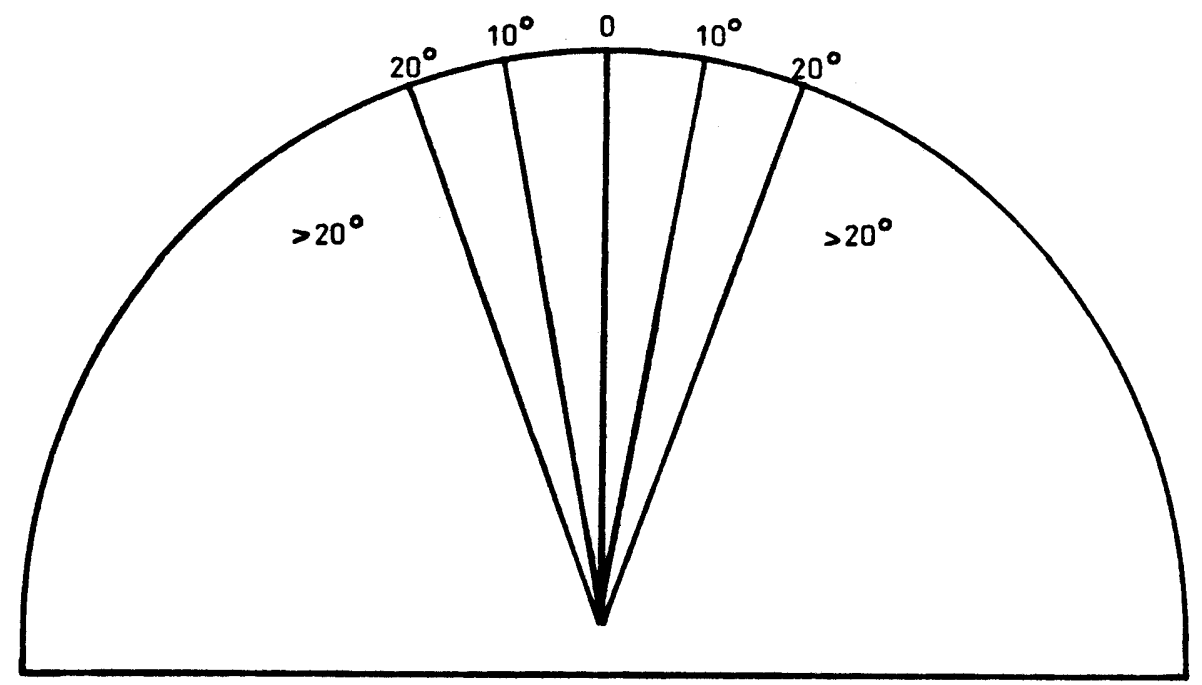

Figure 3. Degrees of relaxation utilized in the coding categories. 
Once the degrees of postural relaxation were determined, the coding categories were set up. As shown in the table below, each coding category consisted of a combination of relaxation, body orientation, and accessibility.

TABLE I

THIRTEEN CODING CATEGORIES FOR SCORING POSTURAL POSITIONS
(1) Least
(2) Least
(3) Least
(4) Least
Direct
Indirect
Direct
Indirect
Open
Open
Closed
Closed
(5) Moderate
(6) Moderate
(7) Moderate
(8) Moderate
Direct
Indirect
Direct
Indirect
Open
Open
Closed
closed
(9) Extreme
(10) Extreme
Indirect
(11) Extreme
(12) Extreme
Direct
Open
Direct
Indirect
Open
Closed
Closed

(13) Other

After the mutually exclusive and exhaustive coding categories were determined, the author took 36 photographs of a friend for the purpose of training the coders in the categories. Eighteen of these photographs appear on the following pages exemplifying the coding categories. 


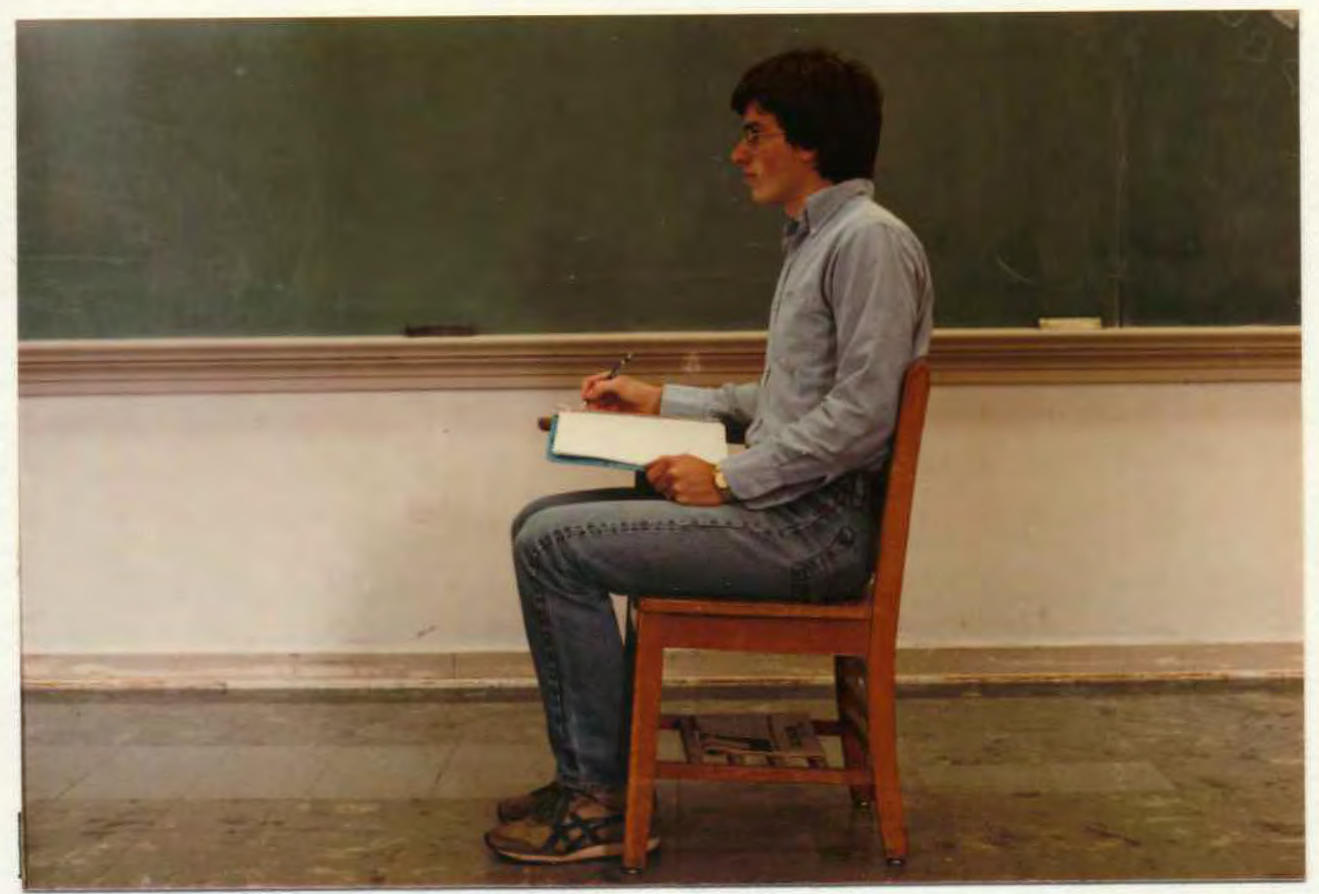

Figure 4. Coding Category 非 - Least relaxation, Direct orientation, Open position.

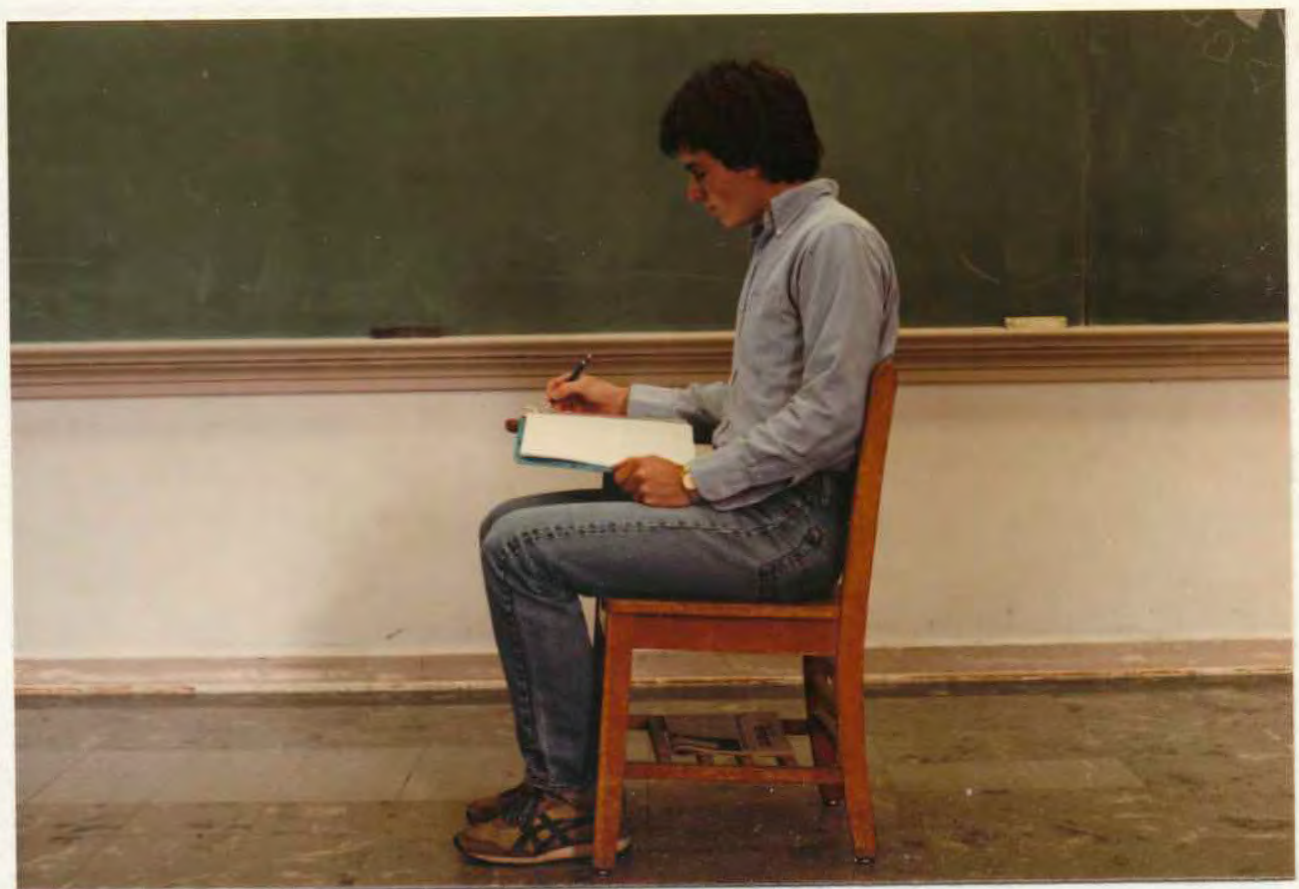

Figure 5. Coding Category 非 - Least relaxation, $\overline{\text { Indirect }}$ orientation, Open position. 


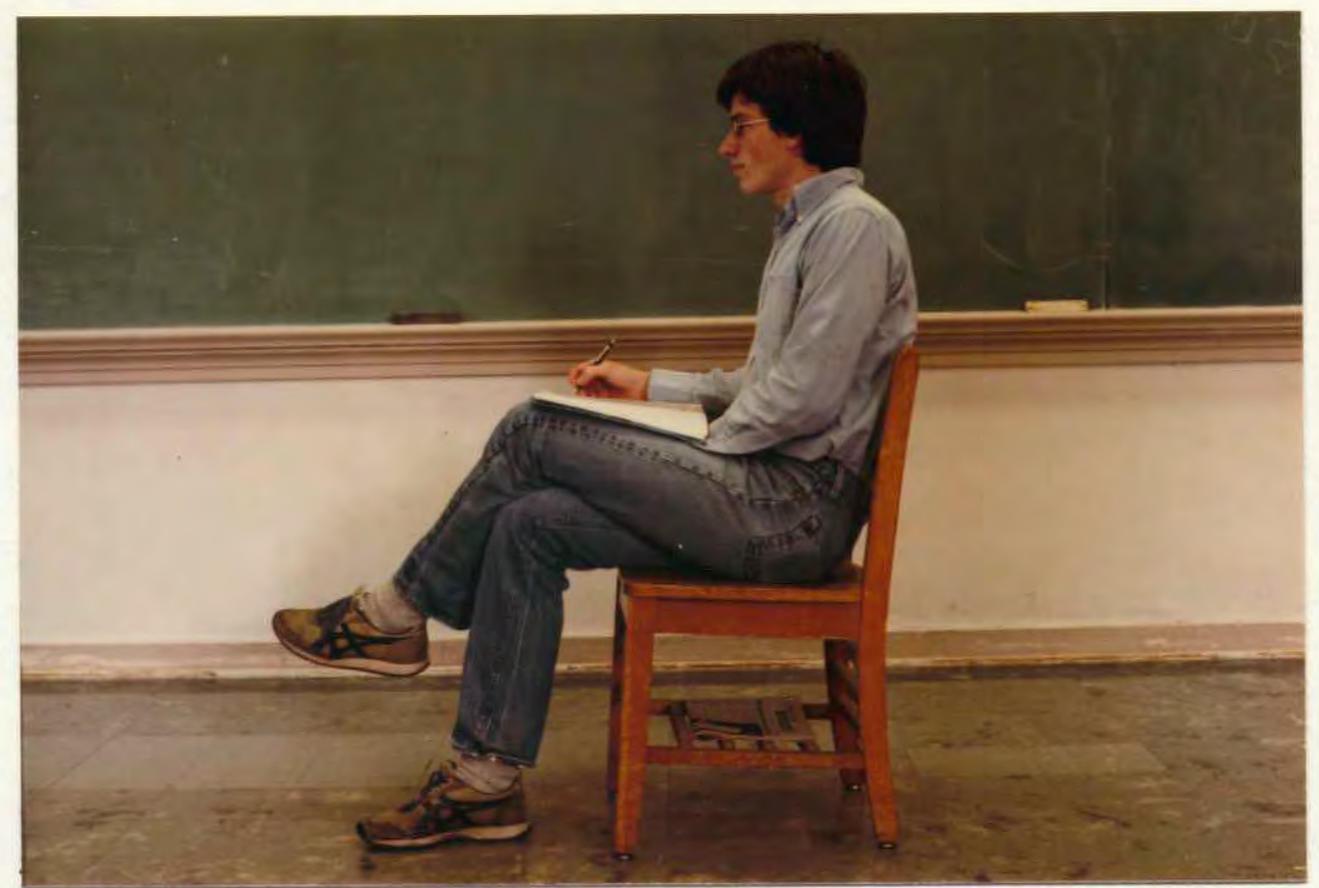

Figure 6. Coding Category \#3 - Least relaxation, Direct orientation, Closed position.

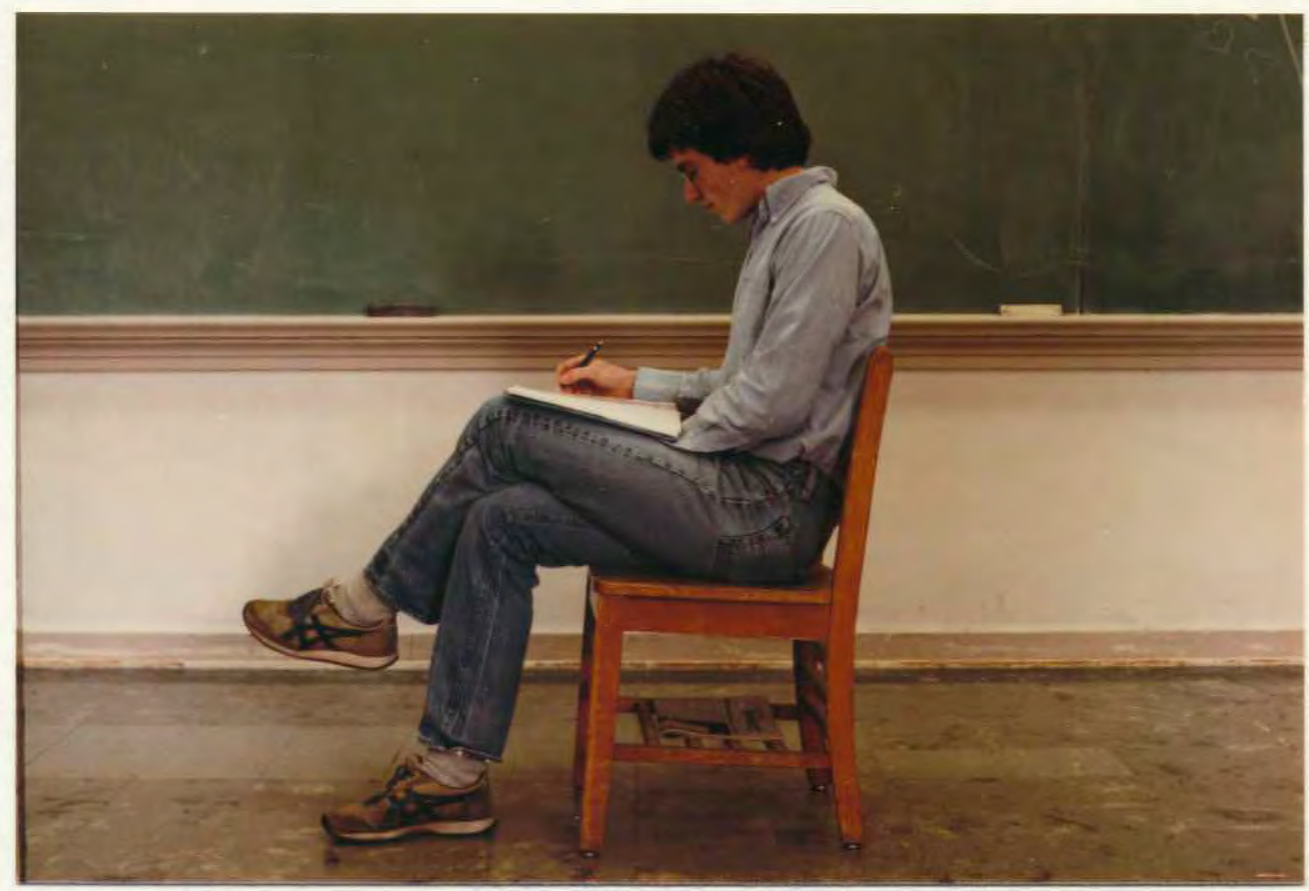

Figure 7. Coding Category $\$ 4$ - Least relaxation, Indirect orientation, Closed position. 


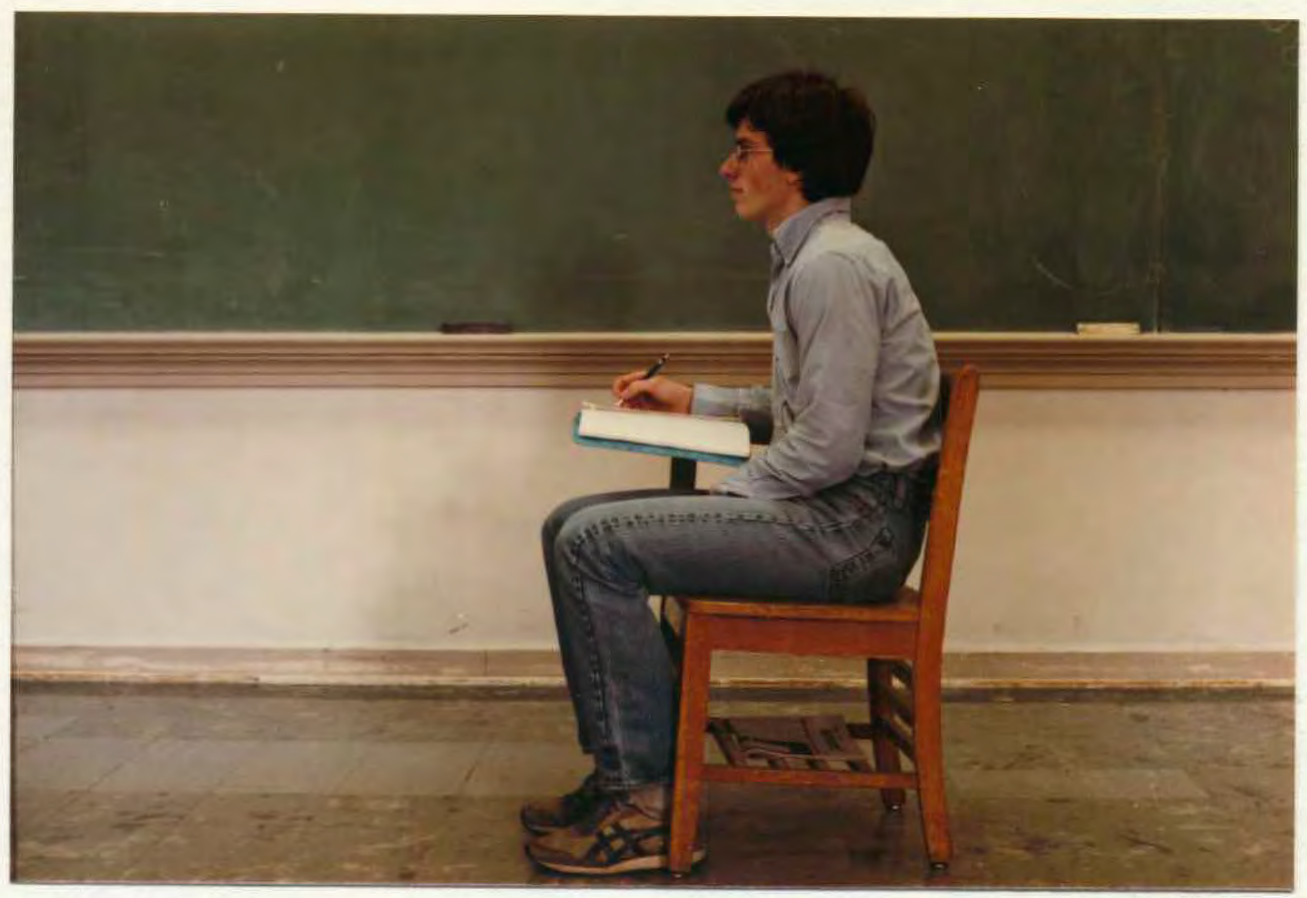

Figure 8. Coding Category \#5 - Moderate relaxation, Direct orientation, Open position (photograph 1).

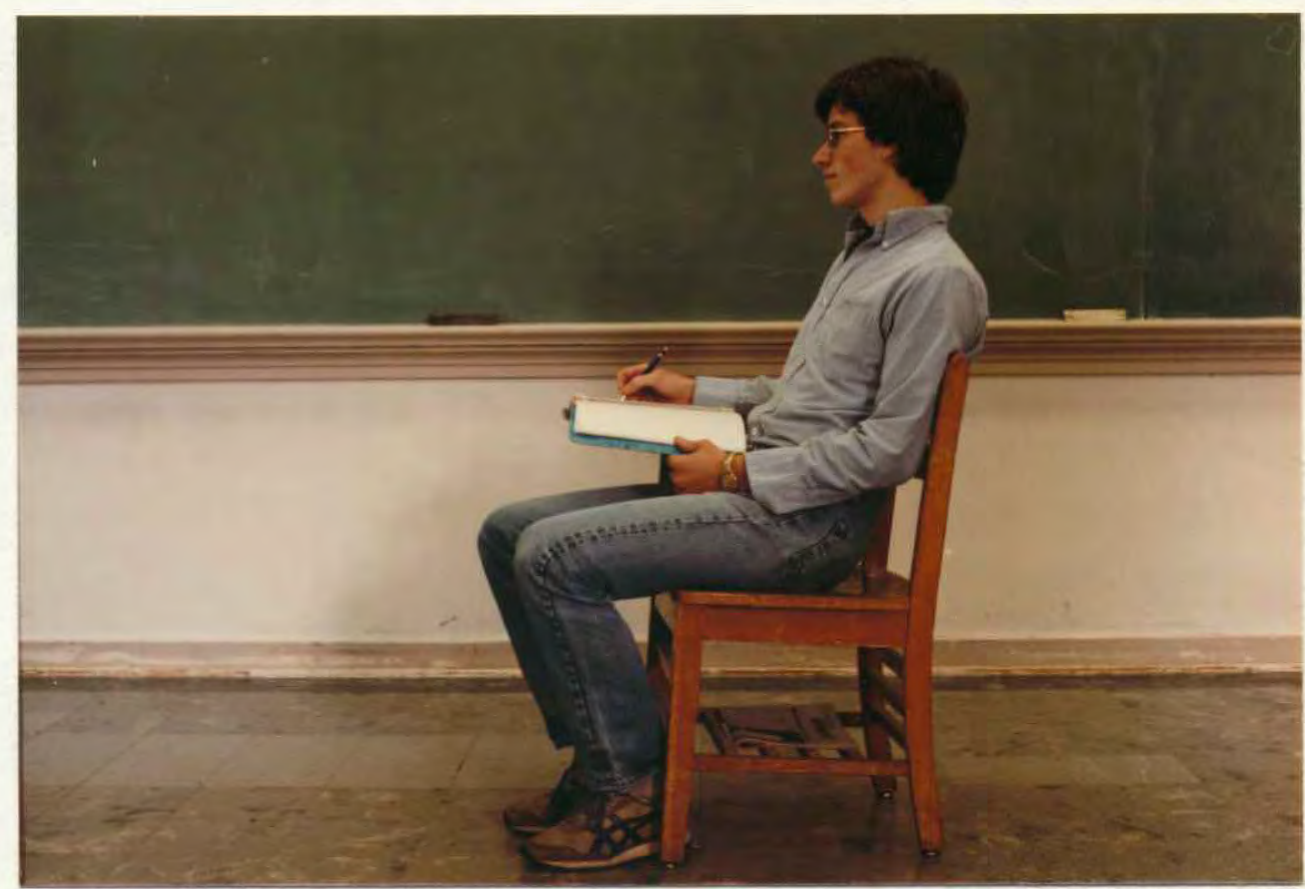

Figure 9. Coding Category 非 - Moderate relaxation, Direct orientation, Open position (photograph 2). 


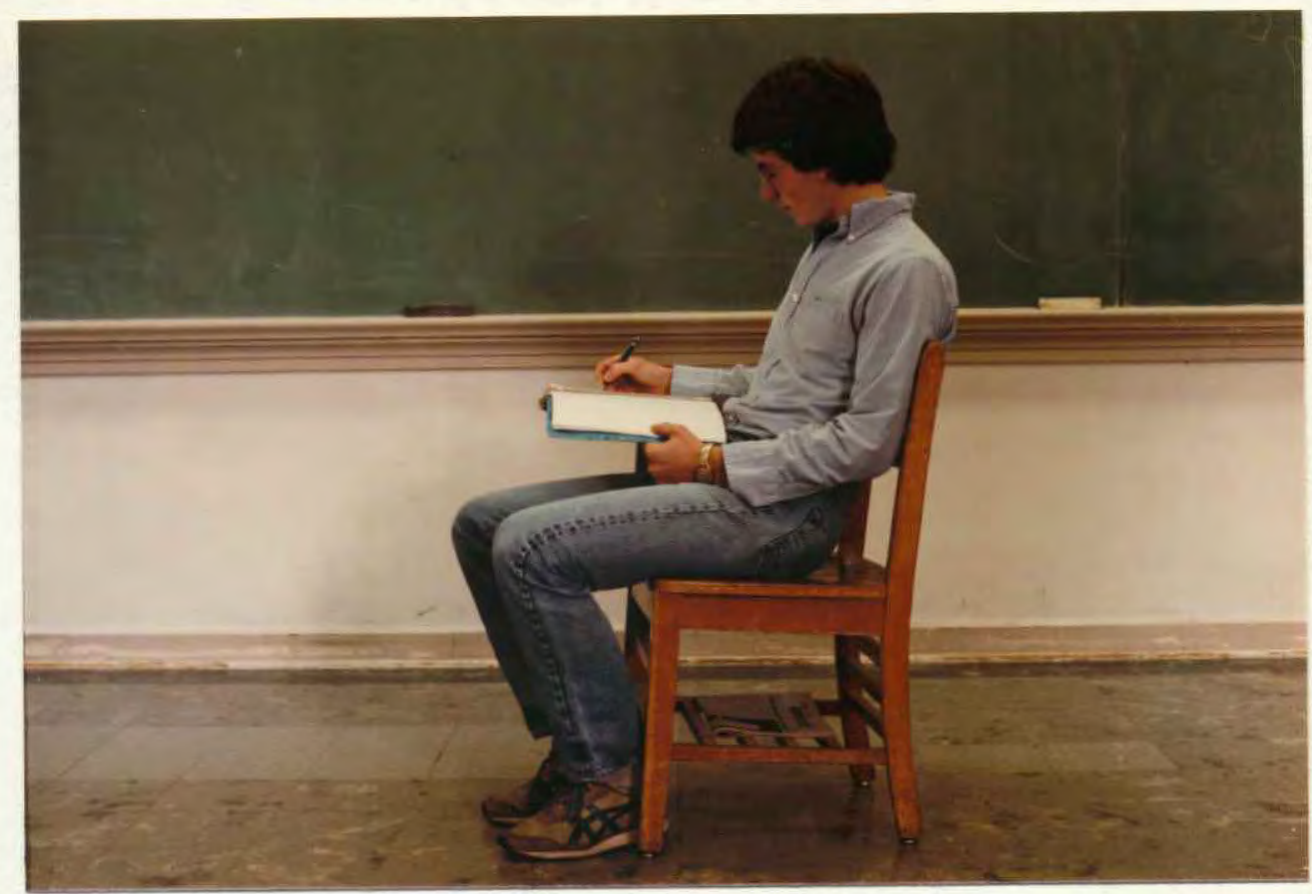

Figure 10. Coding Category \#6 - Moderate relaxation, Indirect orientation, Open position (photograph 1).

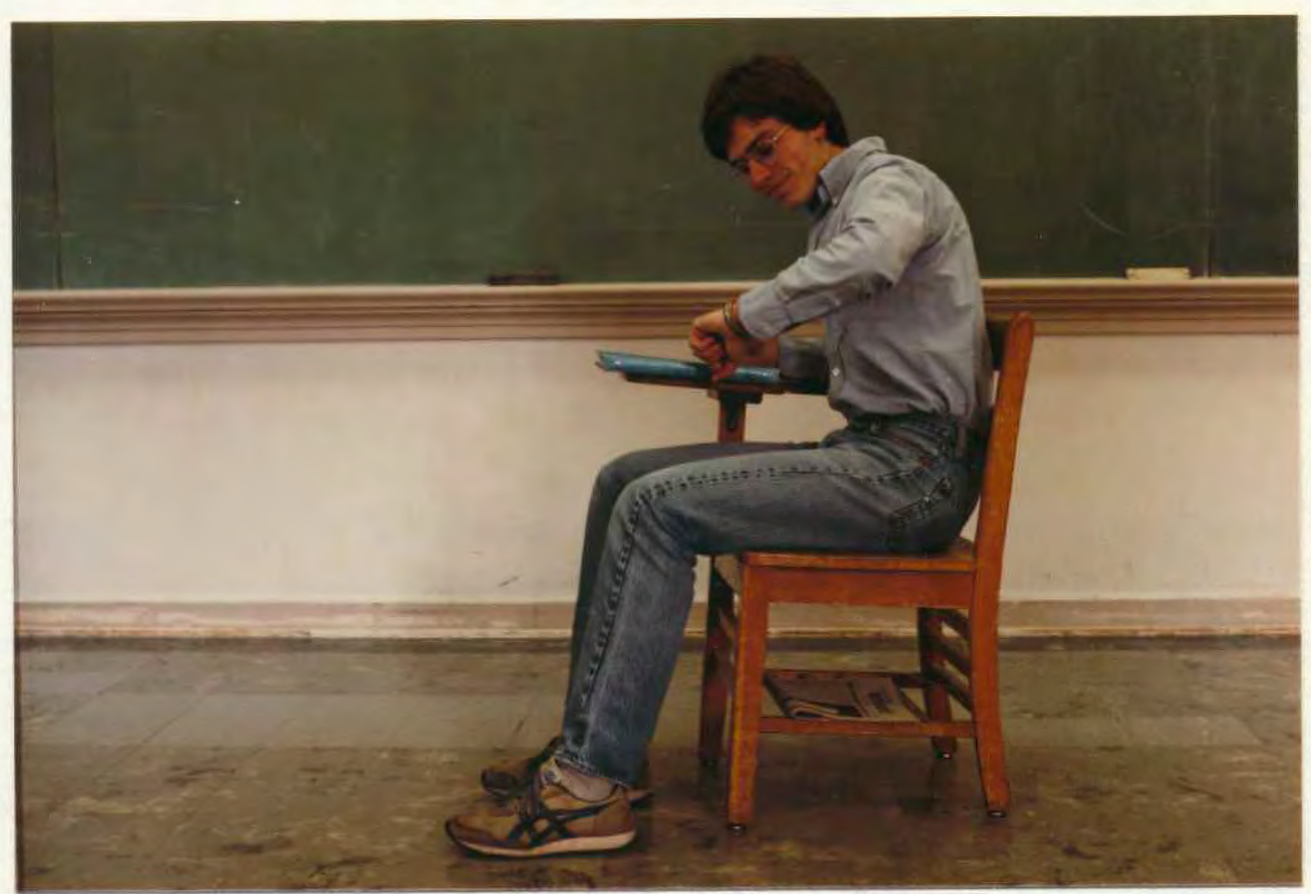

Figure 11. Coding Category 非 - Moderate relaxation, Indirect orientation, Open position (photograph 2). 


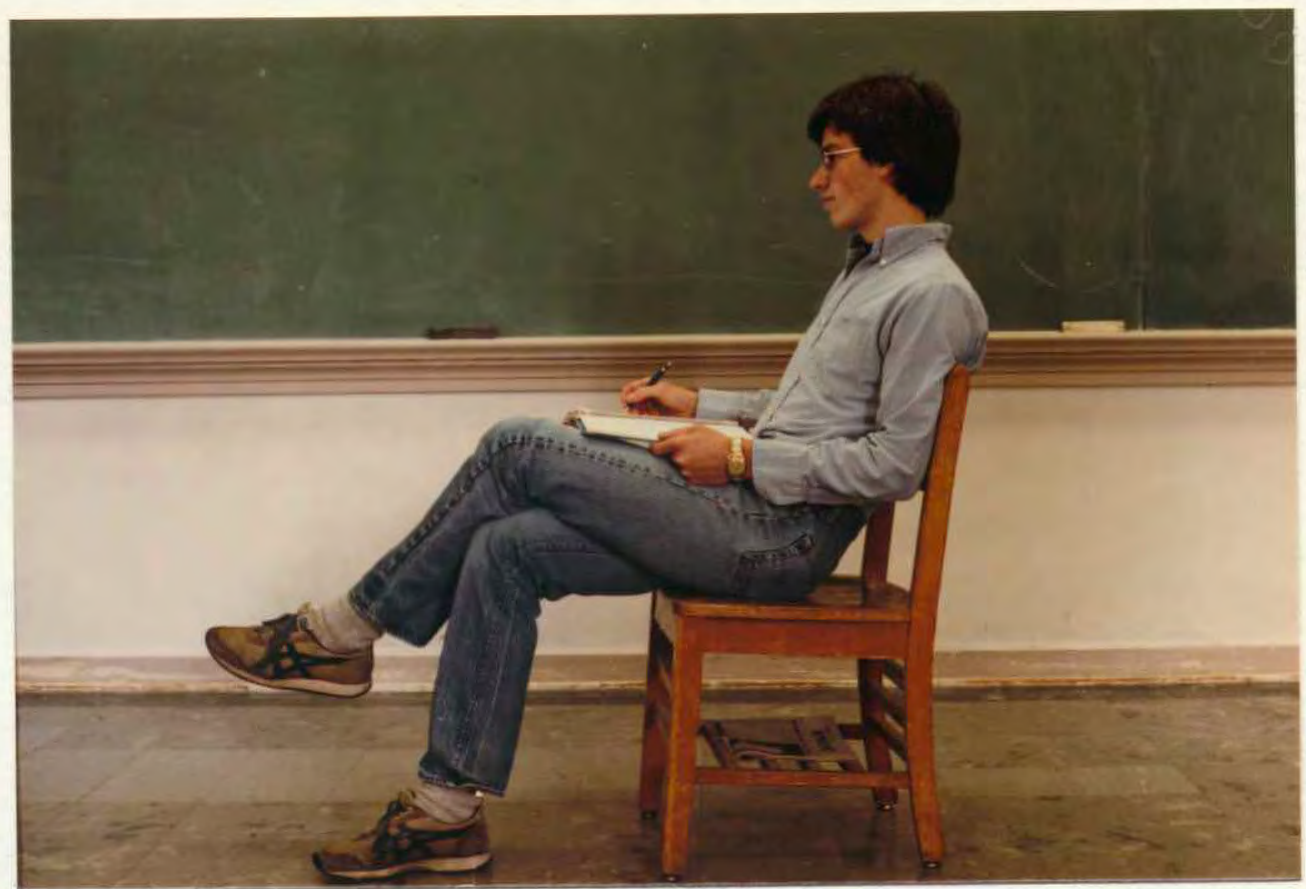

Figure 12. Coding Category \#7 - Moderate relaxation, Direct orientation, Closed position.

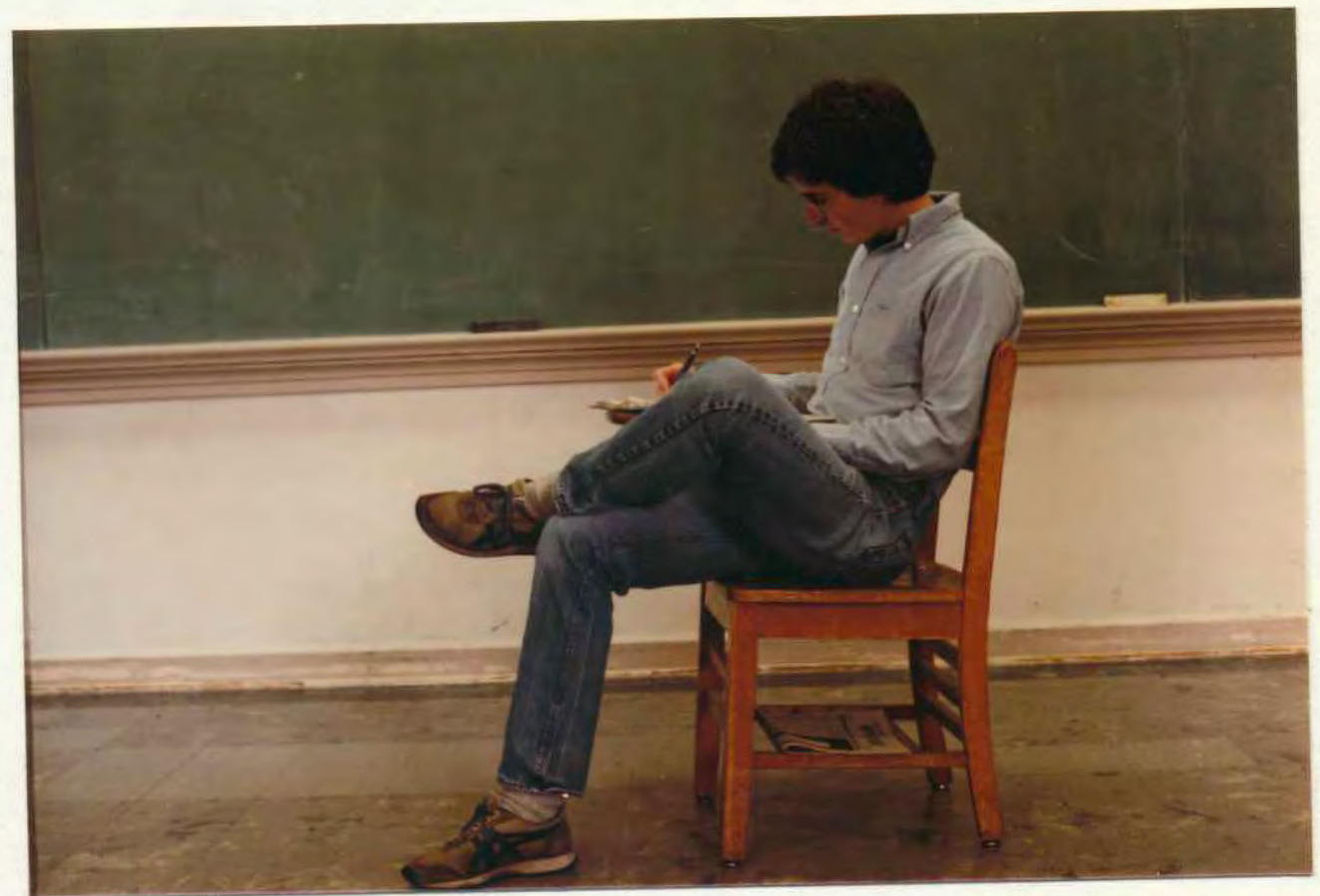

Figure 13. Coding Category \#8 - Moderate relaxation, Indirect orientation, Closed position. 


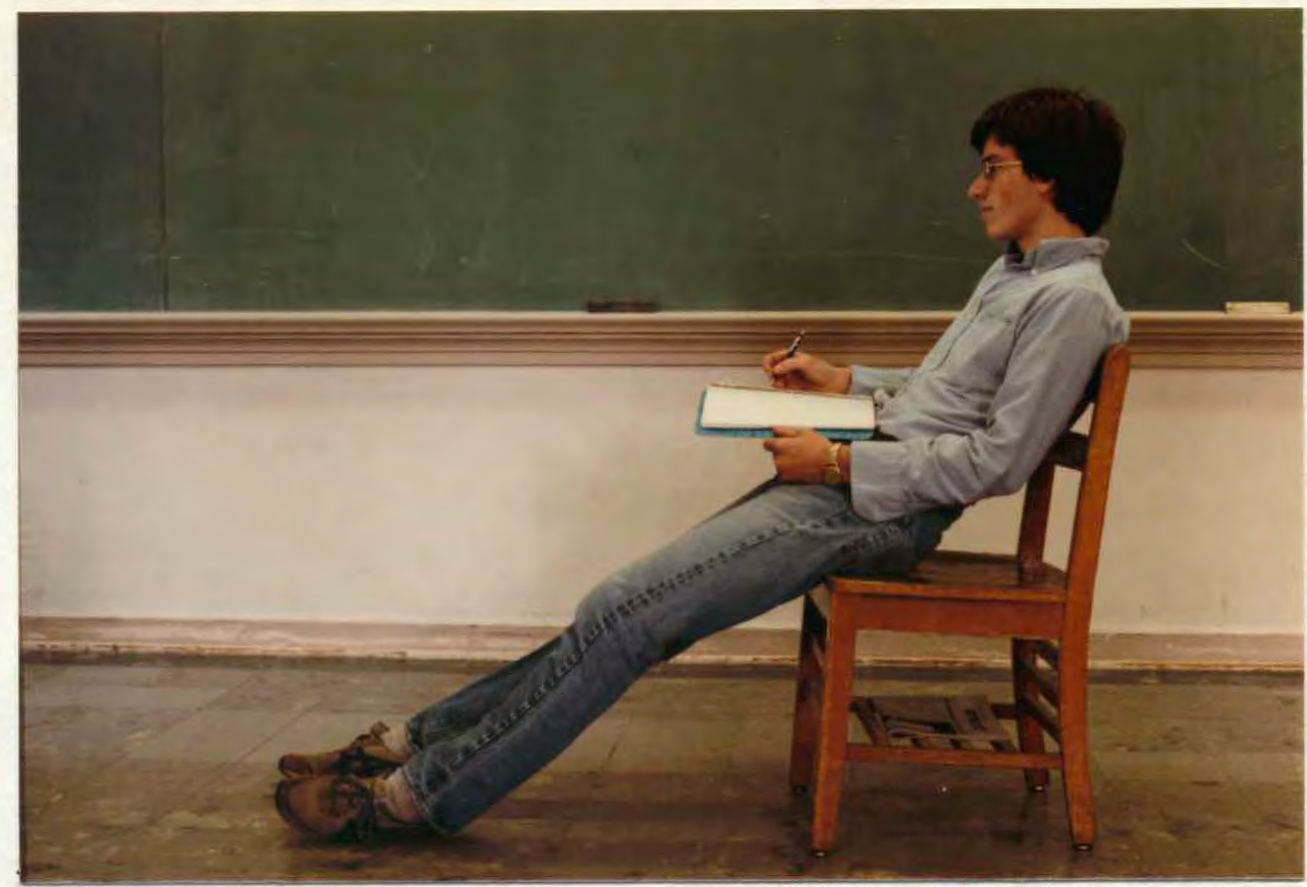

Figure 14. Coding Category 非 - Extreme relaxation, Direct orientation, Open position (photograph 1).

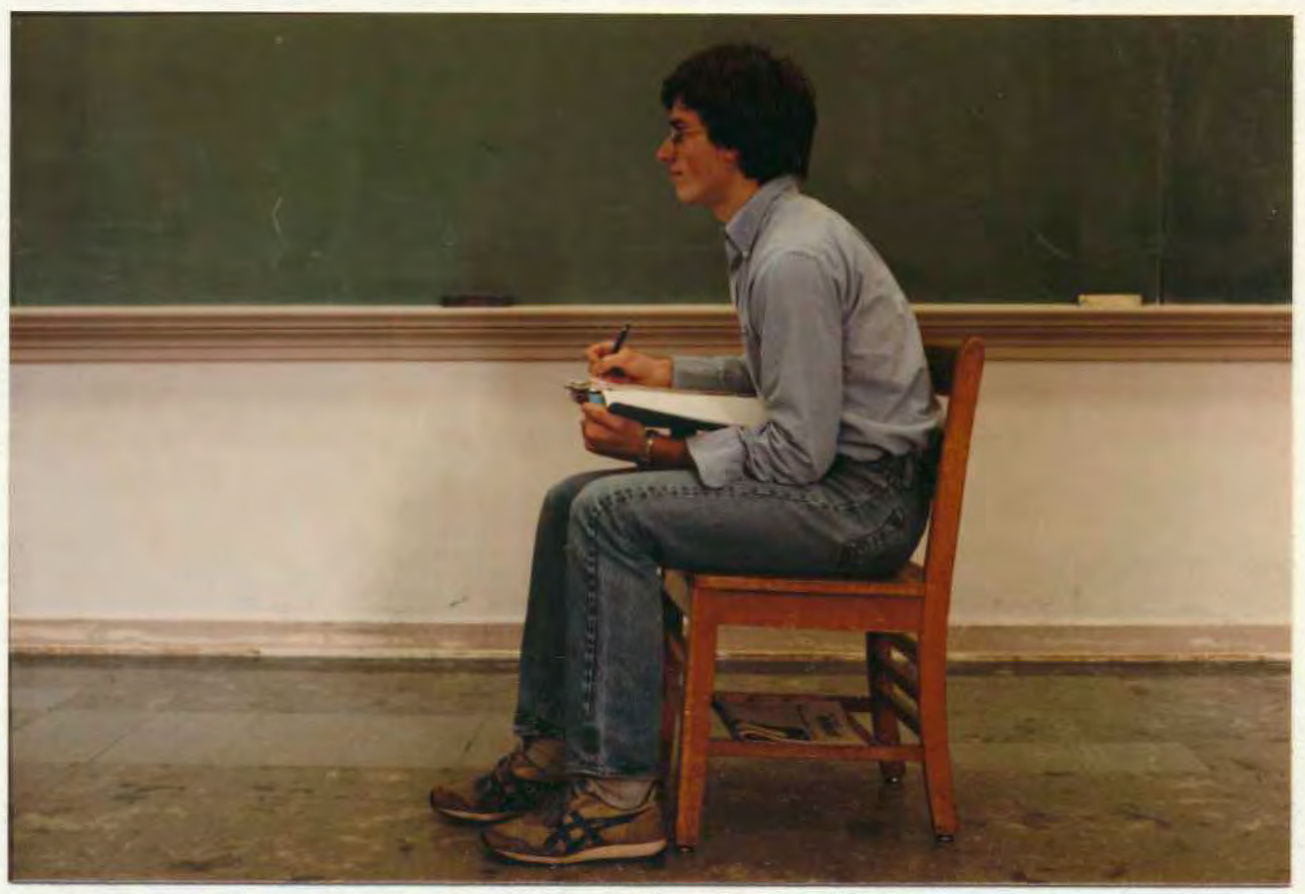

Figure 15. Coding Category $\|_{1} 9$ - Extreme relaxation, Direct orientation, Open position (photograph 2). 


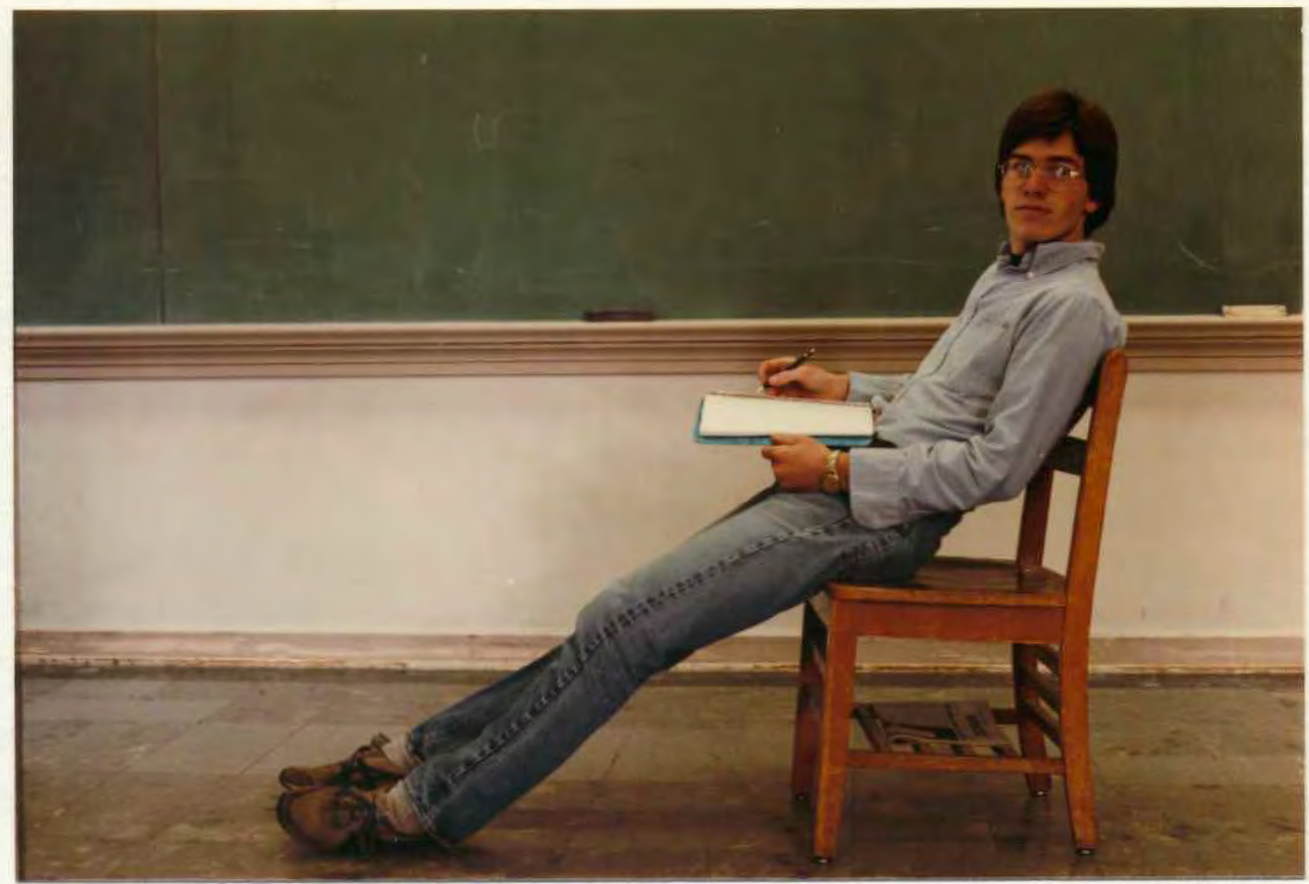

Figure 16. Coding Category $\#_{10}$ - Extreme relaxation, Indirect orientation, Open position (photograph 1).

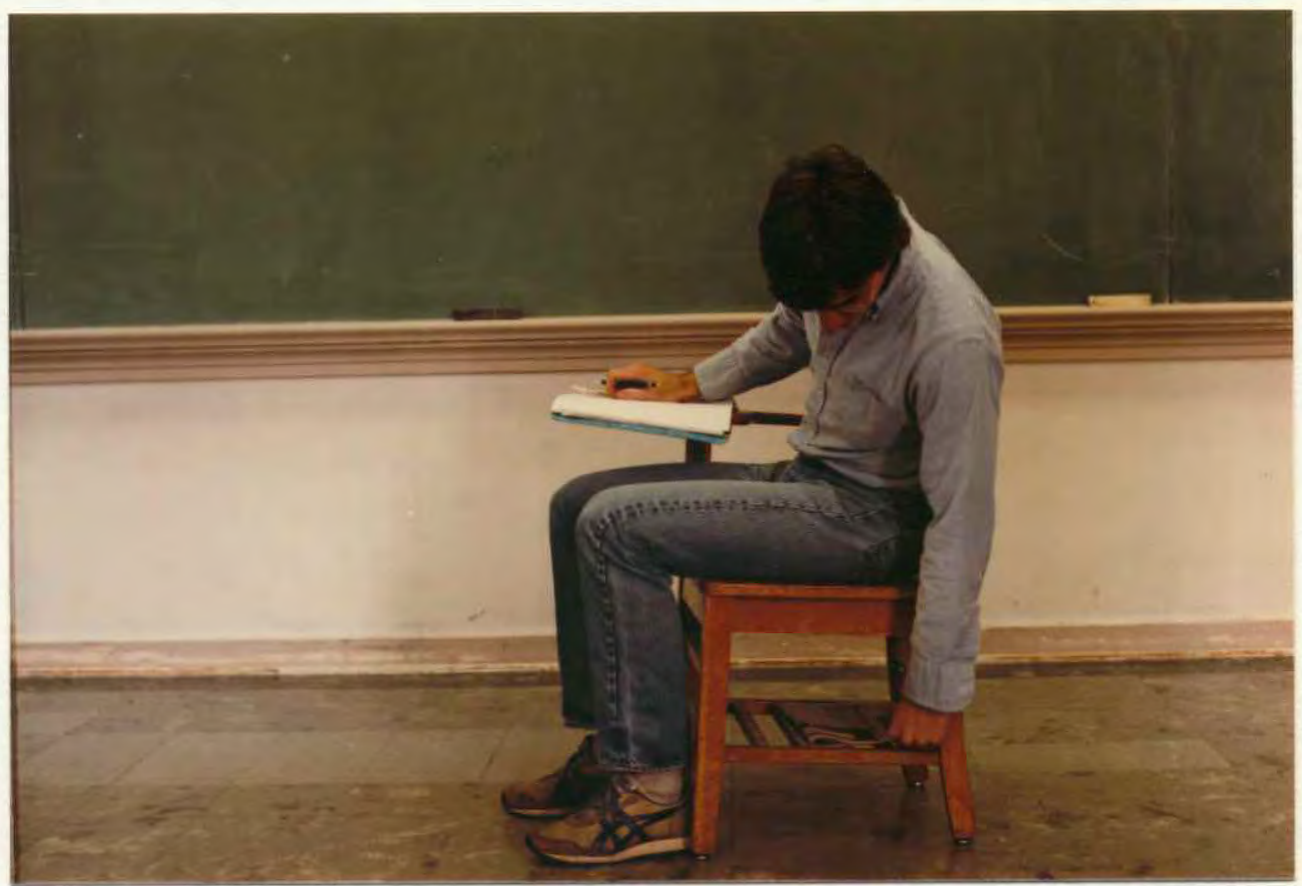

Figure 17. Coding Category $\# 10$ - Extreme relaxation, Indirect orientation, Open position (photograph 2). 


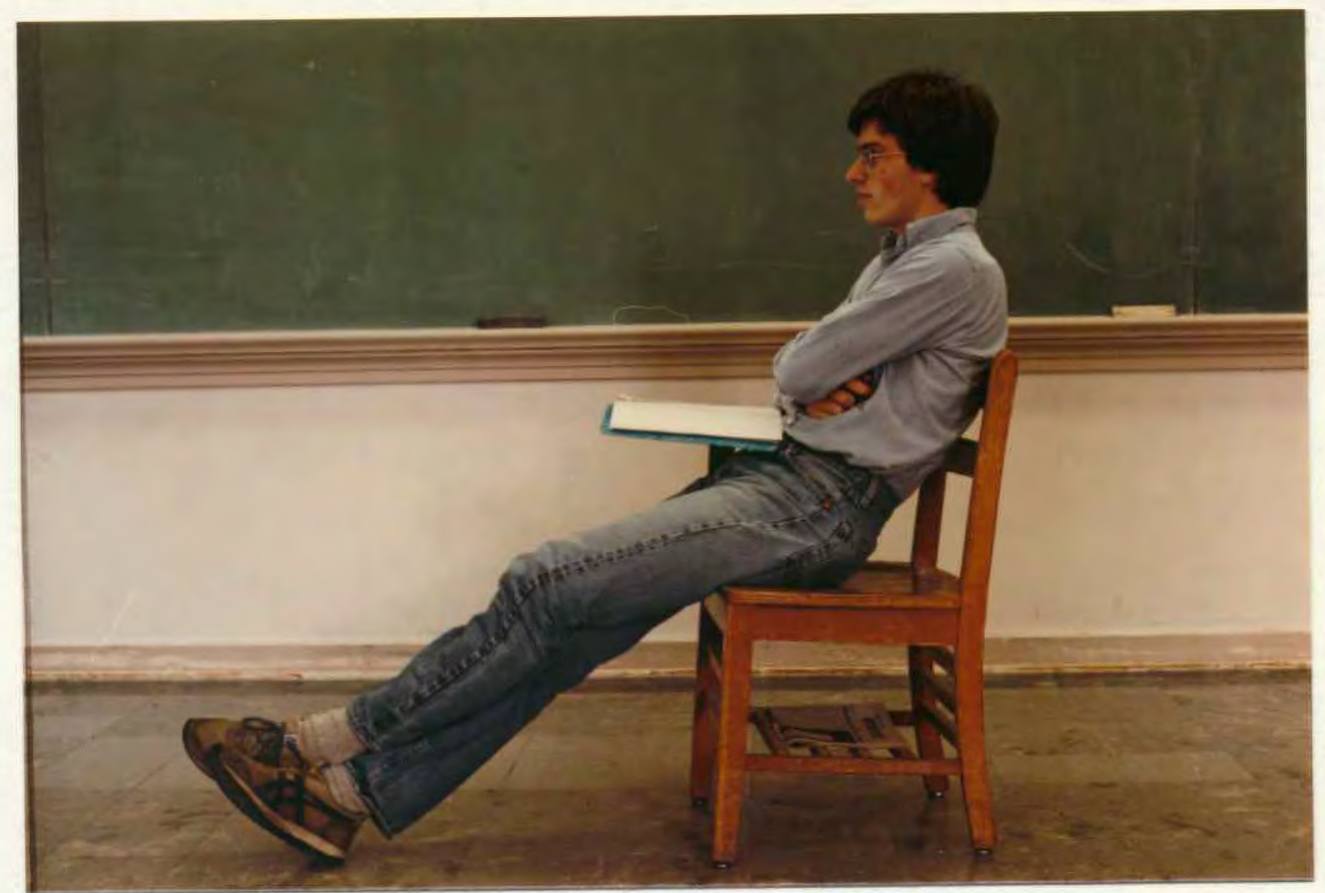

Figure 18. Coding Category 非l - Extreme relaxation, Direct orientation, Closed position (photograph 1 ).

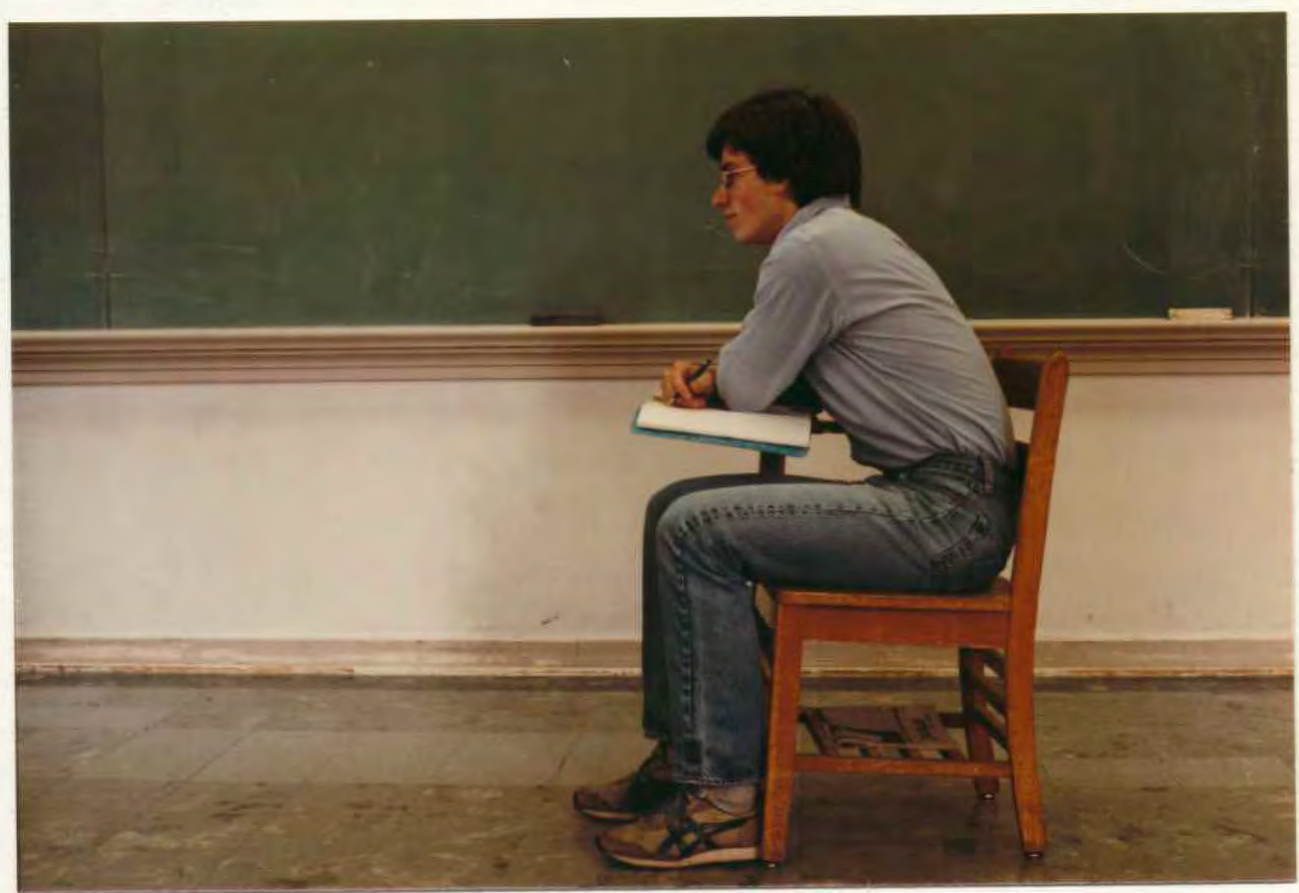

Figure 19. Coding Category 非l - Extreme relaxation, Direct orientation, Closed position (photograph 2). 


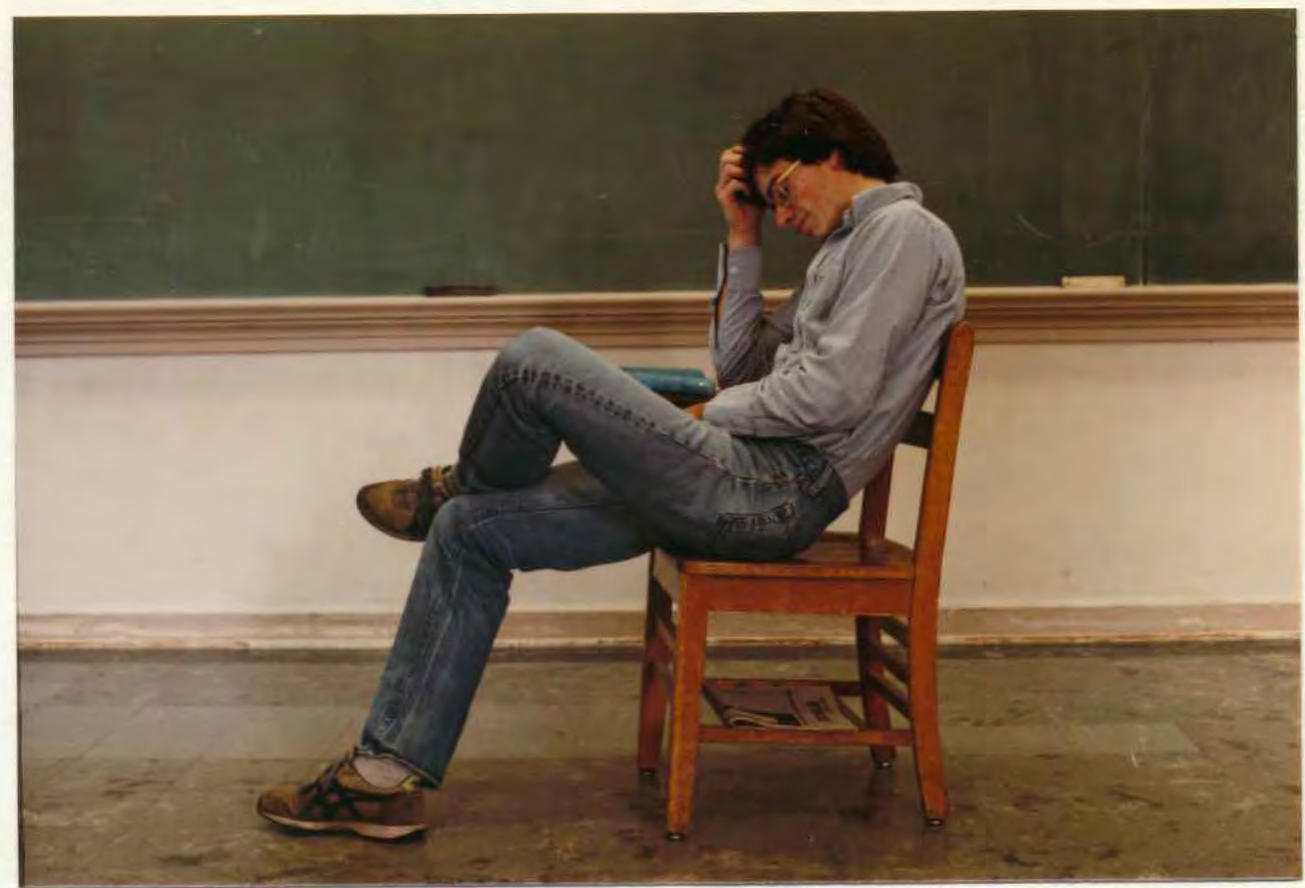

Figure 20. Coding Category $\# 12$ - Extreme relaxation, Indirect orientation, Closed position (photograph 1).

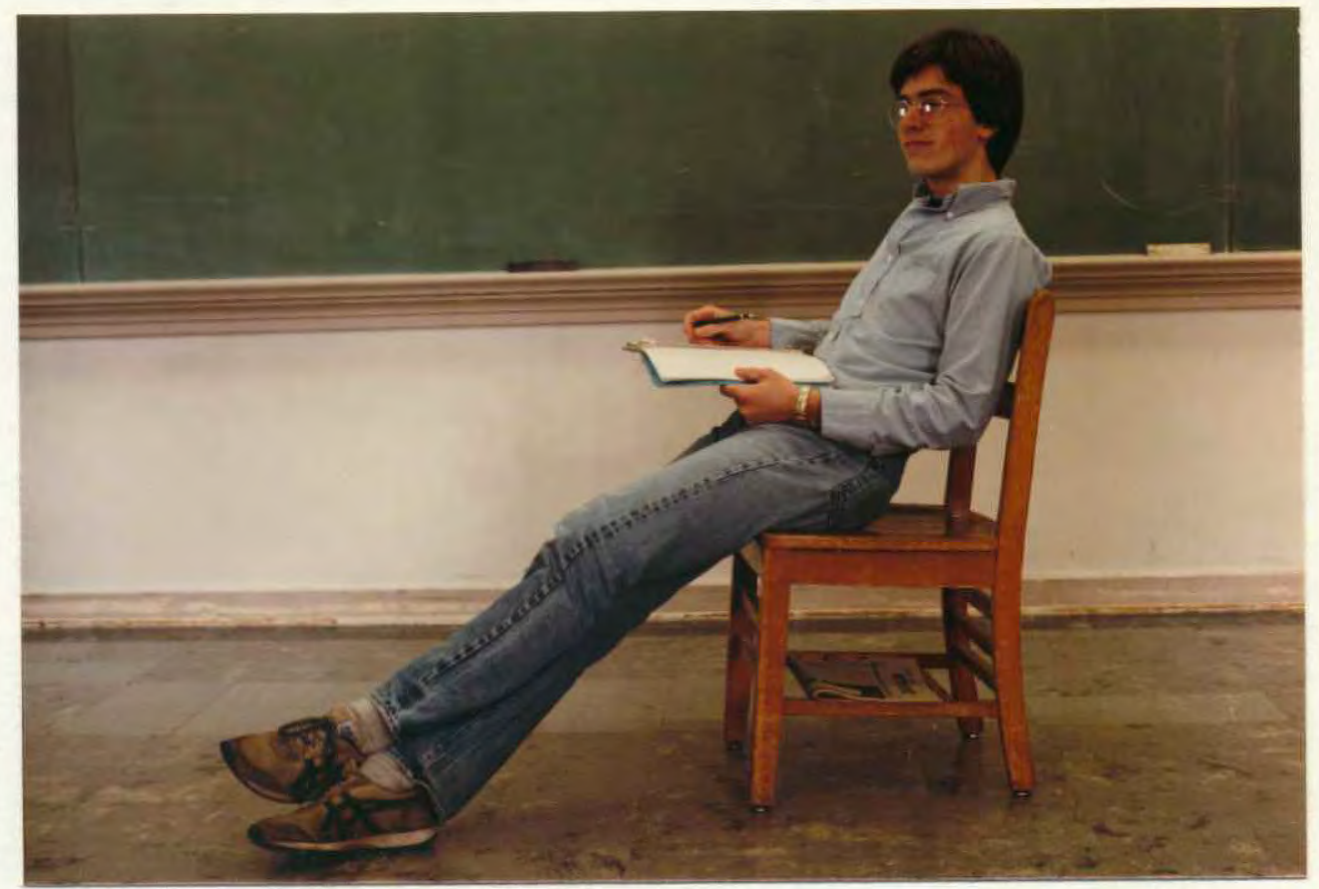

Figure 21. Coding Category \#12 - Extreme relaxation, Indirect orientation, Closed position (photograph 2). 


\section{Recruitment and Training of Coders}

The coders who assisted in this study were four female and four male undergraduates at Portland State University. In order to make certain that the coders would complete the coding and take it seriously the author set up a research practicum and invited students to enroll in it for one hour of credit. Several classes in the Speech Communication Department were visited in order to announce this practicum; enrollment was based on the understanding that students were partaking in a research project in the study of postural behavior (Appendix B). Specifics of the study were not revealed at this time.

The coders were required to undergo three training sessions in order to learn the coding categories used in the coding scheme. Discussion of each postural position occurred and slides were presented on the postural positions and discussed until there was a consensus among the coders as to the classification of each postural position. Once the author was secure in the knowledge that a high reliability between coders could be maintained, the actual coding commenced.

Coding took place in a coding center set up in $\mathrm{NH} 24$ at Portland State (Appendix $\mathrm{C}$ ). The coding center was equipped with a desk, video recorder, television set, Panasonic tape recorder, list of instructions (Appendix D), assignment sheet, and coding sheets (Appendix E). It was also provided with photographs of the 18 postural positions and explicitly defined categories were written up for reference if needed by the coders.

The coders were given five weeks in which to code 13-16 subjects that were utilized in either the pilot or final studies. In order to 
establish independence of observation, none of the coders scored both members of the same dyad, nor were coders informed about the true nature of the study until all the data were compiled. A final meeting was scheduled for the author and the coders in order to inform them more specifically of the nature of the study as well as the results.

\section{Attentiveness Measures}

The investigation included use of three attentiveness measures to determine the level of attentiveness of subjects in the study. The first instrument, the Dyadic Attentiveness Measure (Appendix F) was given to each subject after they had interacted for 20 minutes in a dyad. This measure was comprised of 12 questions selected from a 30-item scale developed by Norton and Pettegrew (1979, Appendix G).

Only 12 questions were selected from the Norton and Pettegrew (1979) instrument for the following reasons: (1) six of the items in the test were not seen by Norton and Pettegrew as contributing to the development of the attentiveness construct, (2) item number 7 was said by the authors to be a bad item because it's wording was ambiguous and difficult to interpret, and (3) the other items in the test were omitted because of redundancy, failure to make it into a linkage model, or because they were not applicable to the present investigation. Each of the 12 items chosen for the Dyadic Attentiveness Measure had shown significance when factor analyzed by Norton and Pettegrew, and were included in their graphic representation using McQuitty's elementary linkage technique (Norton and Pettegrew, 1979, p. 23; Appendix H). The items chosen for the measure were slightly reworded to appropriately fit with the present 
study. For each of the 12 questions a five-point likert scale was used that ranged from "strongly agree" to "strongly disagree." The 12 items of this measure were added into a single composite in order to calculate a subject's attentiveness score. End points were consistently weighted 5 and 1. A subject scored a maximum of 60 and a minumum of 12 .

The second measure, the Perception of Partner's Attentiveness

Scale (Appendix I) was given to the partners of each subject in the study. These measures were filled out after the 20 minute dyadic interaction and were attached to the self-report measure. This test consisted of 10 evaluative-type semantic differential scales designed to assess the partner's perception and evaluation of the subject's attentiveness. The 10 items were added into a single composite in order to calculate a subject's score. End points were consistently weighed 7 and 1 . A subject could score a maximum of 70 and a minumum of 10 . The 10 items selected for this measure were derived from adjectives used in the pertinent literature on attentiveness.

The final measure, the Coder's Global Report of Attentiveness (Appendix J) was given to eight independent coders who viewed the visual part of the subject's dyadic interaction and coded the subject's postural positions via videotape. The independent coders were assigned at random to the subjects with two coders viewing each subject. This measure was a combination of the first two measures. Of the 12 questions from the Dyadic Attentiveness Measure, seven were selected. Five were not applicable as they dealt with the audio part of the video and coders were not exposed to this. The wording of the seven questions used was slightly changed in order to fit the context. The second part of the Coder's Global Report of Attentiveness was the same as the Perception of Partner's 
Attentiveness Scale. The scoring on this measure was the same as with the first two. This final measure was filled out by two coders and the scores were averaged in order to give one composite score. On this measure a subject could score a maximum of 105 and a minumum of 17 .

The scores on each of the three measures were correlated with the actual behavior of individuals. The higher a subject's score, the higher the assumed level of attentiveness and the expectation of specific postural positions; the lower a subject's score, the lower the assumed level of attentiveness and the expectation of different postural positions.

\section{Subjects}

Sixty-six subjects comprised the sample used in the study; demographic data pertaining to the subjects appears in the analysis of data. of the 66 , four were disqualified because technical difficulties with the video camera rendered the visual picture inadequate for coding, five subjects were used in the pilot study, and 57 subjects were used in the final study. Two experimental groups were formed by the 57 subjects in order to insure as broad-based a sample as possible. Group 1 consisted of 35 subjects that were videotaped at Portland State University; Group 2 consisted of the remaining 22 subjects that were videotaped in the home environment. The first group of subjects were students at PSU and were approached in the cafeteria, classrooms, study centers, library, or hallways and asked to participate in a 30 minute study. These subjects were paid $\$ 2.50$ for their involvement (Appendix $K$ ). The second group were friends, co-workers, or acquaintences of the author and were asked to participate in a study on dyadic interaction. Once they agreed to be involved in the study, they were scheduled for a 30 
minute period in which they were videotaped and given two short tests. These sessions occurred in the subject's home or the home of a mutual friend and were conducted in the Portland and Eugene metropolitan areas. There was no attempt to manipulate the scheduling of dyadic interaction in terms of pairing based on sex, age, educational level, occupation, relationship, or length of relationship. It was acceptable if participants wanted to be videotaped with their friends or if dyadic partners did not know each other prior to the taping session. It was the intent of the author that subjects feel as comfortable as possible with the taping session while at the same time obtaining as wide a variation in individual and relational types as possible.

Group 1

All of the subjects in the first group were scheduled in dyads to meet in NH 45 at PSU. In this room, a Newvicon Color video camera (NV 3150) and a Panasonic VCR VHS recorder (NV-8200) were set up at one end of the $20^{\prime} \times 10^{\prime}$ room. As subjects entered the room they were asked to take seats at the end opposite the camera and were given the following information:

1. They were involved in a study about dyadic interaction and would be videotaped for 20 minutes while they carried on a conversation on any topic(s) they wished.

2. There was no specific way in which they were to act during the 20 minutes and that they could move their chairs any way they wished as long as they stayed within the $8^{\prime} \times 5^{\prime}$ black lines that were marked on the floor.

3. There will be no one in the room with them and the audio would be turned off on the recorder so that their conversation was completely confidential.

4. The videotape would not be shown publicaly and would be seen only by two trained coders and myself. 
5. At the end of the 20 minutes, they will be given two questionnaires to fill out which would take from three to five minutes.

6. Again, that there was no correct way to behave but to be as natural as possible.

Subjects were then asked to sign a consent form stating that they were willing to participate in this investigation.

Following the experimenter's instructions, the video recording equipment was activated and the participants were told they could begin. The experimenter left the room during the actual interactions, returning 20 minutes after the initiation of a given interaction. Following the return of the experimenter, subjects were given the Dyadic Attentiveness Measure and the Perception of Partner's Attentiveness Scale and asked that there be no discussion during this time.

Brief postinteraction interviews with subjects indicated that none were particularly apprehensive about or inhibited by the presence of the video equipment. Thus, based on this information, the effect of knowing that they were being videotaped should have had minimal impact on their behavior. In that most subjects expressed a desire to view themselves on tape, subjects were shown about 60 seconds of the videotape. Subjects were then paid $\$ 2.50$ for their time and thanked for their participation. Those few subjects that questioned what the experiment was all about were briefly informed about the general nature of the study and asked to refrain from talking about it with anyone for at least a period of 30 days.

\section{Group 2.}

The second group of subjects differed from the first in the following ways: 
1. They were filmed with a Magnavox video camera and Hitachi VHS portable VCR system (VC770).

2. They were usually present while the video equipment was being set up.

3. They were filmed in their home or a friend's home.

4. They were not shown any segments of the tape.

5. They were not paid.

6. They were more completely informed about the nature of the study after their involvement.

With the exception of a few technical and scheduling problems, the videotaping went smoothly. Subjects were indexed in order of taping (Appendix L) and subsequently assigned randomly to coders. The experimental phase of the study was completed within a 13 day span.

\section{Summary}

In summary, the purpose of the present study was to determine the association between 12 specific postural positions and an individual's measured level of attentiveness. In order to empirically test the hypotheses set forth, the experimenter designed a coding scheme to mutually exclusive and exhaustive categories of postural positions. These categories were used by eight trained coders who observed 57 videotaped subjects that were each involved in 20 minutes of dyadic interaction.

That the level of attentiveness of subjects might be assessed, three measures were developed from an attentiveness measure successfully used by Norton and Pettegrew (1979) and from pertinent literature on attentiveness. The results of the measures, completed by the subject, the subject's partner, and independent coders, were correlated with the actual behavior of the subject. 
The participants in the study made up two groups: the first group consisted of 35 students from PSU and the second group consisted of 22 subjects selected outside the university. Videotaping of subjects took 13 days and coding of the subjects from the videotapes spanned a fiveweek period. Lastly, the postural positions each subject displayed while interacting were compared with the data on attentiveness. The pilot study, final study, and analysis and interpretation of results follow. 


\section{CHAPTER $V$}

\section{ANALYSIS AND INTERPRETATION OF RESULTS}

\section{Pilot Study}

The purpose of the pilot study was to test the workability of the experimental design and to examine the interrater reliability between coders.

\section{Experimental Design}

Essentially, the pilot study experiment ran smoothly and according to plan. With the exception of the four subjects lost as a result of technical difficulties in videotaping, all other technical obstacles were overcome.

A total of five subjects were used for analysis in the pilot study. These subjects were chosen from the first few videotaped sessions and were randomly assigned to coders. Once the videotaping was completed and the coding center established, the coding commenced. The sampling technique employed was discontinuous probe sampling in which scoring was done instantaneously at the end of 30 second intervals. The intervals were stimulated by a whistle that was prerecorded on a tape recorder and played during the coding sessions. In order that neither technical nor editorial functions in videotaping would cause data to be lost, each dyad was actually taped for 21 minutes. When assessment of coded intervals occurred, 21 minutes were in fact available for coding. Thus, each 
subject was coded for 21 minutes at 30 second intervals making 42 discrete coded observations per subject. In order to assess interrater reliability, each subject was coded twice by two different coders making a total of 84 coded intervals for each subject. Consequently, the pilot study data produced 420 coded intervals for analysis.

Assessment of Interrater Reliability

After the coding of pilot was completed, a matrix was used to compile the observations rendered by each of the sets of paired coders. Once all single matrices were finished, a summary matrix, involving the observations of all pairs of coders, was devised. Figure 22 on the following page shows the results of this endeavor. Independence of observations was maintained by randomly assigning coders to different subjects and making certain that a coder did not code both subjects in any one dyad.

The scoring procedure for assessing interrater reliability was the analysis, Kappa. This statistic, developed by Cohen (1960), was used as it assessed nominal scale agreement rather than percentage agreement between coders. This type of calculation scales down the observed probabiliby of agreement, giving a new base line for calculating the percentage of agreement (Hollenbeck, 1978). Kappa is simply the correction for chance agreement in the overall proportion of agreements by two coders for the $\mathrm{N}$ cases (Cohen, 1972). It is a reliable statistic assuming the units are independent; the categories are independent, mutually exclusive and exhaustive; and the judges operate independently (Cohen, 1960). Hollenbeck (1978) states that the literature and empirical evidence suggests that Kappa is "... flexible, has desirable statistical properties, and is a superior approach to handling chance agreement" (p. 92). 


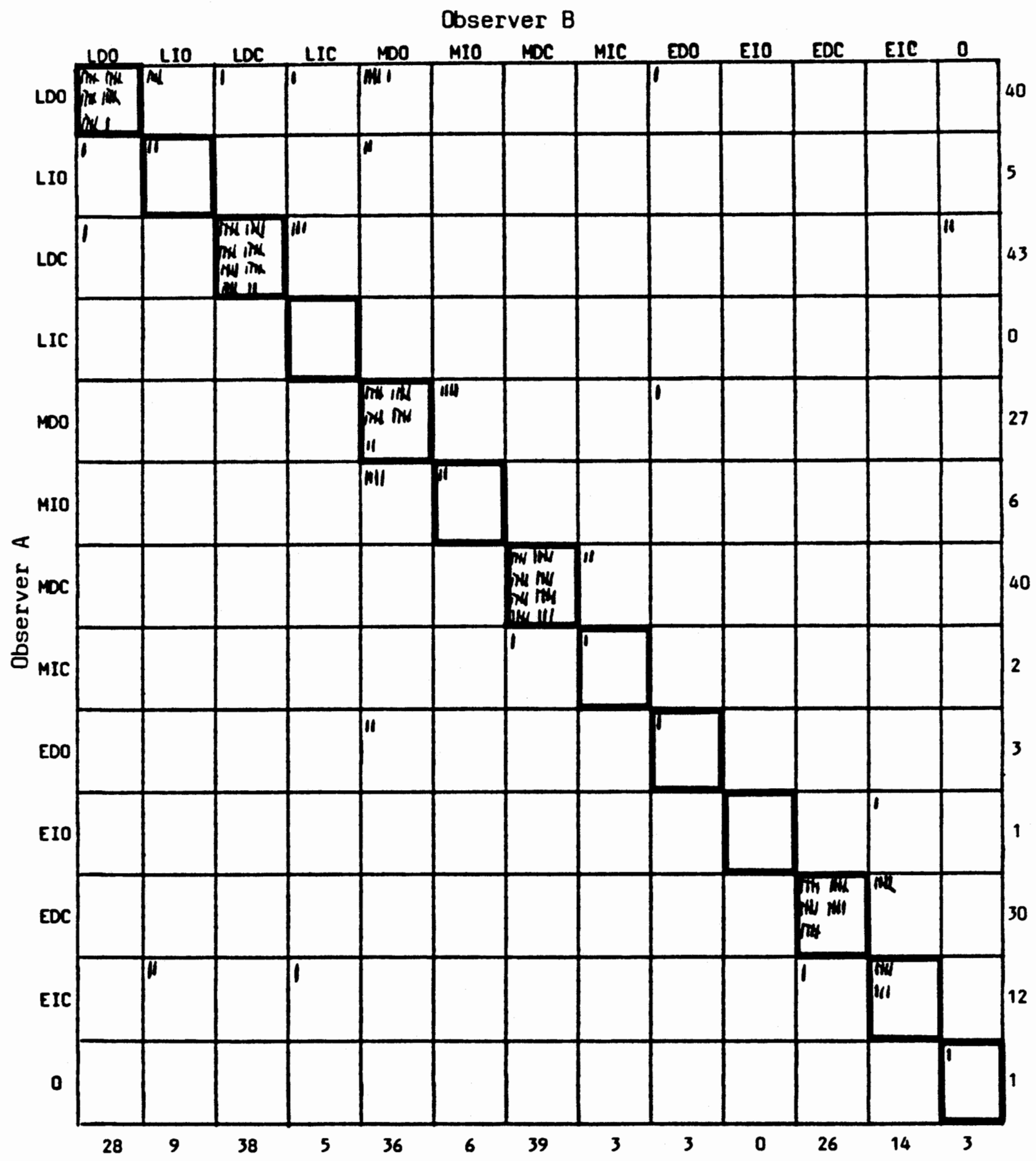

Figure 22. Summary matrix for pilot data for assessment of Cohen's Kappa on interrater reliability. 
In several studies where the properties of Kappa were compared with percentage agreement, Kappa was always the lowest estimate of agreement (Hollenbeck, 1979). Cohen's Kappa was used in this study because it shows the possible chance agreement and the percentage of change agreement that was improved upon.

As a result of implementing Cohen's Kappa with the pilot data, a reliability coefficient of +.74 was reached. This indicates that there was an acceptable reliability among coders.

\section{Discussion}

The results of the pilot study indicated that the investigation was essentially sound and worthy of completion. The experimental design appeared workable, the reliability between coders was sufficiently high so as to warrent continuation of the existing methods and coding categories. Hence, it appeared plausible to assess the association between postural positions and postural shifts and attentiveness on a larger scale by retaining the characteristics of the pilot study for the final study. 
Final Study and Data Analyses

The purpose of this study was to test the relationship between postural positions and postural shifts and attentiveness. The construct of attentiveness, tested here, is defined as the verbal and nonverbal signaling of an individual that the communicative process is working. This facet of the investigation was conducted in order to isolate the postural positions utilized by individuals and the frequency of postural shifts so as to examine their correlations with attentiveness.

\section{Experimental Design}

The execution of the experiment in the final study proved manageable. None of the subjects were lost as the result of technical difficulties, and the visual reproduction of subjects improved as the author, who videotaped all subjects, gained experience. Interrater reliability also improved presumably due to better visual viewing of subjects, their own coding experience, and a more explicit defining of the postural categories by the author.

A total of 57 subjects participated in the final study. The same methodology was implemented here as in the pilot study with regard to assessment of interrater reliability using the statistica Kappa. Additional analyses in the final study include: (1) assessment of the frequency of postural positions, (2) assessment of the association between postural positions and attentiveness, and (3) assessment of the association between postural shifts and attentiveness.

Descriptive Characteristics of the Sample

The 57 subjects that participated in the final study are 
described in Table II. In summary, there were 18 males and 39 females. The ages of the sample varied from age 15 to age 47 with $57.9 \%$ of the sample between the ages of 20 and 29 . The sample was also shown to be highly educated with $50.9 \%$ of the subjects having at least some college, 22.8\% holding bachelor's degrees, and 14\% having some graduate work experience or holding master's degrees. The majority of subjects were students (61.4\%) while the rest were employed in 14 different occupations.

The length of time subjects in each dyad knew each other varied between having just met to having known each other for over 20 years. There were also 10 different types of relationships among subjects with $31.6 \%$ of the subjects describing themselves as friends.

In order to insure different postural positions and different levels of attentiveness for the study, two sample populations were obtained. The first group consisted of 35 students videotaped in an experimental setting at PSU; the second group consisted of 22 subjects videotaped in the home environment. The descriptive characteristics of the sample showed a wide range of ages, similar educational beckground, similar types of occupations, a wide range in length of time subjects knew one another, and a variety of interpersonal relationships.

Assessment of Interrater Reliability

Once coding of the subjects was completed, a matrix was used to compile the observations rendered by each of the paired set of coders. Afterward, the summary matrix shown on page 67 was made by compiling all the observations made by the paired coders.

The interrater reliability improved as a result of changes based on the pilot study. Cohen's Kappa statistic (Appendix M) produced a 
SUMMARY OF DESCRIPTIVE CHARACTERISTICS OF THE SAMPLE

1. Sex: 18-Male 39-Female

2. Age: $8-15-19$ years

$$
\begin{array}{r}
33-20-29 \\
7-30-39
\end{array}
$$$$
9-40-49
$$

3. Highest Educational Level:

$$
\begin{aligned}
& \text { 2- Some high school } \\
& 4 \text { - High school graduate } \\
& 29 \text { - Some college } \\
& 13 \text { - Bachelor's degree } \\
& \text { 3- Some graduate work } \\
& \text { 5-Master's degree } \\
& 1 \text { - Doctoral candidate }
\end{aligned}
$$

4. Occupation:

$$
35 \text { - Student }
$$

22 - Other (as indicated)
(4) Secretary
(3) Unemployed
Cab Driver
Computer Analyst
(2) Accountant
Day Care Teacher
(2) Teacher Educational Coordinator Gerontologist
Instructor
Magician
Printer
Sound Production Vocational Evaluator

5. Length of time subjects in dyads knew each other:

$$
\begin{aligned}
& 15 \text { - just met } \\
& 7-1 \text { to } 5 \text { months } \\
& 4-6 \text { to } 11 \text { months } \\
& 11-1 \text { to } 4 \text { years } \\
& 4-5 \text { to } 9 \text { years } \\
& 6 \text { - } 10 \text { to } 14 \text { years } \\
& 6 \text { - } 15 \text { to } 19 \text { years } \\
& 4 \text { - over } 20 \text { years }
\end{aligned}
$$

6. Relationship between the dyadic subjects:

$$
\begin{aligned}
& \text { 15- Experiment partner } \\
& 4 \text { - Brother/sister } \\
& 18 \text { - Friend } \\
& 4 \text { - Boyfriend/girlfriend } \\
& 2 \text { - Co-worker } \\
& 2 \text { - Spouse } \\
& 4 \text { - Cousin } \\
& 4 \text { - Classmate } \\
& 2 \text { - Tutor/student } \\
& 2 \text { - Mother/son }
\end{aligned}
$$


Observer B

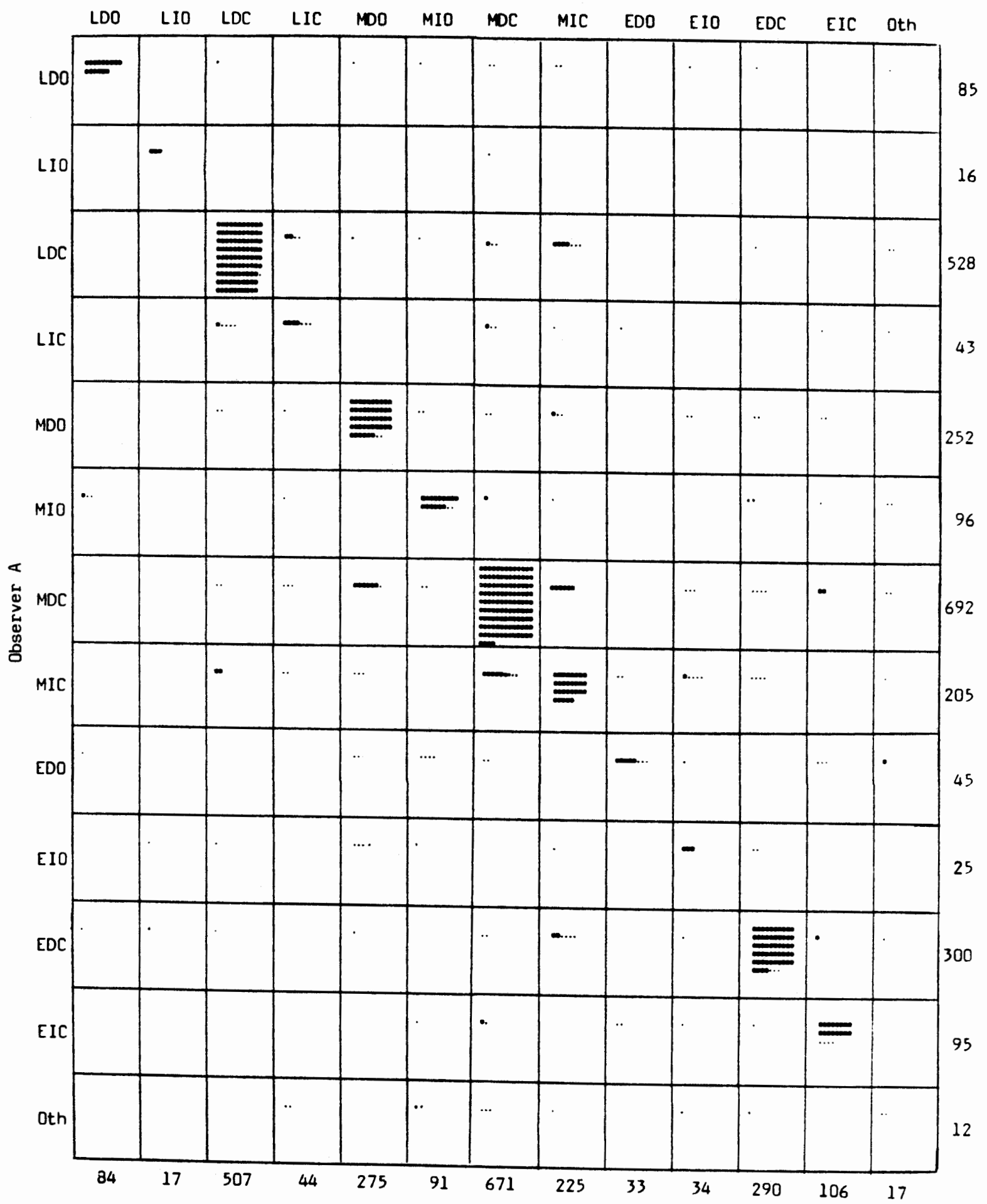

Figure 23. Summary matrix for final study for assessment of Cohen's Kappa on interrater reliability.

Key: $0=5$ corresponding observations.$=1$ corresponding observation 
reliability coefficient of +.83 . Inspection of the figures shows that 4788 actual observations were made by eight coders of 57 subjects, each involved in 21 minutes of dyadic interaction. Each subject was coded every 30 seconds providing a total of 42 coded intervals. Since all subjects were observed by two coders, the coded intervals totaled 84 . The coded intervals were compared between coders supplying a total of 2394 intervals for the sample. Of this total, there was interrater agreement on 2055 of the intervals.

The methodology of an independent sampling of units used in this investigation has allowed a reliability check on the proportion of joint judgments regarding each coded interval. The fact that Cohen's Kappa is high at +.83 is quite significant and indicates a high degree of stability between coders after chance agreement has been excluded.

Assessment of Frequency of Postural Positions

The data collected from the coding of the subjects revealed that certain postural positions were more common among the sample than others. Figure 24 on the following page indicates that the postural position that most frequently occurred was a combination of moderate relaxation, direct orientation, and a closed body position (MDC); this position accounted for $29.4 \%$ of the total number of agreed upon observations made by coders. This postural position was followed by least relaxation, direct orientation, and a closed body position (LDC) at $23.4 \%$ of the total, and extreme relaxation, direct orientation, and a closed body position (EDC) at $13.3 \%$.

The least common postural positions assumed by the sample were a combination of least relaxation, indirect orientation, and an open 


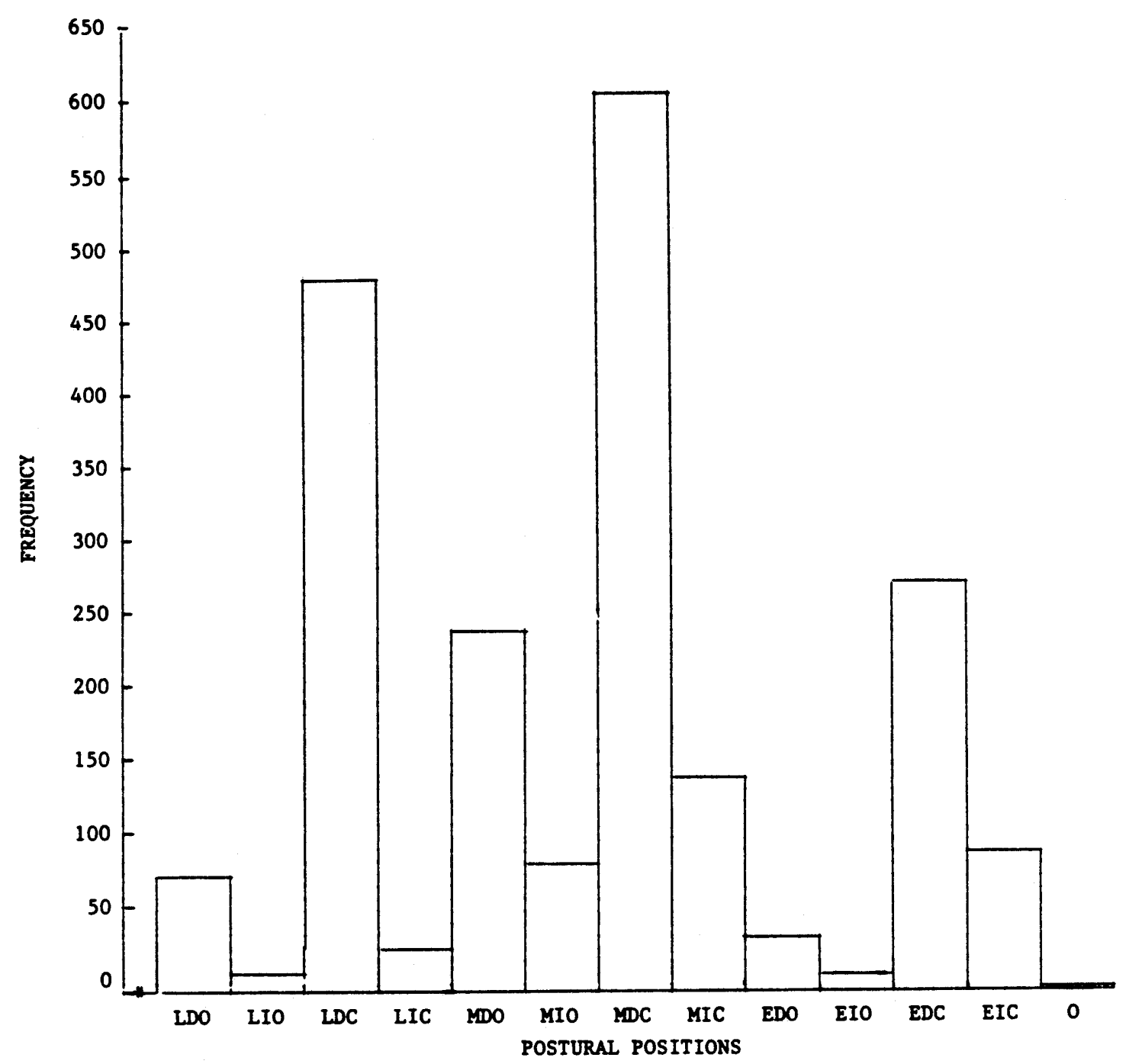

Fiqure 24. Histogram of postural positions assuned by 57 coded subjects.

body position (LIO) and extreme relaxation, indirect orientation, and an open body position (EIO). Each of these positions accounted for $.7 \%$ of the total number of agreed upon observations.

When each of the three components of postural position (relaxation, orientation, and accessibility) were assessed separately, moderate relaxation accounted for $51.5 \%$ of the number of total agreed upon observations. Least relaxation followed at $28.9 \%$ and extreme relaxation accounted for 19.5\%. Direct was the most common orientation occurring $82.4 \%$ of the 
time, and a closed body position was assumed $78.4 \%$ of the time.

In summary, it is possible to infer that the most common postural position in this sample, occurring $66.1 \%$ of the time, included direct orientation of the head and shoulders, closed extremities of either the upper or lower body (or both), and a range of body relaxations with moderate relaxation being assumed by the majority of subjects.

\section{Analysis of Hypothesis 1}

\section{$H_{1}$ : An individual's level of attentiveness in a seated dyadic interaction will produce a high direct correlation with the specific postural positions he or she assumes.}

Two separate data analyses were conducted using the Honeywell 6640 at Portland State University in order to assess the strength of the association between attentiveness and specific postural positions. First, using subprogram "Pearson Corr" in the Statistical Packages for the Social Sciences (SPSS) (Nie et al., 1975), Pearson product-moment correlation coefficients were obtained in order to inspect both the direction and strength of relationships that might exist among positions and between positions and attentiveness measures. Second, using subprogram "New Regression" in SPSS, a multiple regression was completed in order to describe the predictive relationships of the postural variables to the assessment criteria. Results from the analyses will now be detailed.

Correlations on Hypothesis 1. Correlation reflects reasoning incorporating the concept of how scores vary within a distribution. In interpreting a correlation, Williams (1979, p. 122) says that the following three things are important to consider when given a particular value for 
I: (1) the direction indicated by the sign of the coefficient (whether or not the measures vary directly [positively] or inversely [negatively]), (2) the magnitude of the coefficient (this varies from a zero or negligible level to a level that may approach perfect correlation at 1.0), and (3) whether the obtained $\underline{\underline{r}}$ is significant or not (what is the probability of obtaining the value of $\underline{\underline{r}}$ that was actually found).

In this analysis, of primary interest were the correlations between the three attentiveness measures and the specific postural positions subjects' assumed. The observed correlations between each of these measures and the postural positions are indicated in Table III.

TABLE III

PEARSON PRODUCT-MOMENT CORRELATION COEFF ICIENTS INDEXING DEGREE OF RELATIONSHIP BETWEEN THE OAM, PPAS, CGRA AND THE POSTURAL POSITIONS USED IN THE CODING SCHEME

$\begin{array}{cccccccccccccc} & 1 & 2 & 3 & 4 & 5 & 6 & 7 & 8 & 9 & 10 & 11 & 12 & 13 \\ & \text { LDO } & \text { LIO } & \text { LDC } & \text { LIC } & \text { MDO } & \text { MIO } & \text { MDC } & \text { MIC } & \text { EDO } & \text { EIO } & \text { EDC } & \text { EIC } & \text { Oth } \\ \text { DAM } & -.00 & -.31 & +.46 & -.05 & -.06 & -.39 & +.06 & -.20 & -.09 & -.05 & -.21 & -.18 & -.21 \\ \text { PPAS } & +.11 & -. .45 & +.18 & -.05 & -.03 & -.23 & +.11 & -.20 & -.02 & -.09 & -.14 & -.08 & -.31 \\ \text { CGRA } & +.11 & -.35 & +.26 & -.29 & +.30 & -.37 & +.05 & -.15 & +.22 & -.24 & -.17 & -.34 & -.08\end{array}$

Thirteen Coding Categories for Scoring Postural Positions

\begin{tabular}{|c|c|c|c|c|c|c|c|c|}
\hline $\begin{array}{l}\text { Relaxation: } \\
\text { Orientation: } \\
\text { Accessibility: }\end{array}$ & (1) & $\begin{array}{l}\text { Least } \\
\text { Direct } \\
\text { Open }\end{array}$ & (2) & $\begin{array}{l}\text { Least } \\
\text { Indirect } \\
\text { Open }\end{array}$ & (3) & $\begin{array}{l}\text { Least } \\
\text { Direct } \\
\text { Closed }\end{array}$ & (4) & $\begin{array}{l}\text { Least } \\
\text { Indirect } \\
\text { Closed }\end{array}$ \\
\hline $\begin{array}{l}\text { Relaxation: } \\
\text { Orientation: } \\
\text { Accessibility: }\end{array}$ & (5) & $\begin{array}{l}\text { Moderate } \\
\text { Direct } \\
\text { Open }\end{array}$ & (6) & $\begin{array}{l}\text { Moderate } \\
\text { Indirect } \\
\text { Open }\end{array}$ & (7) & $\begin{array}{l}\text { Moderate } \\
\text { Direct } \\
\text { Closed }\end{array}$ & (8) & $\begin{array}{l}\text { Moderate } \\
\text { Indirect } \\
\text { Closed }\end{array}$ \\
\hline $\begin{array}{l}\text { Relaxation: } \\
\text { Orientation: } \\
\text { Accessibility: }\end{array}$ & (9) & $\begin{array}{l}\text { Extreme } \\
\text { Direct } \\
\text { Open }\end{array}$ & (10) & $\begin{array}{l}\text { Extreme } \\
\text { Indirect } \\
\text { Open }\end{array}$ & (11) & $\begin{array}{l}\text { Extreme } \\
\text { Direct } \\
\text { Closed }\end{array}$ & (12) & $\begin{array}{l}\text { Extreme } \\
\text { Indirect } \\
\text { Closed }\end{array}$ \\
\hline
\end{tabular}

(13) other 
As shown in the preceding table, the bulk of the coefficients show overwhelmingly small or negligible relationships between the attentiveness measures and the coded postural positions with respect to direction. Of the 39 coefficients produced, 28 were negative and 11 were positive. The levels for magnitude of the coefficients and the type of relationship expressed are listed in the following table with the frequency of occurrence in this analysis.

\section{TABLE IV}

INTERPRETATION OF CORRELATION COEFFICIENTS

AS SUGGESTED BY WILLIAMS (1979)

\begin{tabular}{rlc}
\hline & Magnitude/Relationship Suggested & $\begin{array}{c}\text { Frequency in } \\
\text { this Analysis }\end{array}$ \\
\hline$<.20$ slight; almost negligible relationship & 21 \\
$.20-.40$ low correlation; definite but small relationship & 16 \\
$.40-.70$ moderate correlation; substantial relationship & 2 \\
$.70-.90$ high correlation; marked relationship & 0 \\
$>.90$ very high correlation; very dependable relationship & 0 \\
\hline
\end{tabular}

Noteworthy items are the +.46 coefficient produced by the DAM (self-report) and the LDC position, and the -.45 coefficient produced by the PPAS (partner's report) and the LIO position. Both of these coefficients show a moderate correlation and a substantial relationship between the levels of attentiveness and the postural positions indicated. The remainder of the correlations produced slight or low coefficients revealling definite but small relationships or almost negligible relationships between the variables. In the case of the latter correlations, the magnitude, although low in a statistical sense, is of sufficient consequence in describing the relationships between the variables so as to warrent 
consideration. Significance levels for the 39 coefficients showed that 16 correlations were below the .05 level of chance, indicating significance, and 23 correlations were above this level.

A secondary area of interest in the correlation analysis concerns the degree of relationship between the measures themselves. Table $V$ presents the correlation coefficients produced by these measures.

\section{TABLE $V$}

PEARSON PRODUCT-MOMENT CORRELATION COEFFICIENTS FOR THE DYADIC ATTENT IVENESS MEASURE, PERCEPTION OF PARTNER'S ATTENTIVENESS

SCALE, AND CODER'S GLOBAL REPORT OF ATTENTIVENESS

Measures

DAM and PPAS (self and other)

DAM and CGRA (self and coders)

PPAS and CGRA (other and coders)
Coefficients Produced

$+.25$

$+.42$

$+.40$

The coefficient produced by the first two measures suggests a low correlation and a definite but small relationship between the way in which the self perceived his or her attentiveness the way in which the other perceived this attentiveness. Moderate correlations and substantial relationships are indicated by the second and third coefficients suggesting a higher level of significance was achieved when objective data produced by the coders was paired with the perceptions of the self and the other. Significance levels for these three correlations were well below the .05 level of confidence at $.032, .001$, and .001 respectively. Essentially, the data produced by subprogram "Pearson Corr" in SPSS indicates that attentiveness is not highly correlated in a positive direction with specific postural positions; hence, the hypothesis is 
disproved. Further examination of Hypothesis 1 is presented in the next section.

Regression Analysis on Hypothesis 1. A regression analysis, using subprogram "New Regression" in SPSS, was conducted on the data derived from the final study so that the relationship among the variables could not only be assessed, but could be used as the basis for prediction. This analysis was an attempt to learn which of the postural positions assumed by subjects best predicted attentiveness; the concern here is with descriptive statistics-describing the predictive relationships that occurred. In order to assess the predictive power of the variables, the total variance was divided into "accounted for" components and an estimation was made of the probability that the variance accounted for was greater than could occur by chance alone.

Utilizing this multiple regression analysis, more than one predictor variable was brought to bear in predicting the scores on a given variable. This method is a way of describing the relative degree of contribution of a series of variables in the multiple prediction of a variable. An important feature in this regression subprogram is the "stepwise" procedure which makes possible the development of the regression equation one variable at a time until some criterion is reached that indicates that further predictors are unnecessary. Thus, variables were selected in the order of their ability to contribute to the overall prediction. Two additional features of the "New Regression" are the more rigorous default and tolerance levels than were used in the standard "Regression" subprogram. Default values for "New Regression" are .05 for F-to-enter and .01 for tolerance; levels in the old regression are 
much lower at 1.0 for $\mathrm{F}$-to-enter and 0.001 for tolerance.

In the regression analysis, the three attentiveness measures were treated as dependent variables and the 13 postural positions were used as predictor variables. The succeeding tables report the results of this analysis showing in particular those variables that contributed most highly to the regression equation.

\section{TABLE VI}

SWEEP MATRIX SHOWING DEGREE OF CONTRIBUTION OF VARIABLES IN THE MULTIPLE PREDICTION OF DAM

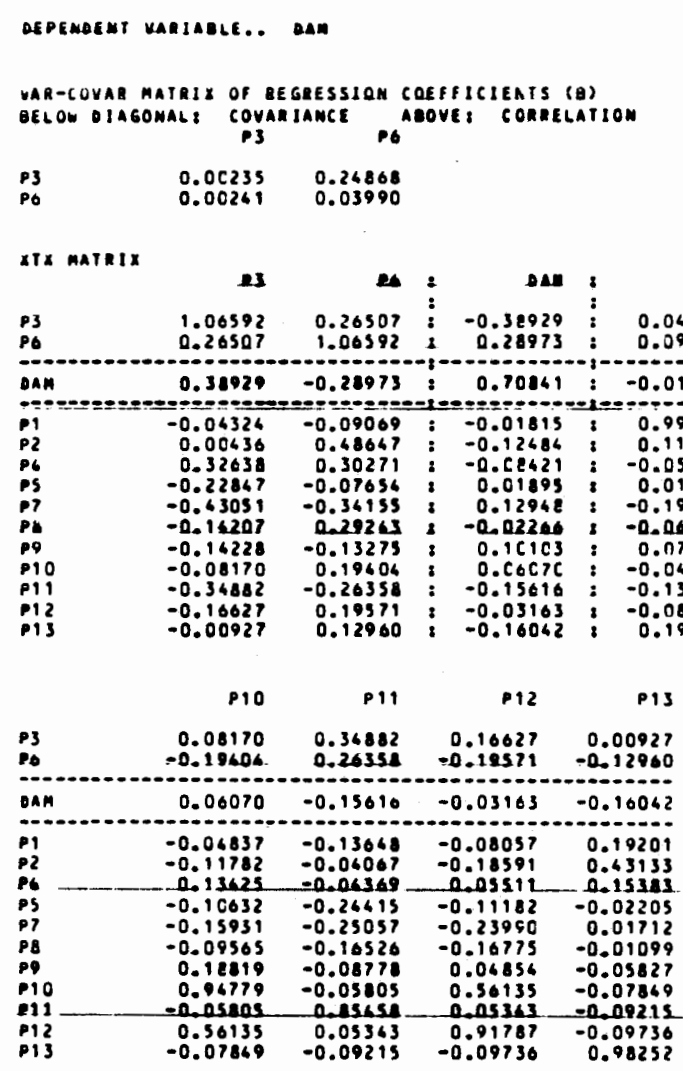


TABLE VII

\section{SWEEP MATRIX SHOWING DEGREE OF CONTRIBUTION OF VARIABLES IN THE MULTIPLE PREDICTION OF PPAS}

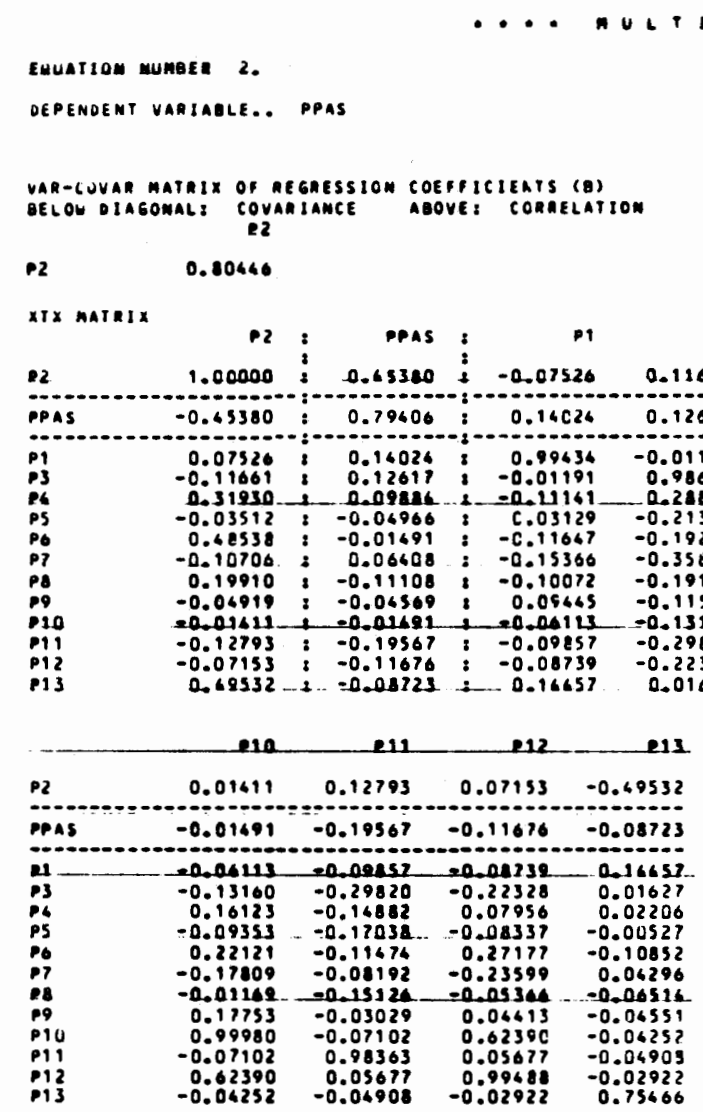


TABLE VIII

SWEEP MATRIX SHOWING DEGREE OF CONTRIBUTION OF VARIABLES IN THE MULTIPLE PREDICTION OF CGRA

DEPENDEMT VARIAGLE.. CGRA

val-cuYar matrix or acgResSION COEFFIGIEATS (H)

BE LOW DIAGOMAL: COVAMIAMCE PS PBOVE: CORRELTION

$\begin{array}{lllll}\text { Po } & 0.26981 & 0.06758 & 0.32527 & -0.29760 \\ \text { P5 } & 0.06480 & 0.03777 & 0.18536 & 0.08251 \\ \text { PS } & 0.02181 & 0.00665 & 0.01667 & -0.30299\end{array}$

$\begin{array}{lrrrr}\text { is } & 0.02187 & 0.00665 & 0.21667 & -0.30299 \\ \text { 16 } & -0.26657 & 0.02537 & -0.06173 & 2.50318\end{array}$

\begin{tabular}{|c|c|c|c|c|c|c|c|c|c|c|c|c|}
\hline Ix whes & PG & D 5 & 13 & P6 & : & CGRA & $:$ & P1 & P2 & P? & Po & p 9 \\
\hline $\begin{array}{l}\text { P6 } \\
\text { PS } \\
\text { OS } \\
\text { P6 }\end{array}$ & $\begin{array}{r}1.17626 \\
0.05310 \\
0.30178 \\
-0.35108\end{array}$ & $\begin{array}{l}0.05310 \\
1.05913 \\
0.21218 \\
0.09236\end{array}$ & $\begin{array}{r}0.39179 \\
0.21184 \\
1.23162 \\
-0.365 C 7\end{array}$ & $\begin{array}{r}-0.35108 \\
0.09236 \\
-0.36507 \\
1.18317\end{array}$ & 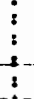 & $\begin{array}{r}0.22655 \\
-0.31846 \\
-0.33377 \\
0.27529\end{array}$ & $\begin{array}{l}\vdots \\
\vdots \\
:\end{array}$ & $\begin{array}{r}0.00993 \\
-0.01364 \\
0.01886 \\
0.06513\end{array}$ & $\begin{array}{r}-0.61128 \\
0.00663 \\
0.07762 \\
-0.26671\end{array}$ & $\begin{array}{r}0.35693 \\
0.35764 \\
0.69929 \\
0.03963\end{array}$ & $\begin{array}{r}-0.27558 \\
0.17215 \\
-0.16379 \\
0.05395\end{array}$ & $\begin{array}{r}0.13203 \\
-0.37683 \\
0.06050 \\
-0.09289\end{array}$ \\
\hline CGEA & -0.22655 & a.31146. & 0.33377 & -0.27529 & : & 0.65812 & : & 0.06428 & -0.10135 & 0.13838 & 0.03505 & 0,11112 \\
\hline $\begin{array}{l}p 1 \\
02 \\
07 \\
08 \\
08 \\
p 9 \\
010 \\
111 \\
112 \\
113\end{array}$ & $\begin{array}{r}-0.06993 \\
0.01128 \\
-0.35693 \\
0.29558 \\
-0.13203 \\
0.116126 \\
-0.26120 \\
0.17862 \\
0.07662\end{array}$ & $\begin{array}{r}0.01364 \\
-0.00143 \\
-0.33764 \\
-0.17215 \\
0.37683 \\
-0.10020 \\
-0.26262 \\
=0.11131 \\
-0.00915\end{array}$ & $\begin{array}{l}-0.01880 \\
-0.07767 \\
-0.69929 \\
-0.16379 \\
-0.08650 \\
-0.15324 \\
-0.38659 \\
-0.21007 \\
-0.07010\end{array}$ & $\begin{array}{r}-0.06513 \\
0.06671 \\
-0.03963 \\
-0.05395 \\
0.09289 \\
0.16903 \\
-0.07426 \\
0.01642 \\
0.17998\end{array}$ & $\vdots$ & $\begin{array}{r}0.06928 \\
-0.10135 \\
0.13438 \\
0.03505 \\
0.11112 \\
-0.07961 \\
-0.10965 \\
=0.16921 \\
0.01693\end{array}$ & $\begin{array}{c}\vdots \\
\vdots \\
\vdots \\
\vdots \\
\vdots \\
\vdots\end{array}$ & $\begin{array}{r}0.98794 \\
0.12828 \\
-0.19380 \\
-0.06528 \\
0.07573 \\
-0.03817 \\
-0.13600 \\
-0.07565 \\
0.20233\end{array}$ & $\begin{array}{r}0.12828 \\
-0.71231 \\
0.00605 \\
0.06771 \\
-0.01162 \\
-0.15165 \\
-0.03151 \\
-0.20025 \\
0.39324\end{array}$ & $\begin{array}{r}-0.19380 \\
0.00805 \\
0.05031 \\
-0.16205 \\
-0.17216 \\
-0.19201 \\
-0.33962 \\
-0.27771 \\
0.01533\end{array}$ & $\begin{array}{r}-0.06528 \\
0.04771 \\
-0.16205 \\
0.86437 \\
-0.03282 \\
-0.10671 \\
-0.20965 \\
-0.18403 \\
-0.00649\end{array}$ & $\begin{array}{r}0.07573 \\
-0.01162 \\
-0.17216 \\
-0.03282 \\
0.03639 \\
0.021578 \\
0.00828 \\
0.01558 \\
-0.06425\end{array}$ \\
\hline
\end{tabular}

\begin{tabular}{|c|c|c|c|c|}
\hline & P1O & P11 & P12 & P13 \\
\hline $\begin{array}{l}\text { P6 } \\
\text { P5 } \\
\text { P3 } \\
\text { P4 }\end{array}$ & $\begin{array}{r}-0.16126 \\
0.10020 \\
0.15324 \\
-0.16903\end{array}$ & $\begin{array}{l}0.26120 \\
0.26262 \\
0.38459 \\
0.07426\end{array}$ & $\begin{array}{r}-0.17062 \\
-0.11336 \\
0.210 C ? \\
-0.05687\end{array}$ & $\begin{array}{r}-0.07662 \\
-0.00915 \\
0.07010 \\
-0.17998\end{array}$ \\
\hline CGAA & -0.07961 & -0.10965 & -0.16921 & 0.01693 \\
\hline $\begin{array}{l}P 1 \\
P 2 \\
P 7 \\
P 8 \\
P 9 \\
P 10 \\
P 11 .\end{array}$ & $\begin{array}{r}-0.03212 \\
-0.15165 \\
-0.19201 \\
-0.16671 \\
0.21579 \\
0.91713 \\
-0.02600\end{array}$ & $\begin{array}{r}=0.13600 \\
-0.03151 \\
-0.33962 \\
-0.20965 \\
0.00828 \\
-0.07600 \\
0.22222\end{array}$ & $\begin{array}{r}=0.02563 \\
-0.20025 \\
-0.27771 \\
-0.18613 \\
0.08556 \\
0.54193 \\
0.02116\end{array}$ & $\begin{array}{r}-0.20233 \\
0.39324 \\
0.01533 \\
-0.00649 \\
-0.06425 \\
-0.10363 \\
-0.06652\end{array}$ \\
\hline $\begin{array}{l}\text { P12 } \\
\text { P13 }\end{array}$ & $\begin{array}{r}0.56193 \\
-0.10363\end{array}$ & $\begin{array}{r}0.02816 \\
-0.08652\end{array}$ & $\begin{array}{r}0.90217 \\
-0.10831\end{array}$ & $\begin{array}{r}-0.10831 \\
0.95463\end{array}$ \\
\hline
\end{tabular}


Essentially, the author was looking for the predictive pattern or combinations of categories that accounted for the variance. The aspects of the regression equation that were analyzed in order to assess this were: (1) the percentage of variance explained by each of the predictor positions, (2) the percentage of shared variance between multiple predictors and criterion variables, and (3) the resulting highest contributions to the regression equation. The following tables detail how the postural positions regressed on the variables attentiveness.

TABLE IX

SUMMARY TABLES FOR THE DAM, PPAS, AND CGRA DISPLAYING STATISTICS IN THE REGRESSION EQUATION

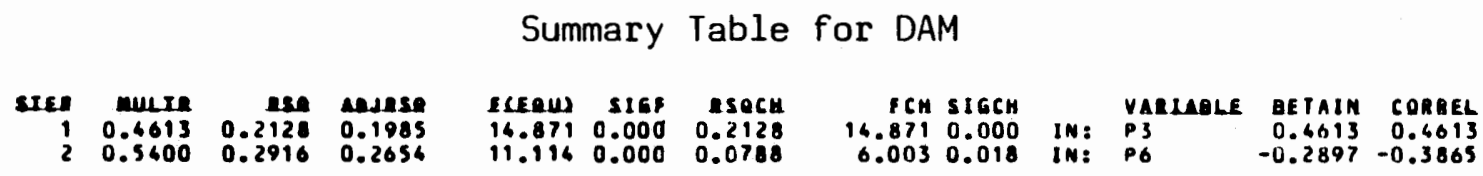

Summary Table for PPAS

Sisa mut

$\begin{array}{rr}0.20 & \text { nesese } \\ 0.2059 & 0.1915\end{array}$

Heats sisp asech

$16.2640 .000 \quad 0.2059$

$\begin{array}{rlrr}\text { ECH } \$ 16 C H & & \text { VARLABLE DETAIM CORREL } \\ 16.266 & 0.000 \text { IN: P2 } & -0.4538 & -0.6338\end{array}$

Summary Table for CGRA

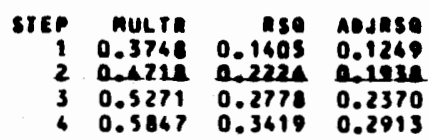

$\begin{array}{lll}\text { (E)US } & 516 f & \text { nSECH } \\ 0.990 & 0.006 & 0.1605 \\ 2.231 & 0.001 & 0.0221 \\ 0.797 & 0.001 & 0.0552 \\ 6.753 & 0.00 C & 0.0661\end{array}$

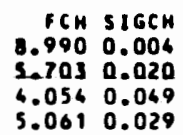

$\begin{array}{llr}\text { VARLABLE } & \text { BETAIN } & \text { COAMEL } \\ \text { IN: PG } & -0.3748 & -0.3768 \\ \text { IHE PS } & 0.2866 & 0.2939 \\ \text { IN: PS } & 0.2688 & 0.2538 \\ \text { IN: PS } & -0.2753 & -0.2885\end{array}$

The stepwise progression allowed the development of the regression equation to occur step-by-step until predictions were reached that further progressions were unnecessary. The limited number of steps that were required in these equations can be noted in the column at the far left. The statistics in this subprogram produced a multiple $\underline{\mathbf{r}}, \underline{\mathbf{r}}^{2}$, adjusted $\underline{\mathbf{r}}$, 
and standard error. These correlation coefficients tell what proportion of the variance of the predicted variables was accounted for by two predictor variables. In order to see the relative contribution of each predictor variable to this variance, each correlation coefficient of a predictor variable was multiplied with the predicted variable by its respective beta (B) coefficient. Each of the preceding equations shows a multiple $\underline{\mathbf{r}}$ in the moderate range between .37 and .58 . Significance levels of $F$ ranged between .000 and .004 .

Those positions with the highest individual predictive capability on the criterion variable were P3 (LDC) on DAM at $21 \%$, P2 (LIO) on PPAS at $21 \%$, and P6 (MIO) on CGRA at 14\%. The majority of the postural positions accounting for the remainder of the variance had limited predictive power. The amounts of variance explained by multiple positions are indicated in the $\underline{\mathbf{r}}$ square change column (RSQCH). As can be determined from the tables, the percentage of shared variance between the weighted predictor postitions P3 and P6 on DAM was 29\%; of the predictor position P2 on PPAS was 21\%; and among the predictor positions P6, P5, P3, and P4 on CGRA was $34 \%$.

Systematic analysis of the relationship between attentiveness and postural positions reveals that a high direct correlation between these variables was not obtained and Hypothesis 1 was not verified. The multiple regression analysis suggests that while a few of the 12 postural positions predict attentiveness, either directly or inversely, the majority of positions do not contribute to the regression equation or predict the criterion variable. Analysis of the second hypothesis follows. 
Analysis of Hypothesis 2

$H_{2}$ : An individual's level of attentiveness in a seated dyadic
interaction will produce a high inverse correlation with
the number of his or her postural shifts in position.

In addition to an assessment of the association between specific postural positions and an individual's level of attentiveness, an analysis of postural shifts and their relation to attentiveness was performed. As might be expected, participants in the study did not maintain one postural position throughout the 21 minutes of interaction. Individual's changed postural positions in varying amounts; the mean number of postural shifts for the sample was 2.5 .

A postural shift was defined as an observable change from one postural position to a distinctly different position. In that there were only 12 different postural positions, this was the maximum number of shifts a subject could assume. Movements from one position to another and then back again were not recorded as shifts primarily because this might have distracted coders from their original purpose of scoring the postural positions. Subjects ranged from a stationary postural position in which no shift occurred to assuming as many as nine different postural positions.

In order to assess the relationship between postural shifts and attentiveness, the number of a subjects' shifts and their reported levels of attentiveness were correlated using subprogram "Pearson Corr" in SPSS. The three Pearson product-moment correlation coefficients that were produced are given in Table $X$. 
TABLE $X$

PEARSON PRODUCT-MOMENT CORRELATION COEFFICIENTS FOR THE DAM, PPAS, CGRA, AND THE NUMBER OF POSTURAL SHIFTS

\section{Measures/Shifts}

DAM and number of shifts PPAS and number of shifts CGRA and number of shifts

\section{Coefficients Produced}

$-.26$

$-.38$

$-.44$

Clearly the direction of the coefficients produced confirmed the expectation of an inverse relationship between the variables. Once again following Williams' (1979, p. 128) guidelines for the interpretation of correlation coefficients, the first and second coefficients are low correlations and show definite but small relationships, and the third coefficient shows a moderate correlation and a substantial relationship. Significance levels for the three correlations were at or below the .05 level of probability.

The coefficients produced are similar to previous findings in that a higher level of significance was achieved by correlating the objective reports of coders and the actual behavior of the subject than was achieved from correlations between the self-reports or other-reports and the postural shifts. Results from these correlations show a low to moderate inverse relationship rather than the predicted high correlation that was hypothesized.

\section{Discussion}

The experiments ran extremely well in both the pilot and final studies. There were a limited number of problems and the overall investigation did not have to be altered to any great degree. 
A major concern of the author was the interrater reliability and the operation of the coding center. Interrater reliability was acceptable at +.74 in the pilot study, and very good at +.83 for the final study. This +.09 improvement in reliability is believed to have been achieved for the following reasons: (1) the visual quality of the videotapes improved throughout the experiment, (2) the author learned to specifically request persons wearing such articles of clothing as bulky coats to remove them because they impaired the viewing of the torso lean, (3) coding categories were made more explicit for the final study and more examples were given to coders so that they could better distinguish the degrees of relaxation, orientation, and types of accessibility, and (4) the coders seemed to become more efficient with practice. The author's general observations concerning the coding are that the coders had the most difficulty coding torso lean and coding a subject's transitions between postural positions. Consequently, the subjects who remained in one postural position tended to have a very high interrater reliability and those assuming several positions had a much lower reliability. By inference, accessibility was the easiest portion of the categories to code, probably because it was the most discernible aspect and did not change much for the majority of subjects.

The coders expressed no difficulty in independently operating the coding center. It was assessed that it took approximately 35 minutes for coders to code a subject's 21 minutes of interaction because they were required to find their assigned subjects on the videotape, operate the VTR equipment, and fill out the appropriate attentiveness measure.

The sample population was deemed acceptable for this study with a manageable number of subjects. The descriptive characteristics of the 
sample proved to be broad-based enough to suggest that similar postural and attentive characteristics would be found in other sample populations. This study, however, was not based on a sample that exhibited a wide range of levels of attentiveness, contrarily, most of the subjects scored quite highly in their attentiveness based on the reports and the coding. It was hoped that the group of subjects filmed in the home environment would have been more inattentive as they tended to have longer relationships with their partners, but this did not occur. It is now believed by the author that gathering a sample with a wide distribution in levels of attentiveness would be very difficult because of the very nature of attentiveness. Nevertheless, the sample used for this study did provide the full range of selected postural positions and enough of a range in levels of attentiveness to make some interesting conclusions.

Some postural positions were found to be more commonly assumed by the sample than others. The moderate, direct, closed (MDC) position was the most common, while the least, indirect, open (LIO) along with the extreme, indirect, open (EIO) positions were rarely displayed in comparision. Subjects appeared to be most comfortable in positions that were direct in upper body orientation, closed in positions of the extremities (especially the lower), and moderate in their degree of torso relaxation.

Results from the correlation and regression analyses disproved the first hypothesis indicating that a high direct correlation does not exist between levels of attentiveness and postural positions. The majority of the coefficients ( $54 \%$ ) indicated slight correlations and almost negligible relationships between the attentiveness measures and the coded postural positions. An additional large number ( $41 \%$ ) of the coefficients showed low correlations and definite but small relationships between the variables. 
Two correlations in the analysis proved to be moderate and indicated substantial relationships between the variables. A +.46 correlation coefficient was produced by DAM and the LDC position, and a -.45 correlation coefficient was produced by PPAS and the LIO position. This reveals that from the perspective of the self, a position consisting of least relaxation, direct orientation, and closed accessibility was moderately related to attentiveness. From the perspective of the partner, a position consisting of least relaxation, indirect orientation, and open position was moderately related to inattentiveness. The author presumes that orientation, either direct or indirect, is more indicative of the construct than is an open or closed position.

Regarding the coefficients produced by correlations on the measures themselves, a low correlation and definite but small relationship exists between the perspectives of the self and other. An informal review of the measures reveals that others generally rated their partners more highly than subjects rated themselves. Conjecture on this phenomenon surrounds the notion that persons tend to be less evaluative of others than themselves in such a socially contrived situation. An interesting relationship was expressed by correlations between the independent observers and both the self and other measures. Presumably, the higher correlations here were achieved because the coders did not have to function as participant-observers, perceiving the interaction as a phenomenological experience on one hand, and shifting to ascribe attributions to the behavior of their partner's on the other. The coders were not at risk in expressing their reaction to the interaction and this proved the most accurate estimation of a subject's attentiveness. 
As a result of the regression analysis, three postural positions emerged as significant predictors of attentiveness. LDC and LIO were the best predictors, each accounting for $21 \%$ of the variance of DAM and PPAS respectively, and MIO was also of consequence accounting for $14 \%$ of the total variance of CGRA. Examination of these postural positions in relation to the correlations performed in the previous analysis proves useful. The least relaxation, direct orientation, closed accessibility position, here accounting for a high contribution to predicting the varience on DAM, also produced the highest direct correlation with DAM and provided a moderate correlation coefficient showing a substantial relationship to DAM. The least relaxation, indirect orientation, open accessibility position, contributing $21 \%$ to the prediction of PPAS, produced a high inverse correlation with this measure and revealed a substantial' relationship to this report of attentiveness by others. The moderate relaxation, indirect orientation, open accessibility position produced three low correlations with the measures, and though the relationships were definite but small, they indeed existed and were all in an inverse direction.

These three positions assumed by subjects best predicted levels of attentiveness. The positions $M I O, M D O, L D C$, and $L I C$ were also selected as contributors to the regression equation and sustained the rigorous default and tolerance levels. Further predictors failed to reach these levels and did not account for a significant amount of the variance on any of the criterion measures.

Results from a correlation analysis disproved the second hypothesis indicating that a high inverse correlation does not exist between levels of attentiveness and the number of subjects' postural shifts. The 
predicted direction of the correlation was found but the magnitude of the coefficients was much less than expected. Low coefficients on two of the three correlations showed definite but small relationships between both the DAM and PPAS and postural shifts. The moderate correlation produced by the CGRA and the number of shifts revealed a more substantial relationship between these variables, again presumably because of the objectivity of the independent observers this higher correlation was obtained. Surprisingly, the findings of this investigation are not commensurate with previous research, particularly that of Norton and Pettegrew (1979) who state that, "posture, leaning toward the speaker, maintaining a relaxed posture and showing interest via body attitude go a long way toward expressing an attentive style of communication" (p. 24). The present study suggests very little link between postural positions and an attentive style of communication. Methodological differences in studies no doubt influence results. Norton and Pettegrew (1979) used strictly self-report methods to derive their conclusions. It is assumed that the multiplicity of methods used in this investigation enhanced its validity.

A brief summary of the entire investigation as well as implications for further research are presented in the final chapter of this thesis. 


\section{CHAPTER VI}

\section{SUMMARY AND IMPLICATIONS}

\section{Summary}

As a variable of communicator style and a construct in its own right, attentiveness is the way in which persons verbally and nonverbally express to others transactional messages about how they are to be perceived and how their messages are to be interpreted. The research question most applicable to this relatively new construct is what exactly are those verbal and nonverbal messages that individuals use to signal their attentiveness. Findings of previous research on attentiveness and the behavioral associate empathy, suggest that nonverbal signals are more influential in communicating a sense of attentiveness than are verbal signals. Among the various nonverbal behavioral cues, such as eye contact and proxemics, posture has been identified as the most intimately linked to an attentive style of communication (Norton and Pettegrew, 1979).

This investigation was an attempt to further establish attentiveness as a stylistic construct of communication and a testing ground for the assertion that postural positions are indicative of an individual's level of attentiveness in dyadic interactions.

In all studies, the approach taken by the investigator is significant in determining the direction of the study, the type of research methodology used, and the subsequent and predictable data that is gleaned from the investigation. The methodology utilized in this study was 
categorized as an external variable approach and further classified as a meaning-centered approach for the following reasons: (1) use of experimental methods and quantitative analysis of individual nonverbal behaviors, (2) the relating of specified nonverbal behaviors to an external variable, (3) the focus on individual nonverbal cues, and (4) the inferences made from those cues. This approach was deemed most appropriate because of the limited quantitative information available on the construct of attentiveness and the strong research orientation of the external variable approach which adds essential empirical data to the sparse information on posture and attentiveness.

The research on posture, observations by the author, and related research on the strong relationship between postural positions and communicator attitude provided the basis for the assembling of a tripartite postural configuration for study. When designed to be mutually exclusive and exhaustive, these configurations provided 12 independent postural categories for use in the investigation.

An experiment was designed for this study in order that (1) the association between an individual's postural positions and their reported level of attentiveness might be evaluated, and (2) the association between an individual's postural shifts and their reported level of attentiveness might also be evaluated. Implementing the experiment involved:

1. Construction of a 13-item coding scheme of postural positions that reflected results of past research on posture.

2. Training of eight undergraduate students at Portland State University as coders to assist in gathering empirical data on the 62 videotaped subjects involved in the study. Each coder coded 12-14 subjects and received one hour of credit for this research practicum. 
3. Developing three attentiveness measures for determination of the level of attentiveness of subjects in the study. The Dyadic Attentiveness Measure was given to each subject, the Perception of Partner's Attentiveness was given to the subject's partner, and the Coder's Global Report of Attentiveness was given to independent observers of the subject via videotape. The measures were based on work done by Norton and Pettegrew (1979) and other pertinent literature on attentiveness.

4. Recruiting 62 subjects as the sample population. Two groups were devised as 37 subjects were videotaped at Portland State University and 25 subjects were videotaped in the home environment. Of the 62 subjects, five were used for analysis in the pilot study and 57 were used for analysis in the final study.

5. A pilot study which tested the workability of the experimental design and an assessment of interrater reliability, and a final study that tested the research hypotheses of the investigation by isolating specific postural positions and the frequency of postural shifts in order to examine the correlations of these behaviors with attentiveness.

The experiment comprised the bulk of the study and was conducted without major difficulties. Execution of the experiment provided the appropriate data for analysis of the research hypotheses.

Two separate data analyses were conducted in order to assess the strength of the association between attentiveness and specific postural positions. First, using subprogram "Pearson Corr" in SPSS, Pearson product-moment correlation coefficients were obtained in order to inspect both the direction and strength of the relationships that might exist among positions and between positions and attentiveness measures. Second, using subprogram "New Regression" in SPSS, a multiple regression was completed in order to describe the predictive relationships of the postural 
variables to the assessment criteria.

The data produced by the correlations indicated that attentiveness was not highly correlated in a positive direction with specific postural positions. The majority of coefficients (95\%) indicated slight to low correlations and negligible to definite but small relationships between the variables.

The regression analysis provided systematic analysis of the predictive power of the variables. Results from the multiple regression suggested that while a few of the 12 postural positions predicted attentiveness, the majority of positions did not contribute to the regression or predict the criterion variable. Three postural positions emerged as significant predictors of attentiveness, each accounting for a moderate degree of variance for each of the attentiveness measures. Four additional postural positions were selected as contributors to the regression equations but accounted for low amounts of the variance and showed low predictive relationships to the assessment criteria.

These two data analyses suggested the existence of a low to moderate correlation between an individual's level of attentiveness in a seated dyadic interaction and the specific postural positions he or she assumed, hence, Hypothesis 1 was disproved.

The second hypothesis was not verified as a high inverse correlation was not produced between an individual's level of attentiveness in a seated dyadic interaction and the number of his or her postural shifts in position. A small relationship was shown to exist between postural shifts and the attentiveness measures DAM and PPAS, and a substantial relationship was produced by the CGRA and the number of shifts. This 
suggests that when an individual is attentive there is an indication that he or she may display a low number of postural shifts and that a high number of shifts may be indicative of an individual's inattentiveness, but data on this are inconclusive.

of secondary interest to the investigator were the correlations between the three attentiveness measures. Results show that there exists a small but definite relationship between the way in which the self viewed his or her attentiveness and the way in which the other perceived this attentiveness; a substantial relationship was shown to exist between the way the coders and both the subjects and their partners perceived the interaction. Implication from these analyses indicate that the three measures used in this study to determine a subject's level of attentiveness from their perspective, their partner's perspective, and independent observer's perspectives correlate at a significant enough level to warrent their use in this study, however caution must be exercised in combining the measures for a total attentiveness score.

To sum up, the results of this experiment indicate that there is a predictable low to moderate link between either postural positions or postural shifts and levels of attentiveness. The construct of attentiveness, an important component of communicator style, is believed to be signaled to a large extent nonverbally. While other nonverbal cues may be more indicative of an individual's level of attentiveness, postural behavior is not highly representative of this construct. 


\section{Limitations and Recommendations}

At the end of a study, investigators are likely to be conscious of inherent weaknesses in their methodology or procedures as well as gain insights into how things could have been done in a more appropriate fashion. This author is no exception. The following are various limitations of the study and recommendations for further research in the realm of attentiveness, posture, and implementation of a coding scheme.

The categories utilized in this study represented those postural configurations assumed by most individuals in these seated interactions. From this aspect they were acceptable. In redesigning the categories, however, the author would more specifically define and dissect the categories. By way of example, a subject's torso lean, whether moderate or extreme, could be identified as to whether it was in a forward or backward direction. This would be helpful as the research on attitude and empathy suggests that the direction of a lean is a significant variable in distinguishing communicator attitude and expression of empathy. Another example occurs with the notion of accessibility. The categories used in this study did not differentiate between accessibility of the upper or lower body but recorded that the subject was in a closed position if either the upper or lower extremities were in a closed position. From general observation of the videotapes, the author now believes that it is very common for individuals to sitwith their legs crossed and that this is more indicative of some type of cultural or societal norm than a personal signaling of attentiveness. Contrary to this, an arms-akimbo position seems to be a much better predictor of an attentive style of communication and supports the notion that an individual's extremities should be 
categorized independently.

Essentially it is felt that in developing a comprehensive coding scheme on postural behavior, the following features should be incorporated:

1. An indication of either forward or backward lean of the torso

2. An indication of openness of closedness of the arms and legs, considered separately

3. Notation of the duration of forward or backward lean

4. Notation of the duration of specific postural positions

5. Notation showing whether or not individuals tended to change certain postural positions as the time of the interaction increased,i.e., were subjects more upright at the beginning of the interaction and then changed to a more relaxed torso lean as the interaction progressed.

In order to arrive at figures for a subject's level of attentiveness, three paper-and-pencil measures completed by the self, the other, and two coders, were assessed. The assumption underlying utilization of these three measures was that attentiveness is a behavioral activity signaled by the self and perceived by others. The low to moderate correlations between these measures showed a difference in the perspectives of the three parties. The result of the different interpretations of a person's behavioral activity may relate to metalevel perceptions and attribution theory - an interesting area for further investigation. What is actually occurring and being perceived in this communicative interaction needs addressing so that a more reliable indication of the level of attentiveness of an individual can be attained. One possible refinement in a measure of attentiveness might include the element of message retention; this idea based on the assumption that an individual who is 
attentive is tuned in to and focused on the other, and his or her message retention should reflect this.

The research methodology and experimental design used in this study proved to be more than adequate in providing appropriate and sufficient data for analysis of the research hypotheses. As reiterated throughout the study, the approach taken was an external variable approach with a meaning-centered emphasis. A major criticism by scholars of this approach is that it does not attempt to coordinate both the verbal and nonverbal realms of attentiveness. In this sense, the study did not fit the commonly adopted functional approach of speech communication theorists, but was certainly acceptable. A coordination of verbal and nonverbal aspects of communication would nevertheless be helpful in establishing the construct of attentiveness since verbal communication appears to have a significant place in the repertiore of signals an individual draws upon to communicate attentiveness.

There were no major limitations regarding the experimental design other than a concern about the lack of a wide range of attentiveness in the sample. Future experimental designs could perhaps move out of the laboratory and include the coding of behaviors in real-life, in vivo settings, particularly as coding schemes are perfected and investigators become more skilled at discriminating the various features of attentiveness.

In general, the study was well executed and followed the formats for a sound empirical investigation suggested by the literature and research particular to speech communication. The construct of attentiveness was tested with an established methodological approach and this study provides further knowledge on which future research can be based. 


\section{REFERENCES}

Allport, G.W. and Vernon, P.E. Studies in expressive movements. New York: MacMillan, 1933.

Argyle, M. Social interaction. New York: Atherton Press, 1969.

Argyle, M. Bodily communication. New York: International Universities Press, 1975.

Argyle, M. and Cook, M. Gaze as a signal for interpersonal attitudes and emotions in gaze and mutual gaze. Cambridge: Cambridge University Press, 1976.

Arnett, R.C. Toward a phenomenological dialogue. Western Journal of Speech Communication, 1981, 45, 201-217.

Arnett, R.C. and Nakagawa, G. The assumptive roots of empathic listening: A critique. Communication Education, 1983, 23, 368-377.

Austin, W.M. Some social aspects of paralanguage. Canadian Journal of Linguistics, 1965, 11, 31-39.

Baken, P. Attention: An enduring problem in Psychology. Princeton, New Jersey: Van Nostrand, 1966.

Barker, L.L. and Collins, N.B. Nonverbal and kinesic research. In P. Emmert and W.D. Brooks (Eds.), Methods in research in communication. Boston: Houghton Mifflin, 1970.

Bayes, M.A. Behavioral cues of interpersonal warmth. Jounal of Consulting and Clinical Psychology, 1972, 39, 333-339.

Berger, C.R. Interpersonal communication theory and research: An overview. In Brent D. Ruben (Ed.), Communication yearbook I. New Brunswick: Transaction Books, 1977, 217-228.

Birdwhistell, R. Introduction to kinesics: An annotation for analysis of body motion and gesture. Louisville: University of Louisville Press, 1952.

Birdwhistell, R. Some relationships between American kinesics and spoken American English. In A. Smith (Ed.), Communication and culture. New York: Holt, Rinehart and Winston, 1966.

Birdwhistell, R. Some body motion elements accompanying spoken American English. In L. Thayer (Ed.), Communication: Concepts and perspectives. Washington, D.C.: Spartan Books, 1967. 
Birdwhistell, R. Kinesics and context: Essays on body motion communication. Philadelphia: University of Pennsylvania Press, 1970.

Birdwhistell, R. and Weitz, S. Nonverbal communication. New York: Oxford University Press, 1979.

Blazer, J.A. Leg position and psychological characteristics in women. Psychology, 1966, 3, 5-12.

Braatoy, T.F. Fundamentals of psychoanalytic technique. New York: Wiley, 1954.

Bradley, P.H. and Baird, J.E. Management and communicator style: A correlation analysis. Central States Speech Journal, 1977, 28, 194-203.

Brandt, D.R. On linking social performance with social competence: Some relations between communicative style and attributions of interpersonal attractiveness and effectiveness. Human Communication Research, 1979, 2, 223-237.

Breed, G. The effect of intimacy: Reciprocity or retreat. British Journal of Social and Clinical Psychology, 1972, 11, 135-142.

Breed, G. Looking, blinking and sitting. Journal of Communication, 1974, 24, 75-80.

Bull, P.E. The interpretation of posture through an alternative methodology to role play. British Journal of Social and Clinical Psychology, 1978, 17, 1-6.

Bull, P.E. and Brown, R. The role of postural change in dyadic conversations. British Journal of Social and Clinical Psychology, 1977, $16,29-33$.

Burgoon, J.K. and Saine, T. The unspoken dialogue: An introduction to nonverbal communication. Boston: Houghton Mifflin, 1978.

Christensen, B. Thus speaks the body: Attempts toward a personality from the point of view of respiration and gesture. Oslo: Institute for Social Research, 1963.

Clark, K.B. Empathy: A neglected topic in psychological research. American Psychologist, 1980, 35, 188.

Cohen, J. A coefficient of agreement for nominal scales. Educational and Psychological Measurement, 1960, 20, 37-47.

Cohen, J. Weighted chi square: An extension of the Kappa method. Educational and Psychological Measurement, 1972, 32, 61-74.

Condon, W.S. and Ogston, W.D. A method of studying animal behavior. Journal of Auditory Research, 1967a, 7, 359-365. 
Condon, W.S. and Ogston, W.D. A segmentation of behavior. Journal of Psychiatric Research, 1967b, 5, 221-235.

Cook, J.J. Silence in psychotherapy. Journal of Counseling Psychology, $1964,11,42-46$.

Cook, M. Interpersonal perception. Baltimore: Penguin Books, 1971.

Crystal, D. and Quirk, R. Systems of prosodic and paralinguistic features in English. Hague: Mouton, 1964.

Dance, F.E. Toward a theory of human communication. In F.E. Dance (Ed.), Human communication theory. New York: Holt, Rinehart and Winston, 1967.

Darwin, C.R. The expression of emotions in man and animals. (Orig. publ. 1872) Chicago: University of Chicago Press, 1965.

Davitz, J.R. The communication of emotional meaning. New York: McGrawHill, 1964.

Deutsch, F. Analysis of postural behavior. Psychoanalytic Quarterly, $1947,16,195-213$.

Deutsch, F. Thus speaks the body: An analysis of postural behavior. Transaction of the New York Academy of Science, 1949, 12, 58-62.

Deutsch, F. Analytic posturology. Psychoanalytic quarterly, 1952, 21, 196-214.

Deutsch, J.A. and Deutsch, D. Attention: Some theoretical considerations. Psychological Review, 1963, 70, 80-90.

DiMatteo, M.R., Friedman, H.S., and Taranta, A. Sensitivity to bodily nonverbal communication as a factor in practitioner-patient rapport. Journal of Nonverbal Behavior, 1979, 4, 18-26.

Dittmann, A.T. The relationship between body movements and moods in interviews. Journal of Consulting Psychology, 1962, 26, 480.

Dittmann, A.T., Parloff, M.X., and Boomer, D.S. Facial and bodily expression: A study of receptivity of emotional cues. Psychiatry, 1965, $28,239-244$.

Duncan, S. Nonverbal communication. Psychological Bulletin, 1969, 72, 118-137.

Efron, D. Gesture and environment. New York: Kings Crown, 1941.

Efron, D. Gesture, race and culture. Hague: Mouton, 1972.

Eibl-Eibesfeldt, I. Ethology: The biology of behavior. New York: Holt, Rinehart and Winston, 1975. 
Eisenburg, A.M. and Smith, R.R. Nonverbal communication. Indianapolis: Bobbs-Merrill, 1971 .

Ekman, P. A methodological discussion of nonverbal behavior. Journal of Psychology, 1957, 43, 141-149.

Ekman, P. Body position, facial expression, and verbal behavior during interviews. Journal of Abnormal and Social Psychology, 1964, 68, 295-301.

Ekman, P. Communication through nonverbal behavior: A source of information about an interpersonal relationship. In S. Tomkins and $C$. Izarel (Eds.), Affect, cognition, and personality. New York: Springer, 1965a.

Ekman, P. Differential communication of affect by head and body cues. Journal of Personality and Social Psychology, 1965b, 2, 726-i35.

Ekman, P. The repertoire and nonverbal behavior: Categories, origins, and coding. Semiotica, 1969, 1, 49-98.

Ekman, P., ed. Darwin and facial expression: A century of research in review. New York: Academic Press, 1973.

Ekman, P. and Friesen, W.V. Head and body cues in the judgment of emotion: A reformulation. Perception and Motor Skills, 1967, 24, 711-724.

Ekman, P. and Friesen, W.V. Nonverbal behavior in psychotherapy research. In J. Schlien (Ed.), Research in Psychotherapy. Vol. 3. Washington, D.C.: American Psychological Association, 1968.

Ekman, P. and Friesen, W.V. Nonverbal leakage and clues to deception. Psychiatry, 1969, 32, 88-106.

Ekman, P., Friesen, W.V., and Ellsworth, P. Emotion in the human face. New York: Pergamon Press, 1972.

Ekman, P. and Friesen, W.V. Detecting deception from the body or face. Journal of Personality and Social Psychology, 1974, 29, 288-298.

Exline, R., Gray, D., and Schutte, D. Visual behavior in a dyad as affected by interview content and sex of respondent. Journal of Personality and Social Psychology, 1965, 1, 201-209.

Felipe, N.J. and Sommer, R. Invasions of personal space. Social Problems, $1966,14,206-214$.

Freud, S. The unconscious. (Orig. publ. 1915) In, The standard edition of the complete psychological works of Sigmund Freud. Vol. 14. London: Hogarth, 1957, 159-204. 
Fromm-Reichman, F. Psychoanalysis and psychotherapy. Chicago: University of Chicago Press, 1950.

Garfinkel, H. Studies of the routine grounds of everyday activities. Social Problems, 1964, 11, 225-250.

Haase, R.F. and Tepper, D.T. Nonverbal components of empathic communication. Journal of Counseling Psychology, 1972, 19, 417-424.

Hackney, H. Facial gestures and subject expression of feelings. Journal of Counseling Psychology, 1974, 21, 173-178.

Hall, E. The silent language. Garden City, New York: Doubleday, 1959.

Hall, E. A system for the notation of proxemic behavior. American Anthropologist, 1963, 65, 1003-1026.

Hall, E. The hidden dimension. Garden City, New York: Doubleday, 1966.

Hall, E. Handbook for proxemic research. Washington, D.C.: Society for the Anthropology of Visual Communication, 1974.

Harrison, R.P. and Knapp, M.L. Toward an understanding of nonverbal communication systems. The Journal of Comunication, 1972, 22, 339352.

Harrison, R.P. Beyond words: An introduction to nonverbal communication. Englewood Cliffs, N.J.: Prentice-Hall, 1974.

Hess, E.H. The tell-tale eye. New York: Van Nostrand Reinhold, 1975.

Hewes, E.H. The anthropology of posture. Scientific American, 1957, 196, 122-132.

Hollenbeck, P. Problems of reliability. In G.P. Sackett (Ed.), Observing behavior: Data collection and analysis methods. Vol. II. Baltimore: University Park Press, 1978.

Howell, W.S. The empathic communicator. Belmont, California: Wadsworth, 1982.

James, W. A study of the expression of bodily posture. Journal of General Psychology, 1932, 7, 405-437.

Jones, F.P. and Nara, M. Interrupted light photography to record the effect of changes in poise of the head upon patterns of movement in posture in man. Journal of Psychology, 1955, 40, 125-131.

Jones, F.P., Gray, F.F., Florence, E., Hanson, J.A., and O'Connell, D.N. An experimental study of the effect of head balance on patterns of posture and movement in man. Journal of Psychology, 1959, 47, 247-
258. 
Kendon, A. and Ex, J. Progress report of an investigation into aspects of the structure and function of the social performance in twoperson encounters. Cited in M. Argyle's Social interaction. New York: Atherton, 1969.

Kibler, R.J. Basic communication research considerations. In Philip Emmert and William R. Brooks (Eds.), Method of research in communication. Boston: Houghton Mifflin, 1970, 9-49.

Kline, L.W. and Johannsen, D.F. Comparative role of the face and the facebody-hands as aids in identifying emotions. Journal of Abnormal Social Psychology, 1935, 28, 415-436.

Knapp, M.L. The role of nonverbal communication in the classroom. Theory into Practice, 1971, 10, 243-249.

Knapp, M.L. Nonverbal communication in human interaction. New York: Holt, Rinehart and Winston, 1978.

Knapp, M.L., Wiemann, J.M. and Daly, J.A. Nonverbal communication: Issues and appraisal. Human Communication Research, 1978, 4, 271-280.

Knapp, R.H. The language of postural interpretation. Journal of Social Psychology, 1965, 67, 371-377.

La France, M. and Ickes, W. Posture mirroring and interactional involvement: Sex and sex typing effects. Journal of Nonverbal Behavior, $1981,5,139-154$.

Lamb, W. Posture and gesture. London: Gerald Duckworth, 1965.

Lowen, A. Physical dynamics of character structure: Body form and movement in analytic therapy. New York: Grune and Stratton, 1958.

Lowen, A. The language of the body. New York: MacMillan, 1971.

Machotka, P. Body movement as communication. Dialogues: Behavioral Science Research, 1965, 2, 33-65.

Mahl, G.F. Gestures and body movements in interviews. In J. Shlein (Ed.), Research in psychotherapy. Vol. 3. Washington, D.C.: American Psychological Association, 1968.

Makworth, J.F. Vigilance and attention. Middlesex, England: Penguin Books, 1970.

Maslow, A.H. The expressive component in behavior. Psychoanalytic Review, $1949,56,261,272$.

McGinley, H., LeFevre, R. and McGinley, P. The influence of a communicator's body position on opinion change in others. Journal of Personality and Social Psychology, 1975, 31, 686-690. 
McGinley, H., Nicholas, K. and McGinley, P. Effects of body position and attitude similarity on interpersonal attraction and opinion change. Psychological Reports, 1978, 42, 127-138.

Mehrabian, A. Attitudes in relation to the forms of communicator-object relationship in spoken communications. Journal of Personality, 1966, $34,80-93$.

Mehrabian, A. Orientation behaviors and nonverbal attitude communication. Journal of Communication, 1967, 17, 324-332.

Mehrabian, A. Inference of attitudes from the posture, orientation, and distance of a communicator. Journal of Consulting and Clinical Psychology, 1968a, 32, 296-308.

Mehrabian, A. Relationship of attitude to seated posture, orientation and distance. Journal of Personality and Social Psychology, 1968b, $30,10-26$.

Mehrabian, A. Methods and design: Some referents and measure of nonverbal behavior. Behavior Research Method and Instruction, 1969a, 1, 203209.

Mehrabian, A. Significance of posture and position in the communication of attitude and status in relationships. Psychological Bulletin, $1969 b, 71,359-372$.

Mehrabian, A. When are feelings communicated inconsistently? Journal of Experimental Research in Personality, 1970, 4, 198-212.

Mehrabian, A. Nonverbal behavior of feeling. Journal of Experimental Research in Personality, 1971a, 5, 64-73.

Mehrabian, A. Silent messages. Belmont, California: Wadsworth, 1971b.

Mehrabian, A. Nonverbal communication. Chicago: Aldine-Atherton, 1972.

Mehrabian, A. Silent messages: Implicit communication of emotions and attitudes. (2nd ed.) Belmont, California: Wadsworth, 1981.

Mehrabian, A. and Friar, J.T. Encoding of attitude by a seated communicator via posture and position cues. Journal of Consulting and Clinical Psychology, 1969, 33, 330-336.

Mehrabian, A. and Russell, J.A. The basic emotional impact of environments. Perception and Motor Skills, 1974, 38, 283-301.

Mehrabian, A. and Williams, M. Nonverbal concomitants of perceived and intended persuasiveness. Journal of Personality and Social Psychology, 1969, 13, 37-58.

Montague, A. Touching. New York: Columbia University Press, 1971. 
Nie, N.H. Hull, C.H., Jenkins, J.G., Steinbrenner, K, and Bent, D.H. Statistical Packages for the Social Sciences. New York: McGrawHill, 1975.

Norman, D. Memory and attention. New York: John Wiley, 1976.

Norton, R.W. Communicator style and teacher effectiveness. In B. Ruben (Ed.), Communication yearbook. New Brunswick, New Jersey: Transaction, 1977.

Norton, R.W. Foundations of a communicator style construct. Human Communication Research, 1978, 4, 99-112.

Norton, R.W. and Miller, L.D. Dyadic perceptions of communicator style. Communication Research, 1975, 2, 50-76.

Norton, R.W. and Pettegrew, L.S. Communicator style as an effect determinant of attraction. Paper presented at the annual convention of the International Communication Association, Portland, 1976.

Norton, R.W. and Pettegrew, L.S. Communicator style as an effect determinant of attraction. Communication Research: An International quarterly, 1977, 4, 257-282.

Norton, R.W. and Pettegrew, L.S. Attentiveness as a style of communication: A structural analysis. Communication Monographs, 1979, 46, 13-36.

Norton, R.W. and Warnick, B. Assertiveness as an interpersonal construct. Human Communication Research, 1976, 3, 62-66.

Pettegrew, L.S. An investigation of therapeutic communicator style. In B. Ruben (Ed.), Communication yearbook. New Brunswick, New Jersey: Transaction, 1977.

Phillips, J.R. Relationship of field-dependence-independence to posture judgment of time duration. Perception and Motor Skills, 1977, 44, 931-940.

Pittenger, R.E., Hockett, C.F., and Daneht, J.J. The first five minutes. Ithaca, New York: Martineau, 1960.

Pittenger, R.E. and Smith, H.L., Jr. A basis for some contributions of linguistics to psychiatry. Psychiatry, 1957, 20, 61-78.

Prost, J.H. Varieties of human posture. Human Biology, 1974, 46, 1-19.

Reece, M.M. and Whitman, R.N. Expressive movements, warmth and verbal reinforcement. Journal of Abnormal and Social Psychology, 1962, 64, 234-236.

Reich, W. Character analysis. (Trans. by T.P. Wolfe) New York: Orgone Institute Press, 1945. 
Reusch, J. and Kees, W. Nonverbal communication: Notes on the visual perception of human relations (2nd ed.). Berkeley: Univ. of California Press, 1971.

Rogers, C.R. Client-centered therapy. Boston: Houghton-Mifflin, 1951.

Rosenberg, B.G. and Langer, J. A study of postural gestural communication. Journal of Personality and Social Psychology, 1965, 2, 593-597.

Rosenfeld, H.M. Approval-seeking and approval-inducing functions of verbal and nonverbal responses in a dyad. Journal of Personality and Social Psychology, 1966a, 4, 597-605.

Rosenfeld, H.M. Instrumental affiliative functions of facial and gestural expressions. Journal of Personality and Social Psychology, 1966b, $4,65-72$.

Rosenthal, R., Hall, J.A., DiMatteo, M.R., Rogers, P.L., and Archer, D. Sensitivity to nonverbal communication: The PONS test. Baltimore: John Hopkins University Press, 1979.

Ross, R. Persuasion: Communication and interpersonal relations. Englewood Cliffs, New Jersey: Prentice-Hall, 1974.

Ruben, B.D. Communication and conflict: A system theoretic perspective. Quarterly Journal of Speech, 1978, 64, 208-209.

Sackett, G.P. ed. Observing behavior: Data collection and analysis methods. Vol. II. Baltimore: University Park Press, 1978.

Sapir, E. The unconscious patterning of behavior in society. In D. Mandelbaum (Ed.), Selected uritings of Edward Sapir in language, culture and personality. Berkeley: University of California Press, 1949.

Scheflen, A.E. The significance of posture in communication systems. Psychiatry, 1964, 27, 316-331.

Scheflen, A.E. On the structuring of human communication. American Behavioral Scientist, 1967, 10, 8-12.

Scheflen, A.E. Body language and the social order: Communication as behavioral control. Englewood Cliffs, New Jersey: Prentice-Hall, 1972.

Scheflen, A.E. How behavior means. Garden City, New York: Anchor Books, 1974.

Scheflen, A.E. Human territories: How we behave in space-time. Englewood Cliffs, New Jersey: Prentice-Hall, 1976.

Scherer, K.R. and Ekman, P. Handbook of methods in nonverbal behavior research. Cambridge: Cambridge University Press, 1982.

Schiedel, T.M. Persuasive speaking. Glenview, Illinois: Scott, Foresman, 1967. 
Schlosberg, H. Three dimensions of emotion. Psychological Review, 1954, $61,81-88$.

Simons, H.W. ed. Prologue. In Gerald R. Miller and Herbert W. Simons (Eds.), Perspective on communication and conflict. Englewood Cliffs: Prentice-Hall, 1974, 4.

Simons, H.W. Persuasion: Understanding, practice, and analysis. Boston: Addison-Wesley, 1976.

Smith, W.L. Postural and gestural communication of $A$ and $B$ therapist types during dyadic interviews. Journal of Consulting and Clinical Psychology, 1972, 39, 29-36.

Sommer, R. The distance for comfortable conversation: A further study. Sociometry, 1962, 25, 111-116.

Sommer, R. Small group ecology. Psychological Bulletin, 1967, 67, 145-152.

Stewart, J. Editor's introduction. Communication Education, 1983a, 23, $365-367$.

Stewart, J. Interpretive listening: An alternative to empathy. Communication Education, 1983b, 23, 379-391.

Stockwell, R.P., Bowen, J.D., and Silva-Fuenzalida, I. Spanish juncture and intonation. Language, 1956, 32, 641-665.

Strom, R. and Ray, W. Communication in the affective domain. Theory into Practice, 1971, 10, 268-275.

Thomas, A.P. and Bull, P. The role of pre-speech posture change in dyadic interaction. British Journal of Social Psychology, 1981, 20, 105-111.

Trager, G.L. Paralanguage: A first approximation. Studies in Linguistics, $1958,13,1-12$.

Trager, F.L. Taos III: Paralanguage. Anthropological Linguistics, 1960, $2,24-30$.

Trager, G.L. The typology of paralanguage. Anthropological Linguistics, $1961,3,17-21$.

Trout, D.L. and Rosenfeld, H.M. The effect of postural lean and body congruence on the judgment of psychotherapeutic rapport. Journal of Nonverbal Behavior, 1980, 4, 176-190.

Truax, C.B. and Carkhuff, R.R. Toward effective counseling and psychotherapy. Chicago: Aldine-Atherton, 1967.

Tucker, R.K., Weaver, II, R.L., and Berryman-Fink, C. Research in speech communication. Englewood Cliffs: Prentice-Hall, 1981. 
Waldron, J. Judgment of like-dislike from facial expression and body posture. Perceptual and Motor Skills, 1975, 41, 799-804.

Watzlawick, P., Beavin, J., and Jackson, D. Some tentative axioms of communication. In D.C. Mortensen (Ed.), Basic readings in communication theory. San Francisco: Harper and Row, 1973.

Wiener, M. and Mehrabian, A. Language within language: Immediacy, a channel in verbal communication. New York: Appleton-Century-Crofts, 1968.

Williams, F. Reasoning with statistics. San Francisco: Holt, Rinehart and Winston, 1979.

Wilmot, W.W. Metacommunication: A re-examination and extension. In Brent D. Ruben (Ed.), Communication yearbook 4. New Brunswick: Transaction Books, 1980, 61-69. 


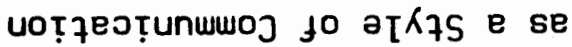

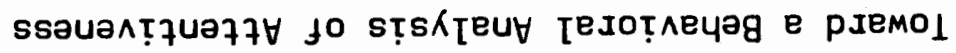

SJJIONJdd $\forall$ 


\title{
APPENDIX A
}

\author{
BRANDT'S CONCEPTUAL DEF INITIONS AND \\ EMPIRICAL INDICATORS OF COMMUNICATIVE STYLE
}

\section{ATTENTIVE}

Definition - a tendency to listen, to show interest in what the other is saying, and to deliberately react in such a way that others know they are being listened to.

Indicators - (1) amount and duration of eye contact, (2) frequency with which a communicator repeats, rephrases, or paraphrases the other's statements back to him or her, (3) frequency of requests for additional information pertaining to a previous statement made by the other, (4) a communicator's body-postural orientation.

\section{DOMINANT}

Definition - a tendency to "take charge" of the interaction and/or to attempt to lead or control the behaviors of others in it.

Indicators - (1) frequency of speaking, (2) direction of topic(s) of conversation, (3) frequency of interrupting behavior, (4) amount of direct glances at the other.

OPEN

Definition - a tendency to reveal personal things about the self, to easily express feelings and emotions, and to be frank and sincere.

Indicators - (1) frequency of statements of personal opinion or experience, (2) freqeuncy of "high-risk" self-disclosive statements, (3) frequency of attempts to facilitate openness in the conversation as a whole.

Definition - a tendency to provide frequent eye contact, to use facial expressions, and to gesture often.

Indicators - (1) vocal fluctuations in range, pitch, and loudness, (2) frequency and variety of body movements, (3) frequency and variety of facial expressions, (4) eye movements, (5) amount of "communicative" gesturing. 


\section{RELAXED}

Definition - a tendency to be calm and collected, not nervous, under pressure, and to not show nervous mannerisms.

Indicators - (1) leaning back in one's chair, (2) degree of "steadiness" in the voice, (3) frequency of verbal nonfluencies (inversely related to relaxedness), (4) frequency of mentioning apprehension or nervousness concerning the interaction, (5) postural rigidity.

\section{FRIENDLY}

Definition - a tendency to be encouraging to others, to acknowledge others' contributions to the interaction, and to openly express admiration.

Indicators - (1) frequency of agreement and/or acknowledgement of the worth of the other's statement, (2) frequency of smiles, forward leans, and other gestures of warmth and friendliness, (3) frequency of statements reflecting interest in the other's statements, (4) frequency of reinforcing or "stroking" statements.

\section{IMPRESSION LEAVING}

Definition - a tendency to be remembered because of what one says and/or the way one says it.

Indicators - (1) frequency of unique nonverbal mannerisms or gestures, (2) frequency of unique verbal expressions.

\section{CONTENTIOUS}

Definition - a tendency to be argumentative or overtly hostile towards others.

Indicators - (1) frequency of challanging statements, (2) attempts at pushing one's points or opinions in order to make them appear in the right, (3) frequency of disagreement with the other, (4) frequency of aversive nonverbal behaviors such as frowns or negative head shakes, (5) frequency of contemptous statements made about the other.

\section{PRECISE}

Definition - a tendency to use very specific language and to try to be very accurate and specific about what one means by what one says.

Indicators - (1) frequency of giving examples and illustrations to clarify a statement, (2) use of definitions, (3) choice of words 
with specific meanings, (4) use of "big" or polysyllabic words (5) frequency with which a communicator elaborates on a previous statement (6) grammatical correctness of speech.

From David R. Brandt, "On Linking Social Performance with Social Competence: Some Relations Between Communicative Style and Attributions of Interpersonal Attractiveness and Effectiveness," Human Communication Research 2 (Spring 1979): 227-228. 


\section{APPENDIX B}

\section{COURSE DESCRIPTION FOR RESEARCH PRACTICUM}

\section{SPEECH COMMUNICATION}

RESEARCH PRACTICUM - SP 408A

\section{1 credit}

Pass/No pass or graded option

Students enrolled in this course will be partaking in an independent research project in the study of nonverbal communication. Each student will be trained to code certain nonverbal behavior from video tapes of dyadic interaction.

Hours for coding will be set around the student's schedule. There will be no written work or examinations, and a text is not required. Time involvement is estimated at about 15 hours of coding throughout Fall Quarter and 5-10 additional hours for class sessions and training. The first class session will be held Thursday, September 29 at 3:00 p.m. in room NH 26. If you cannot attend this first meeting and are interested in being a coder, please call me at 227-2699.

Practicum coordinator: Phone:

Professor of Record: Dr. Robert Vogelsang Speech Communication Department
Ray Coker

227-2699

Dr. Robert Vogelsang
Speech Communication 


\section{APPENDIX C \\ PHOTOGRAPH OF CODING CENTER}

The photograph below shows how the coding center, located in Neuberger Hall, room 24, was organized.

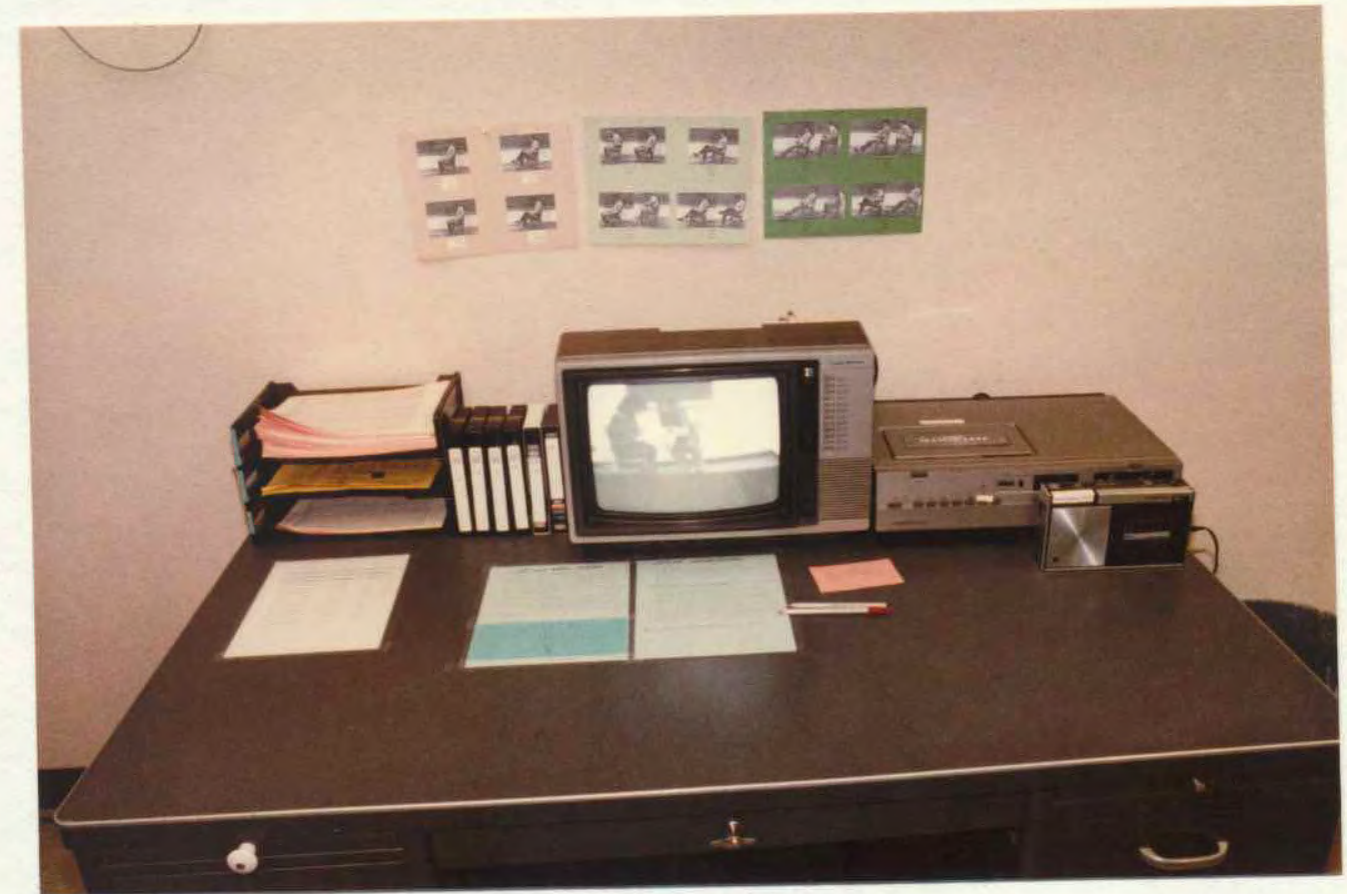




\section{APPENDIX D}

\section{INSTRUCTIONS TO CODERS}

Please follow these instructions when coding:

1. Return key to the office.

2. Check the assignment slot for subject(s) you are to code.

3. Fill out the coding sheet (your name, subject's number, sex, and counter number).

4. Turn on the TV and power switch for the video recorder.

5. Set the TV on channel 5 (make sure the sound is off).

6. Insert the video cassette and rewind.

7. Set the counter at zero.

8. Run FF/cue until you come to the correct counter number.

9. When you are ready to code, push play on the video recorder and tape recorder at the same time when the correct number is in place.

10. Code at the sound of the whistle every 30 seconds. Do not miss the sound of the whistle. If you do, draw a line through that number and go on to the next number at the next whistle. When my voice is heard on the tape recorder, it means you are finished coding that subject. You should fill in your coding chart to 1 非

11. You may adjust the bright, picture, color and tint knobs below the screen of the TV.

12. After you have finished coding a subject, fill out the report attached to the coding sheet.

13. Code as long as you like but always finish coding a subject once you have started.

14. After you finish, rewind the tape recorder and video tape, and then turn off the TV and video recorder.

15. Replace the tape in it's case and place your coding sheet(s) in the results slot.

16. When leaving, make sure the lights are out and the door is locked.

Thanks. 
APPENDIX E

CODING CHART

Name:

Subject: M/F Counter number:

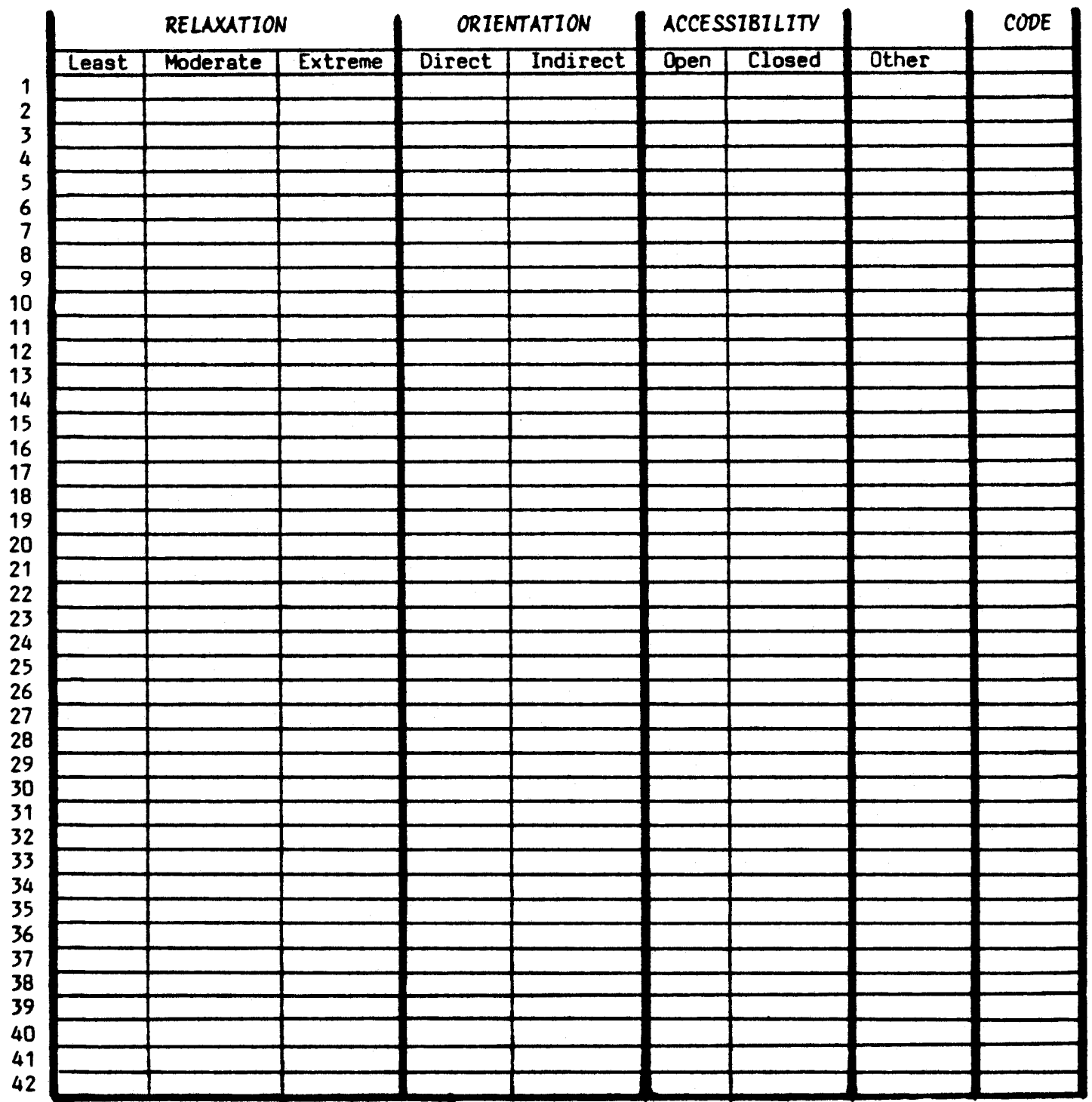




\section{APPENDIX $F$ \\ Dyadic Attentiveness Measure}

Ray A. Coker

Portland State University

Please answer the following questions concerning the conversation you have just had. Check only one category for each question.

1. I wanted the other person to know that I was listening to him/her.

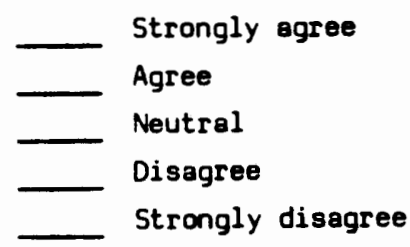

2. Even when I was talking, I was a very alert comunicator.

$\begin{array}{ll}\text { Strongly agree } \\ - \\ - \text { Agree } \\ & \text { Neutral } \\ & \text { Disagree } \\ \square & \text { Strongly disagree }\end{array}$

3. I encouraged the other person to continue talking by saying phrases like, "I see," "uh-huh," "I understand," or "that's very interesting."

$\begin{array}{ll}\text { Strongly agree } \\ - & \text { Agree } \\ & \text { Neutral } \\ & \text { Disagree } \\ & \text { Strongly disagree }\end{array}$

4. I encouraged the other person to continue talking by frequently nodding my head during the conversation.
Strongly agree
Agree
Neutral
- Disagree
Strongly disagree

5. In this conversation, I was a very careful listener.

Strongly agree

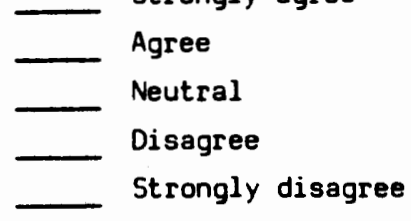


6. I encoureged the other person to continue talking by frequently smiling during the conversation.

\begin{tabular}{|c|}
\hline Strongly agree \\
\hline $\begin{array}{l}\text { Agree } \\
\text { Neutrel }\end{array}$ \\
\hline $\begin{array}{l}\text { Diaagree } \\
\text { Strongly diaagree }\end{array}$ \\
\hline
\end{tabular}

7. I encouraged the other peraon to continue talking by looking at him/her.

Strongly agree
$\square-$ Agree
$\square$
$\square$

8. I could repeat back to the other person what was meant by most of what he/she said.

Strongly agree
$\square$
$\square$
$\square$
$\square$
$\square$ Neutral
Disegree
Strongly disagree

9. I deliberately reacted in such a way that the other person would know I was listening to him/her.

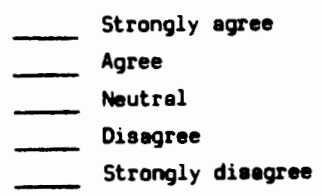

10. I encouraged the other person to continue talking by leaning toward the person.

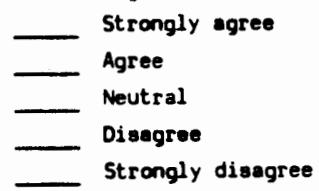

11. In this conversation, I was en extremely attentive communicator.

Strongly ogree
- Agree
Neutral
$\square$
$\square$ Disegree
Strongly disagree

12. I was good at knowing the exect feelings of the other person from their communication.

Strongly agree
- Agree
Neutral
$-\begin{aligned} & \text { Disagree } \\ & \text { Strongly disagree }\end{aligned}$




\section{APPENDIX G}

\section{ATTENTIVENESS MEASURE BY NORTON AND PETTEGREW (1979)}

The following items showed significance in the factor analysis done by Norton and Pettegrew. Items altered for use in the Dyadic Attentiveness Measure are indicated by an asterisk.

3 I [do not] have a habit of asking for clarification from the other person if I am unclear on what was said.**

4 Other people often come to me when they need somebody to listen to them.

* 5 I want people to know that I am listening to them.

* 6 Even when I am doing most of the talking, I am a very alert communicator.

7 Often people think I am listening to them when I am not.

8 When I communicate in a general one-to-one situation, I always am a careful listener.

* 9 When I communicate in a general one-to-one situation, I always am a very careful listener.

10 I am a very passive communicator.

11 I have a habit of restating what the other person said if I am unclear on what was said.

12 Usually I can read another person "like a book."

13 I try to read between the lines when I am listening to another person.

14 Many times I pretend not to be listening (even though I am) to the other person.

*15 I have a habit of encouraging the other person to continue talking by frequently smiling during the conversation.

16 I am a very submissive communicator.

17 I have a habit of encouraging the other person to continue talking by frequently relating similar experiences during the conversation. 
18 When I communicate in a general one-to-one situation, I always am very attentive.

*19 I have a habit of encouraging the other person to continue talking by frequently nodding my head during the conversation.

20 I [do not] have a lot of energy when I communicate.**

21 I often listen because I am too anxious to say anything.

*22 I have a habit of encouraging the other person to continue talking by saying phrases like "I see," "Uh-huh," "I understand," or "That's very interesting."

23 I frequently notice a lot of different ways to interpret what a person says.

*24 I am very good at knowing the exact feelings of other people.

*25 I have a habit of encouraging the other person to continue talking by leaning toward the person.

*26 I can always repeat back to a person exactly what was meant.

*27 Usually, I deliberately react in such a way that people know that I am listening to them.

28 I really like to listen very carefully to people.

*29 I am an extremely attentive communicator.

*30 I have a habit of encouraging the other person to continue talking by looking at him or her.

31 I am very good at knowing the exact feelings of other people from their communication.

32 Other people would say that I am an extremely attentive communicator.

**Norton and Pettegrew (1979) note that items 3 and 20 may be bad items, and say, "A tentative interpretation, however, is to reverse the wording of the items" (p. 20). 


\section{APPENDIX H}

\section{STRUCTURE OF ATTENTIVENESS VARIABLES USED BY NORTON AND PETTEGREW (1979)}

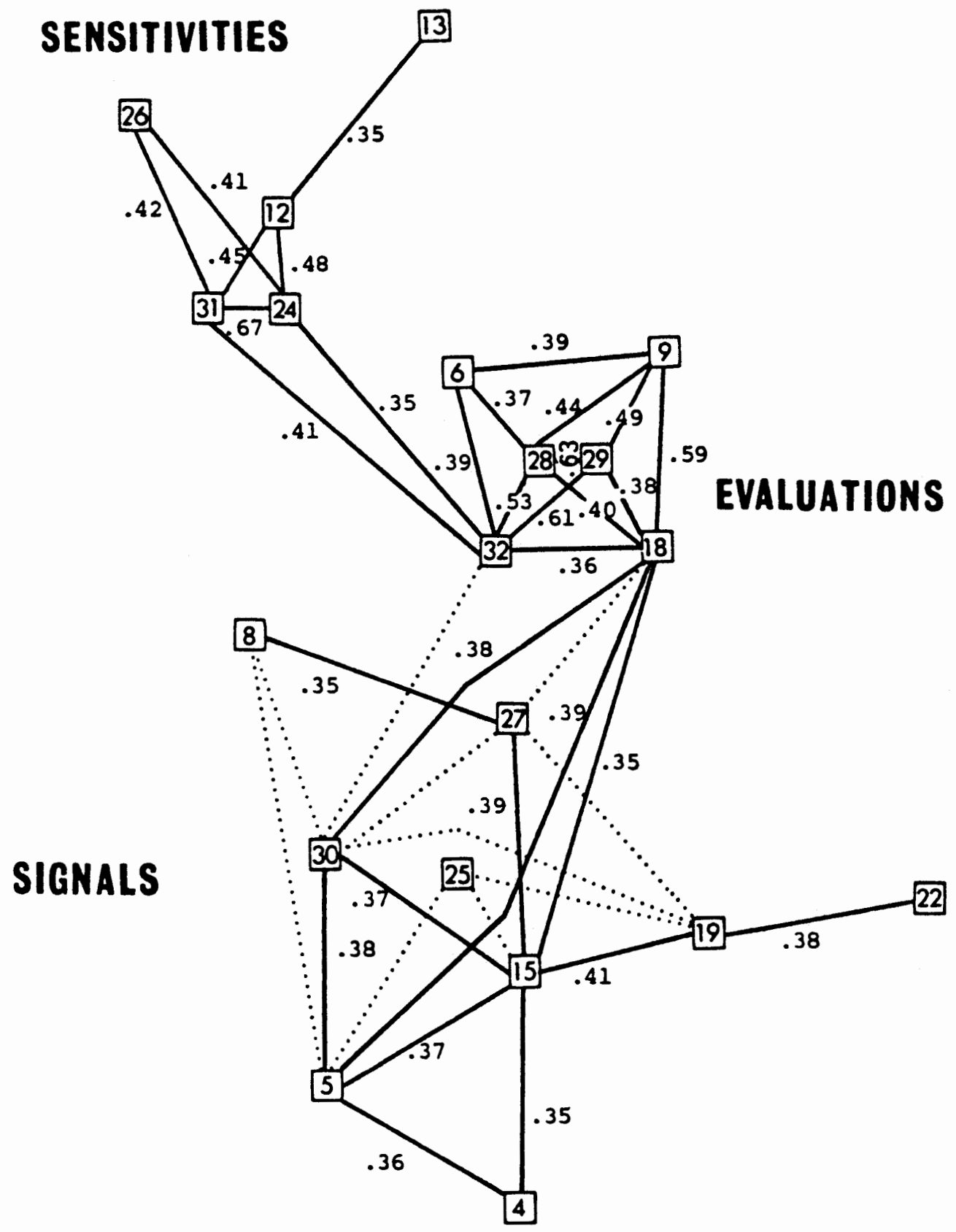


Your number:

Partner's number:

1. Listening

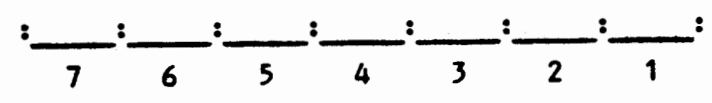

Preoccupied

2. Alert

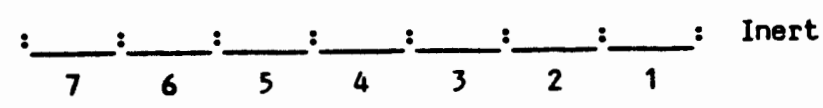

3. Aware

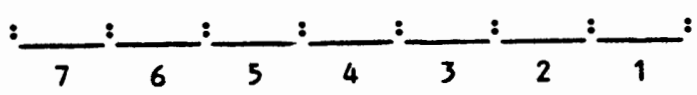

Unaware

4. Comprehending

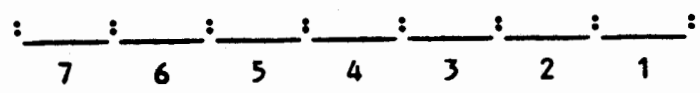

Misunderstanding

5. Tuned in

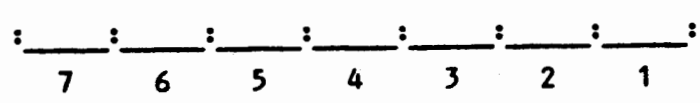

: Tuned out

6. Sensitive

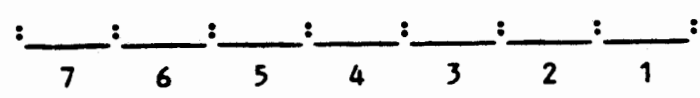
: Insensitive

7. Interested

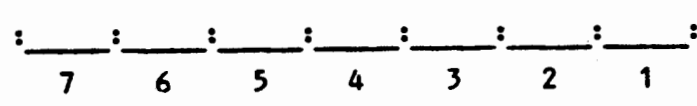
: Disinterested

8. Eager

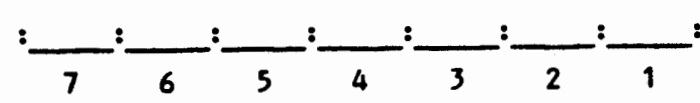
- Indifferent

9. Active

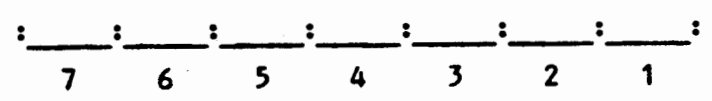
Passive

10. Attentive

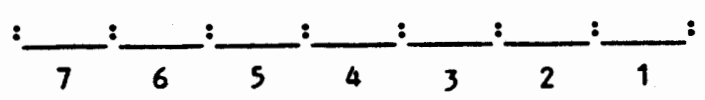
Inattentive 


\section{APPENDIX J \\ CODER'S GLOBAL REPORT OF ATTENT IVENESS}

Ray A. Coker

Portland State University

1. The person coded wanted the other to know that he/she was listening.

$\begin{array}{ll}- & \begin{array}{l}\text { Strongly agree } \\ \text { Agree } \\ \square\end{array} \\ \square & \text { Neutral } \\ \square & \text { Disagree } \\ & \text { Strongly disagree }\end{array}$

2. Even while talking, the person coded was a very alert communicator.

Strongly agree
- Agree

$\square$ Neutral
$\square$ Disagree
- Strongly disagree

3. The person coded encouraged the other person to continue talking by frequently nodding his/her head during the conversation.

$\begin{array}{ll}\text { Strongly agree } \\ & \text { Agree } \\ & \text { Neutral } \\ & \text { Disagree } \\ & \text { Strongly disagree }\end{array}$

4. In this conversation the person coded appeared to be a very careful listener.
Strongly agree
- Agree
Neutral
Disagree
Strongly disagree

5. The person coded encouraged the other person to continue talking by frequently looking at $\mathrm{him} / \mathrm{her}$.

Strongly agree
Agree
$\square$
$\square$


6. The person coded encouraged the other person to continue telking by leaning toward him/her.

Strongly agree
- Agree
Neutral
- Disagree

$-\quad$ Strongly disagree

7. In this conversation, it appeared that the coded person was an extremely attentive communicator.

$\begin{array}{ll}\text { Strongly agree } \\ - \text { Agree } \\ & \text { Neutral } \\ & \text { Disagree } \\ & \text { Strongly disagree }\end{array}$

Please place a check mark above the appropriate number on the following scale.

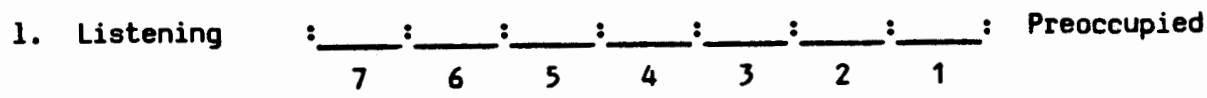

2. Alert

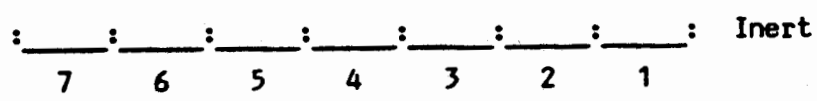

3. Aware

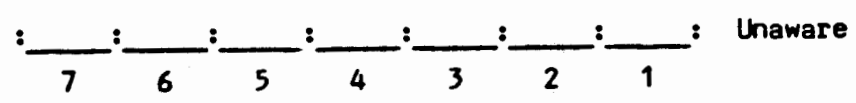

4. Comprehending :

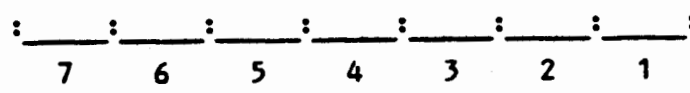

: Misunderstanding

5. Tuned in

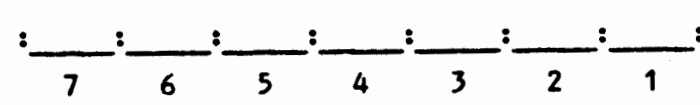
: Tuned out

6. Sensitive

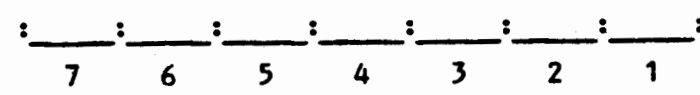
: Insensitive

7. Interested

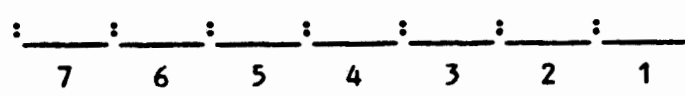
- Disinterested

8. Eager

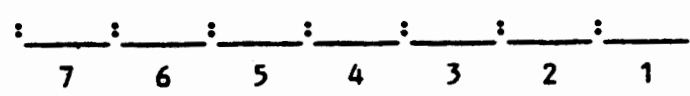
: Indifferent

9. Active

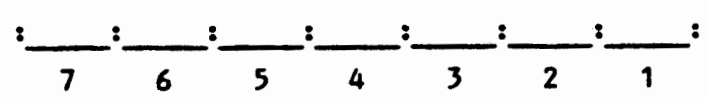
Passive

10. Attentive

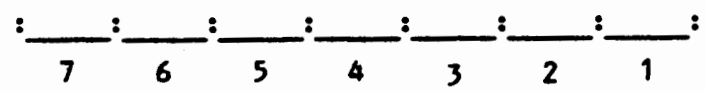
- Inattentive 


\section{APPENDIX $K$}

\section{APPOINTMENT REMINDER FOR SUBJECTS FROM PSU}

Volunteers are needed for a study on dyadic interaction. Volunteers will meet at a prearranged time for a 30 minute period where they will be videotaped in dialogue with one other person. The dialogue will be followed by two short tests, and volunteers will receive $\$ 2.50$ for their time.

*A person can sign up for only one 30 minute period.

*A person may sign up a friend to interact with them in the same time period.

*Videotaped interactions will not be shown publicly.

Day:

Time:

Room $45 \mathrm{NH}$

If you cannot make your prearranged time please call Ray Coker (227-2699). 


\section{APPENDIX L}

\section{INDEXING OF SUBJECTS ON VIDEOTAPE}

Tape 1

Subjects 15-16 Counter 0

15 female on left

16 female on right

Subjects 17-18 Counter 522

17 female on left

18 female on right

Subjects 19-20 Counter 899

19 male on left

20 female on right

Subjects 51-52 Counter 1201

51 male on left

52 female on right

Subjects 53-54 Counter 1454

53 female on left

54 male on right

Subjects 49-50 Counter 1675

49 male on left

50 male on right

Tape 2

Subjects 5-6 Counter 0 5 male on left

6 female on right

Subjects 7-8 Counter 507

7 female on left

8 female on right

Subjects 9-10 Counter 867

9 male on left

10 male on right

Subjects 11-12 Counter 1191

11 female on left

12 female on right

Subjects 13-14 Counter 1464

13 female on left

14 male on right

Subjects 43-44 Counter 1701

43 female on left

44 female on right

Tape 3

Subjects 21-22 Counter 0

21-male on left

22 male on right

Subjects 23-24 Counter 501

23 female on left

24 female on right

Subjects 46-47 Counter 890

46 male on left

47 female on right

Subjects 37-38 Counter 1187

37 female on left

38 fenale on right
Subjects 39-40 Counter 1444

39 male on left

40 female on right

Subjects 41-42 Counter 1671

41 fenale on left

42 female on right

Tape 4

Subjects 25-26 Counter 0

25 female on left

26 female on right

Subjects 27-28 Counter 512

27 female on left

28 female on right

Subjects 29-30 Counter 881

29 male on left

30 male on right

Subjects 31-32 Counter 1178

31 female on left

32 female on right

Subjects 33-34 Counter 1447

33 male on left

34 female on right

Subjects 35-36 Counter 1667

35 female on left

36 male on right

Tape 5

Subjects 55-56 Counter 0

55 male on left

56 female on right

Subjects 57-58 Counter 508

57 female on left

58 female on right

Subjects 59-60 Counter 872

59 female on left

60 female on right

Subjects 61-62 Counter 1172

61 female on left

62 female on right

Tape 6

Subjects 63-64 Counter 0 63 female on left 64 male on right

Subjects 65-66 Counter 514 65 female on left 66 female on right

Subjects 67-68 Counter 884 $67 \mathrm{male}$ on left 68 male on right 


\section{APPENDIX M}

COHEN'S KAPPA STATISTIC ON DATA FROM FINAL STUDY

$N=$ Number of intervals or observations

$N_{0}=$ Number of observations that are the same or in agreement

$N_{e}=\frac{\text { Column } \times \text { Row }}{N}$ plus the rest of the columns $x$ rows

$P_{0}=\frac{N_{0}}{N}$ Sum of diagonal entries/total of all entries

$P_{e}=\frac{N_{e}}{N}$ Chance proportion action of agreements

$K=\frac{N_{0}-N_{e}}{N-N_{e}} \quad \frac{P_{0}-P_{e}}{1-P_{e}}$

$$
\begin{aligned}
& N=2394 \\
& N_{0}=2055 \\
& \mathrm{~N}_{\mathrm{e}}=\frac{84 \times 85}{2394}+\frac{17 \times 16}{2394}+\frac{507 \times 528}{2394}+\frac{44 \times 43}{2394}+\frac{275 \times 252}{2394}+\frac{91 \times 96}{2394}+ \\
& \frac{671 \times 692}{2394}+\frac{225 \times 205}{2394}+\frac{33 \times 45}{2394}+\frac{34 \times 25}{2394}+\frac{290 \times 300}{2394}+\frac{106 \times 95}{2394}+ \\
& \frac{17 \times 12}{2394}=2.98+.11+111.82+.79+28.95+3.65+193.96+19.27 \\
& +.62+.35+36.34+4.21+.08=403.13 \\
& P_{0}=\frac{2055}{2394}=.86 \\
& P_{e}=\frac{403.13}{2394}=.17 \\
& K=\frac{2055-403.13}{2394-403.13}=.83 \\
& \frac{.86-.17}{1-.17}=\frac{.69}{.83}=.83
\end{aligned}
$$

